NBER WORKING PAPER SERIES

\title{
CAN SIMPLE PSYCHOLOGICAL INTERVENTIONS INCREASE PREVENTIVE HEALTH INVESTMENT?
}

\author{
Johannes Haushofer \\ Anett John \\ Kate Orkin \\ Working Paper 25731 \\ http://www.nber.org/papers/w25731 \\ NATIONAL BUREAU OF ECONOMIC RESEARCH \\ 1050 Massachusetts Avenue \\ Cambridge, MA 02138 \\ April 2019, Revised December 2019
}

Supported by grant NIH UH2 NR016378 to JH. We thank Jane Dougherty, Daniel Mellow, Moritz Poll, and the Busara Center for Behavioral Economics for research assistance; Clair Null, Michael Kremer, and the WASH Benefits Kenya team for collaboration and advice; and Nava Ashraf, David Laibson, Xavier D'Haultfoeuille, Alessandro Iaria, and Pedro Rey-Biel for comments. The pre-analysis plan for this study is registered at https://www.socialscienceregistry.org/trials/2850/history/27566. The views expressed herein are those of the authors and do not necessarily reflect the views of the National Bureau of Economic Research.

NBER working papers are circulated for discussion and comment purposes. They have not been peerreviewed or been subject to the review by the NBER Board of Directors that accompanies official NBER publications.

(C) 2019 by Johannes Haushofer, Anett John, and Kate Orkin. All rights reserved. Short sections of text, not to exceed two paragraphs, may be quoted without explicit permission provided that full credit, including () notice, is given to the source. 
Can Simple Psychological Interventions Increase Preventive Health Investment?

Johannes Haushofer, Anett John, and Kate Orkin

NBER Working Paper No. 25731

April 2019, Revised December 2019

JEL No. D91,I12,O12

\begin{abstract}
$\underline{\text { ABSTRACT }}$
Behavioral constraints may explain part of low demand for preventive health products. We test the effects of two light-touch psychological interventions on water chlorination and related health and economic outcomes using a randomized controlled trial among 3750 women in rural Kenya. One intervention encourages participants to visualize alternative realizations of the future; one builds participants' ability to make concrete plans. Both interventions include information on health benefits of chlorination. After twelve weeks, both interventions increase the share of households who chlorinate drinking water and reduce child diarrhea episodes. Analysis of mechanisms suggests both interventions increase self-efficacy-beliefs about one's ability to achieve desired outcomes - as well as the salience of chlorination. They do not differentially affect beliefs and knowledge about chlorination (compared to a group who receive only information), nor affect lab measures of time preferences or planning ability. Results suggest simple psychological interventions can increase use of preventive health technologies.
\end{abstract}

Johannes Haushofer

Woodrow Wilson School

Princeton University

427 Peretsman-Scully Hall

Princeton, NJ 08540

and Busara Center for Behavioral Economics,

Nairobi, Kenya

and also NBER

haushofer@princeton.edu

Anett John

CREST

5 Avenue Henry Le Chatelier

91120 Palaiseau

FRANCE

anett.john@ensae.fr
Kate Orkin

University of Oxford

Merton College

Merton Street

Oxford, OX14JD

United Kingdom

kate.orkin@merton.ox.ac.uk

A randomized controlled trials registry entry is available at

https://www.socialscienceregistry.org/trials/2850/history/27566 


\section{Introduction}

Individuals often fail to invest in preventive healthcare, even when such investments cost little and individuals are aware of their benefits. ${ }^{1}$ An estimated two thirds of deaths of children under 5 could be averted with cheap preventive technologies (Dupas 2014a). A prominent example is chlorination of drinking water, which is highly effective in reducing prevalence of diarrhea, particularly among young children (Arnold and Colford Jr 2007). Diarrhea is the second leading cause of death worldwide among children aged $1-5$, contributing to nearly half a million deaths in 2015 (Wang et al. 2016). It is a leading cause of morbidity, and stunts healthy growth in children through enteric dysfunction (Richard et al. 2013). In many settings, chlorine for water is readily and cheaply available, but infrequently used by individuals without access to clean water. In our study areas in Kenya, only 3 percent of households used chlorine before any intervention (Null et al. 2018), although a month's supply costs only KES 25 (USD 0.25). Interventions which provide chlorine for free, often in combination with information or marketing campaigns, increase usage to between 23 and 60 percent, but even after these interventions, take-up remains far below complete (Kremer et al. 2011a; Dupas et al. 2016; Null et al. 2018; Luoto et al. 2014).

A growing body of evidence suggests that behavioral or psychological constraints may explain some of the low demand for preventive health products. For example, demand for commitment products suggests a role of present bias in health decisions (Schilbach 2018; Bai et al. 2017; Giné, Karlan, and Zinman 2010; DellaVigna and Malmendier 2006; Royer, Stehr, and Sydnor 2015). The success of planning interventions argues for a role of planning skills and limited attention(Stadler, Oettingen, and Gollwitzer 2009; Milkman et al. 2013; Milkman et al. 2011). Most recently, economists have started to explore the role of beliefs about oneself - from self-image to agency and sense of control over one's life - in determining health behavior (Ghosal et al. 2019; Banerjee, la Ferrara, and Orozco 2018; Baranov et al. 2017).

In this paper, we present evidence from a field experiment in rural Kenya which studies the role of behavioral constraints in limiting the use of chlorine to treat drinking water, by targeting these constraints directly with simple psychological and informational interventions. We allocate 3750 young women to four treatment groups. The first group received a two-session group intervention where participants visualized alternative realizations of the future, depending on their behavior in the present ("Visualization" or "V"). The intervention aimed to make future outcomes more vivid and

\footnotetext{
${ }^{1}$ For instance, providing insecticide-treated bed nets reduces incidence of malaria, which increases both farmworker productivity (Dillon, Friedman, and Serneels 2014) and farm yields (Fink and Masiye 2015). Bleakley (2010) estimates that a child who grew up malaria-free earns 50 percent more throughout their adult life. However, demand for bed nets is low and price sensitive (Cohen and Dupas 2010; Dupas 2014b). Similarly, treating intestinal parasites improves child health and school attendance (Miguel and Kremer 2004), growth (Bobonis, Miguel, and Puri-Sharma 2006), test scores (Ozier 2018), and adult wages (Baird et al. 2016), yet take-up is low at non-zero prices (Kremer and Miguel 2007).
} 
tangible in participants' minds, thus increasing their perceived value relative to the more immediate costs required to attain them. The second group received a two-session intervention that helped participants to undertake activities that they were struggling to do regularly, by making concrete, specific plans, anticipating potential obstacles, and establishing routines ("Planning" or "P"). Both interventions required participants to think about how their current behavior affects their future outcomes. To isolate the effects of the psychologically active elements of these treatments, a third, active control group received all elements of the intervention except the psychologically active components ("Active Control" or "AC" intervention): these participants also gathered as a group, but to discuss "psychologically inactive" topics. In addition, all three groups received a short information module about the benefits of chlorination ("Information" or "INF" intervention), to hold beliefs about chlorination constant across groups. Finally, we compare these treatments to a fourth, pure control group ("PC"), who were simply surveyed at endline. Thus, our groups are "V+INF", "P+INF", "AC+INF", and "PC". The comparison between the three "active" treatment groups and the pure control group gives the total effect on targeted behaviors of providing interventions such as ours in other, similar settings. The comparison between the two "psychological" treatment groups and the $\mathrm{AC}+\mathrm{INF}$ group tests the effect of interventions specifically targeting the ability to visualize the future or to make and execute plans, respectively, over and above those targeting lack of information.

We report economically large and statistically significant effects of our interventions on our main outcome of interest, chlorination of household drinking water, measured objectively through a chemical test in unannounced household visits. Specifically, in the Visualization and Planning groups relative to the pure control group, we find significant increases of 27 and 18 percent (6 and 4 percentage points), respectively, in the share of households whose drinking water contains chlorine twelve weeks after the interventions. In line with these findings, both the Visualization and Planning treatments significantly reduce the number of diarrhea episodes in children: Visualization reduces diarrhea by 37-39 percent (9 percentage points) relative to both the active and the pure control group, and Planning by 21-30 percent (5-7 percentage points), respectively. In contrast, the effect in the active control group relative to the pure control group is small and not statistically significant for both chlorination and diarrhea.

These interventions are extremely cost-effective by the standards of the World Health Organization (WHO). Delivery of the interventions cost approximately USD 4 per household, or USD 1.33 per child. If we assume, conservatively, that the treatment effects of the visualization and planning interventions are 38 and 21 percent reductions (from the active control comparisons) in diarrhea for 3 months, and that the effects then immediately go to zero, the cost per Disability-Adjusted Life Year (DALY) saved is USD 110 for the visualization and USD 199 for the planning intervention. ${ }^{2}$ The WHO classifies an intervention as "cost-effective" for a cost per DALY saved below USD

\footnotetext{
${ }^{2}$ See Appendix A for detailed cost effectiveness calculations.
} 
4525, and "highly cost-effective" below USD 1508. By comparison, deworming projects have a cost per DALY saved of USD 28 - USD 70/DALY, and malaria bed nets of USD 100/DALY. ${ }^{3}$

The effect of our interventions is not limited to the health domain, but also extends to economic behavior: the Visualization intervention caused a statistically significant 26 percent increase in the amount saved per week (pre-specified as a secondary outcome). Effects were larger than those of the Planning intervention (significant at the ten percent level). In addition, the Planning intervention decreased the total self-reported hours of work in the last three months by 22 percent (although earnings did not decline, consistent with increased efficiency of work). We see no effects on use of other widely available preventive health products, such as vaccines or antenatal checkups, nor in non-health investments (such as in children's education), all pre-specified as exploratory outcomes. We conclude that light-touch psychological interventions may be most effective when participants also receive information emphasizing the benefits of a particular behavior change.

We also test if our psychological interventions have larger effects in villages where infrastructure lowers the effort and time costs of chlorination. We conducted our intervention in the study sites of a previous trial, the "WASH Benefits" study (Null et al. 2018). In this study, villages were randomly assigned to receive chlorine dispensers placed at the water source, and dispensers had been maintained after the trial. Our treatment effects on chlorination are somewhat larger in villages with dispensers, although differences are mostly statistically insignificant. Thus, we observe weak evidence that, when psychological, information and time cost/effort constraints are alleviated simultaneously, effects on behavior may be larger than when cost and access barriers remain.

Finally, we use lab-in-the-field methods and psychological questionnaires to study the mechanisms through which these treatment effects operate. We show, first, that differences in behavior are not explained merely by differences in beliefs about the efficacy of chlorine, or increased knowledge about chlorination. All three "active" treatment groups received the information treatment and show similar improvements in their belief that chlorination can prevent diarrhea, and in knowledge about using chlorine. But the effects of psychological treatments on chlorination and diarrhea are larger than the effects of pure information (i.e. the Active Control arm).

We then provide suggestive evidence in favor of two potential psychological channels accounting for the larger effect of the psychological interventions compared to the Active Control. First, we show large and significant effects of both the Visualization and Planning treatments, of 0.16 and 0.12 SDs, on a self-efficacy scale, which was pre-specified as one of three hypothesized mechanisms. ${ }^{4}$

\footnotetext{
${ }^{3}$ WHO figures: https://www.who.int/bulletin/volumes/93/2/14-138206/en/. Deworming: https://www.givewell.org/international/technical/programs/deworming/cost-effectiveness. Bed nets: https://forum.effectivealtruism.org/posts/HbunzTyFPRwcYihg6/long-lasting-insecticide-treated-netsusd3-340-per-life

${ }^{4}$ While the visualization intervention was primarily targeted towards time preferences, and the planning intervention towards planning skills, the design of both interventions required a strong mapping between current behavior and future outcomes. Specifically, visualizing alternative realizations of the future depending on current
} 
The larger coefficient in the Visualization treatment may explain why we observe somewhat larger effects on chlorine and diarrhea in this group, though none of the differences between Visualization and Planning are significant.

Second, in a "salience" task, we find that the psychological treatments focus participants' attention on chlorination more than the information treatment alone, even 10 weeks after the intervention. This effect is not present for other future-oriented behaviors (savings and farm investment), and thus not simply a consequence of becoming more forward-looking in general. ${ }^{5}$ While the Visualization and Planning interventions were designed to be domain-general, they use water treatment as an example behavior, often in the context of engaging stories or exercises. Together, these findings suggest that psychological interventions which build self-efficacy and successfully focus attention on a target behavior may be more effective than standard information campaigns.

Our psychological interventions do not significantly affect laboratory measures of time preferences, neither using an incentivized real-effort task, nor using multiple price lists over money. They also have no measurable impact on cognitive functions linked to planning, nor on a self-reported psychological scale measuring whether people took actions to achieve their goals. Furthermore, they do not affect lab measures of risk preferences. These results suggest that deeper underlying preferences and cognitive functions may not respond strongly to light-touch interventions. In contrast, self-efficacy and attention appear more malleable. A caveat is that we do not measure changes in participants' ability to simulate future utility (à la Gabaix and Laibson 2017). Especially the Visualization intervention may have improved forecasting abilities, which could explain differential impacts between the Visualization and the Planning intervention (notably, that savings increase in the former but not in the latter).

Although we cannot completely rule out that treatment effects may reflect social desirability bias in answering questions related to the content of the intervention, it is unlikely that such effects account for our findings. Most importantly, we observe increases in objectively measured chlorine content of stored household drinking water during unannounced household visits. The visits were closely concentrated in time within each village (thus making them hard to anticipate), and the treatment effects are robust to controlling for within-village chlorine test delay. We also observe no treatment effects on self-reported scales capturing other socially desirable behaviors specifically mentioned

behavior requires the belief that current behavior can affect future outcomes. Similarly, making detailed plans to achieve desired outcomes both requires and enforces the belief that these outcomes are within the individual's reach. We thus hypothesized that the interactive lectures and exercises in our treatments would strengthen the psychological concept of self-efficacy: Generalized Self-Efficacy (GSE) captures beliefs about one's ability to achieve desirable outcomes, and overcome obstacles (Bandura 1977). It is closely related to the economic concept of believed returns to effort, but commonly understood as domain-general rather than task-specific (Schwarzer and Jerusalem 2010). See Bandura (1997) and Reich and Infurna (2016) for reviews of the literature.

${ }^{5}$ This finding is in line with Zwane et al. (2011), who find people chlorinate water more if they are surveyed 18 times compared to three times, making chlorination more salient. 
in the workshops, such as scales measuring whether one has achieved one's goals in the past week.

Our paper makes several contributions to the existing literature. First, we show that addressing psychological barriers can lead to economically significant increases in the use of preventive health products, and these effects go beyond information alone. Our study builds on a small literature which shows that such light-touch interventions can increase long-term investments, including in health. The Visualization intervention drew on theoretical and empirical studies in economics and psychology suggesting that future visualization techniques may be effective at increasing patient behavior (Gabaix and Laibson 2017; Alan and Ertac 2018; Duckworth et al. 2011), including smoking cessation (Stein et al. 2018) and savings (Hershfield et al. 2011). The Planning intervention was adapted from a low-intensity psychotherapy approach called Behavioral Activation (Lejuez et al. 2011; Ekers et al. 2014) and a behavioral intervention known as "implementation intentions" (Gollwitzer and Sheeran 2006; Duckworth et al. 2013; Morisano et al. 2010). Interventions which help people to execute plans have been shown to improve immunization (Milkman et al. 2011), take-up of preventive screening (Milkman et al. 2013), and exercise (Stadler, Oettingen, and Gollwitzer 2009).

Relatedly, reminders (which counter limited attention) improve compliance with medical treatment regimens (Pop-Eleches et al. 2011) and increase productivity (Hanna, Mullainathan, and Schwartzstein 2014; Beaman, Magruder, and Robinson 2014). Showing videos of role models increases aspirations, savings, educational as well as business investment (Bernard et al. 2018), and reduces prevalence of sexually transmitted disease (Banerjee, la Ferrara, and Orozco 2018). ${ }^{6}$

Another literature documents that limited information may affect economic decisions. People are known to increase investment in preventive health or in high-return opportunities, such as education, after receiving information about benefits and returns (Dupas 2011; Jensen 2010; Jensen 2012; Dinkelman and Martínez 2014). This is also true in the context of drinking water, where information that water is unsafe can lead to substitution to different water sources (Madajewicz et al. 2007; Jalan and Somanathan 2008). However, in other cases, information campaigns have not induced behavior change (Dupas 2009; Duflo, Dupas, and Kremer 2015). In our setting, providing information and changing beliefs alone does not result in behavior change. In contrast, psychologically targeted elements of these interventions, which improve self-efficacy and the salience of the targeted behavior, are necessary to achieve measurable improvements in outcomes. ${ }^{7}$

\footnotetext{
${ }^{6}$ In addition, more involved, multi-session interventions which target self-esteem and self-efficacy improve sex workers' savings and attendance at health checkups (Ghosal et al. 2019) and produce increases in employment McKelway (2018). Multisession interventions that resemble psychotherapy improve patience (Blattman, Jamison, and Sheridan 2017) and reduce automatic decision-making (Heller et al. 2017), reducing violence and antisocial behavior. With depressed mothers, they improve financial empowerment and investment in children (Baranov et al. 2017).

${ }^{7}$ Our results suggest a possible reinterpretation of past findings: some successful "information" interventions may work by combining pure information with psychological elements. For example, information about chlorination provided by promoters may also operate through psychological mechanisms (Kremer et al. 2011b; Kremer et al. 2011a). Indeed, messaging around free safe water products is particularly effective in increasing adoption when it is behaviorally inspired (Luoto et al. 2014).
} 
More narrowly, our paper contributes to research that aims to increase chlorination of drinking water, which has examined price mechanisms (Ashraf, Berry, and Shapiro 2010; Dupas et al. 2016; Kremer et al. 2011b), communal vs. individual persuasion (Kremer et al. 2011a), and combinations of information and subsidies (Ashraf, Jack, and Kamenica 2010; Null et al. 2018; Kremer et al. 2011a). Other researchers working on chlorination have noted that psychological constraints may affect choices about water treatment. ${ }^{8}$ We show that psychological interventions have causal effects on behavior and provide evidence that they work through psychological channels. These findings complement other work on increasing demand for chlorination. Our interventions could therefore be deployed in combination with these other programs, to deliver clean water to the 2 billion people who currently use drinking water contaminated with feces. ${ }^{9}$ They could also be adapted to encourage use of other preventive health products, as well as productive investments more generally.

The remainder of this paper is structured as follows. Section 2 describes the study design. Section 3 describes the interventions. Section 4 describes the outcome variables. Section 5 describes the estimation approach. Section 6 reports results. Section 7 discusses potential mechanisms. Section 8 concludes.

\section{Experimental design}

\subsection{Sampling and randomization}

Our study areas are Bungoma and Kakamega counties in rural Western Kenya. These counties were included in the WASH Benefits study (henceforth WASH) of Null et al. (2018). The WASH study was a cluster-randomized controlled trial, conducted from 2012 to 2014, which included 1,226 villages (Null et al. 2018). Villages were grouped into clusters of one to three neighboring villages. Clusters were then randomized to eight treatment arms, six of which tested household-level water, sanitation, handwashing, and nutrition interventions in isolation and different combinations of interventions. ${ }^{10}$

We sampled 205 villages from the full sample of 1,226 villages. In one treatment group of the WASH study, villages were provided with chlorine dispensers next to water sources, as well as community health promoters. We randomly selected 67 villages from this "Water Quality" (henceforth "dispenser") treatment arm and 67 villages from the "Passive Comparison" arm, which received no interventions. ${ }^{11}$ In the dispenser villages, chlorine dispensers were installed at an average of five

\footnotetext{
${ }^{8}$ For example, in Zambia Ashraf, Berry, and Shapiro (2010) note that women often mentioned being "busy" or "distracted" after gathering water as a reason for buying chlorine but not using it. In Bangladesh, Luoto et al. (2011) note the importance of understanding behavioral barriers to use, after finding that none of four water treatment products had usage rates of above 30 percent, despite the provision of subsidies and extensive information.

${ }^{9}$ https://www.who.int/news-room/fact-sheets/detail/drinking-water

${ }^{10}$ For more information on the WASH Benefits study, see Appendix B.

${ }^{11}$ There were two comparison groups in the original WASH study: an active comparison group, where children's
} 
community water points per village cluster, and refilled as needed. The "Dispensers for Safe Water" program operated by the NGO Evidence Action has since maintained these dispensers, ensured they are filled with chlorine, and retained a local promoter in each community. The randomization has remained intact. An additional 71 villages were selected uniformly from the remaining six WASH Benefits arms in Mumias district, Kakamega county. The inclusion of participants from villages treated by the remaining six arms of the WASH intervention was not planned in our study, but occurred as a result of a coding error at the sampling stage. During the WASH Benefits study, 48 of these 71 villages received one of sanitation, handwashing or nutrition interventions, but no dispensers. However, these additional interventions all took place at the household level, and we exclude households which participated directly in the original WASH study from participation in the present study. In addition, all interventions other than dispensers finished three to four years before our study. For these reasons, we group these 48 villages with the passive comparison villages in our analysis. ${ }^{12}$ The other 23 villages received dispensers, as well as combinations of sanitation, handwashing or nutrition interventions. We group these villages with dispenser villages, as Evidence Action continued to maintain dispensers in these villages. As a robustness check, we exclude these 71 villages from the heterogeneity analysis by "Water Quality" assignment in Appendix F.

In the 205 study villages, we recruited 3750 women aged 18-35 between October 2017 and January 2018. We focus on women because they are primarily responsible for household chores, including collecting water, and thus for water chlorination. We recruit women aged 18-35 as they are most likely to have small children, who in turn are the most vulnerable to water-borne illnesses. With the help of local guides, enumerators visited all households in each included village (see Section B) and conducted a census to determine household eligibility. Enumerators collected demographic information on women that met the screening criteria: i) aged 18-35 inclusive, ii) within this age range, the most senior woman in their household, and iii) their household did not participate in the WASH Benefits study. The target sample of 3750 women represents all eligible women in the 205 villages. As shown in Table 1, the women in our sample are on average 26 years old, 89 percent are married or cohabiting, and they have on average 6 years of education.

We split our sample into three "active" treatment groups and one pure control group. We randomly assigned 992 participants to the "Visualization" (V+INF) group, 991 to the "Planning" $(\mathrm{P}+\mathrm{INF})$ group, 992 to the "Active Control" (AC+INF) group, and 775 to the "Pure Control" group. We stratified the randomization on village of residence, and a wealth index collected

arm circumference was measured, and a passive comparison group, where children were not measured but other outcomes were measured.

${ }^{12}$ Specifically, we exclude women who self-report having participated in the WASH study, and households with children aged either 3-4 or 4-5, depending upon the village's WASH Benefits timing. The reason for this second exclusion is that the WASH Benefits study recruited women in their second or third trimester of pregnancy in 2012. As a result, our sample is composed of women who were exposed to village-level, but not household-level interventions through the WASH Benefits study. 
during the census. ${ }^{13}$ Redundant observations during stratification were equally distributed across treatment groups.

Participants were assigned randomly to attend baseline and intervention sessions either in the morning or in the afternoon. While participants were encouraged to attend the session type assigned to them, they were allowed to switch to the other session time if necessary to minimize attrition. Within a geographical region and within each treatment group, participants were invited to sessions in alphabetical order, based on the first letter of their last name.

\subsection{Design and timeline}

The project was approved by the Princeton (\#7376) and KEMRI (\#536) IRBs. Participants in the three "active" treatment groups participated in three sessions: a combined baseline and first intervention session; a second intervention session one week later; and an endline 10 weeks after the first session. Participants in the pure control group did not participate in the baseline and the first and second intervention sessions, but participated in the endline 10 weeks after the beginning of the study in their village. In addition, households in all four groups received an unannounced visit 12 weeks after the beginning of the study, where enumerators collected a drinking water sample to be assayed for the presence of chlorine.

The baseline and endline sessions lasted about two hours each and consisted of behavioral tasks, psychological questionnaires, and a socioeconomic survey. These measures were collected in "mobile labs" operated by the Busara Center for Behavioral Economics in Bungoma and Kakamega counties, which each accommodated up to 25 participants at a time. The behavioral tasks and psychological questionnaires were presented using touch screen computers, audio instructions, color-coded response buttons using the zTree experimental interface (Fischbacher 2007), which allowed both computer-illiterate and entirely illiterate individuals to participate. Enumerators read instructions to the respondents in Kiswahili to maximize comprehension. ${ }^{14}$ The socioeconomic survey was administered one-on-one by enumerators using tablets.

Each intervention session in the three "active" treatment groups lasted about two hours. Participants were split into cohorts of five for each session, which were run by locally-trained female facilitators. Participants were reconvened in the same cohorts for the second session. No participant was invited for the second session without having already participated in the first session.

Participants received KES 250 (USD 2.50) for participating in the baseline survey and first intervention session, KES 250 for the second session, and KES 350 for participating in the endline

\footnotetext{
${ }^{13}$ The wealth index consisted of the total value of a limited set of assets (bicycles, cellphones, gas stoves, all livestock, radios, sofas and televisions). Participants were split at the median into a "high" and "low" wealth group.

${ }^{14}$ Most Kenyans speak a tribal "mother tongue" at home, Kiswahili as a lingua franca, and English as the language of education and business. The Busara Center uses Kiswahili as the medium of oral communication in most studies with this population.
} 
session. ${ }^{15}$ Participants were reimbursed for their transport costs, using public transport rates from their village of residence to the mobile laboratory. Finally, participants received payments from the experimental tasks, as described in Section 4. Typical total study payments (excluding transport) were around KES 1600 in the active treatment groups, and around KES 750 in the pure control group. Participants were informed of the fixed amounts that they would be paid during the phone call inviting them to a session, and told that they would have the opportunity to earn some extra money during the session. All participants recruited to the sample were invited to attend endline sessions, regardless of whether they attended the baseline and/or intervention sessions. Table A.1 shows the number of participants at each stage of the study.

\subsection{Background on chlorination use}

Child diarrhea is relatively high in our study area, as it is in many parts of the developing world. In the original WASH study control group, diarrhea prevalence in the past 7 days was 27 percent among children aged 1 and 2 (Null et al. 2018); in our pure control group at endline, there have been 0.2 incidences of diarrhea per child under 15 in the last 3 months. Fecal contamination of drinking water is a likely cause of these episodes. Most of the population relies on communal water sources, usually wells with pumps or springs (Null et al. 2018). Women and children collect drinking water in plastic jerry cans, which is then kept in clay storage pots in the home. Water can be contaminated easily as it is removed from storage pots.

Chlorinating water kills many of the pathogens that cause diarrhea. ${ }^{16}$ Absent point-of-collection chlorine dispensers (as installed by WASH), households can purchase dilute chlorine. The main brand of dilute chlorine is WaterGuard, which has been distributed and heavily marketed by the NGO Population Services International (PSI) in Kenya since 2003. WaterGuard is available in most local shops in the study area, and costs KES 25 (USD 0.25) per $150 \mathrm{ml}$ bottle, about 0.2 percent of average monthly earnings. Each bottle treats $1000 \mathrm{l}$ of water (approximately one month to 50 days of household drinking water) (Dupas et al. 2016; Lantagne et al. 2010) and comes with instructions in Swahili and in pictures. There is widespread awareness of this product: even at baseline of the WASH study in 2012, 89 percent had heard of WaterGuard, and 29 percent had used it at least once (Null et al. 2018). Households also believe chlorine is effective: at endline, the pure control group believe, on average, that 71 percent of incidences of diarrhea can be avoided by using chlorine.

However, take-up of chlorination is low. Even using chlorine from a free dispenser requires repeated, proactive behavior. Dispensers are not present at every water point, so people might need

\footnotetext{
${ }^{15}$ USD 1 was equivalent to approximately KES 100 at the time of the study.

${ }^{16} \mathrm{~A}$ meta-analysis finds point-of-use methods of chlorinating drinking water reduce child diarrhea by an average of 29 percent across 21 randomized controlled trials, suggesting unpurified water causes at least some episodes of diarrhea (Arnold and Colford Jr 2007).
} 
to plan their journeys to go past the correct water point. They might also need to make alternative arrangements if the dispenser is not filled, or remind children fetching water to chlorinate it. In non-dispenser villages, women would need to purchase WaterGuard, paying both time and monetary costs, and remember to add it to each batch of water. In our sample at endline, 27 percent of pure control households report having chlorinated their current drinking water supply, 18 percent had detectable free chlorine in their water, and 22 percent had detectable total chlorine. ${ }^{17}$

Taste is mentioned as a potential barrier to chlorination use (Dupas et al. 2016; Ashraf, Berry, and Shapiro 2010). Indeed, it is possible to taste if water has been chlorinated: in a blind taste test among staff of the Busara Center for Behavioral Economics, on average participants correctly identified when drinking water had been treated with chlorine 75 percent of the time. However, we found no statistically significant differences in the taste rating participants gave to chlorinated vs. unchlorinated water (unchlorinated water mean score $=6.21 / 10$, chlorinated water mean score $=6.06 / 10$, $p=0.66, n=90)$. While taste may prevent complete take-up of the product, taste differences are present to the same extent in all arms, so do not confound estimates of treatment effects.

\section{Interventions}

The structure of each session was held constant across treatment groups: each included a short lecture, followed by a story of a woman like them, reflections of how the themes relate to participants' own lives, and finally drawing and list-writing exercises and activities.

\subsection{Treatment 1: Visualization + Information module ("V+INF")}

The objective of the future visualization intervention was to increase internal motivation for patient behavior. The intervention is based on the idea that present utility is easier to imagine than future utility. A substantial body of evidence in psychology shows that people imagine future events in much less detail than immediately upcoming events, focusing on abstract qualities rather than details of execution (see e.g. Gilbert and Wilson 2009, Kahneman et al. 2004, Wilson et al. 2000). For instance, helping out an elderly relative with their tax return next month may be imagined as an act of love, while doing it later today is imagined as hours of painstaking sorting through receipts. In a recent theoretical contribution, Gabaix and Laibson (2017) formalize the idea of as-if discounting, which results from a perfectly patient decision-maker who simulates future utility by combining priors with noisy, unbiased signals about future utility. The model implies that interventions which improve forecasting ability (or forecasting efforts) will lead to more patient

\footnotetext{
${ }^{17}$ See Section 4.1 on the distinction between free and total chlorine. We report free chlorine here for comparison with other studies, but focus on total chlorine as our primary outcome measure.
} 
behavior, without changing the underlying preference parameters. Models of quasi-hyperbolic discounting (Laibson 1997 and O'Donoghue and Rabin 1999) are based on a differential weight given to the present. Despite fundamental differences, both models predict that an increased focus on the future will be associated with fewer dynamic preference reversals. ${ }^{18}$

The theoretical predictions are matched by empirical evidence: in a randomized educational intervention in Turkish primary schools, Alan and Ertac (2018) find that eight weekly classes on "imagining future selves" result in the children making more patient decisions in incentivized choice tasks three years after the intervention. Research in psychology had previously established that participants exposed to vivid imagery of their future selves increased hypothetical retirement savings in laboratory and online studies (e.g. Hershfield et al. 2011). Further evidence on the effects of future visualization techniques comes from the literatures on "best possible selves" (Markus and Nurius 1986; Sheldon and Lyubomirsky 2006; King 2001), "episodic future thinking" (Daniel, Stanton, and Epstein 2013), and "mental contrasting" (though mental contrasting is commonly coupled with planning elements, such as implementation intentions, see e.g., Oettingen, Pak, and Schnetter 2001, Oettingen, Mayer, and Thorpe 2010, and Duckworth et al. 2011).

The core of our intervention was to encourage participants to a) connect their present behavior to outcomes in the future, b) visualize alternative realizations of the future, depending on their current behavior, and c) put themselves in the shoes of their future selves, imagine how they feel, and 'talk' to them. The approach was deliberately visual and emotional, with participants asked to close their eyes repeatedly for several minutes, and to imagine their future selves in as much graphic detail as possible. We hypothesize that increased vividness of the future may affect behavior through a change in time preferences, a change in forecasting skills, or a stronger mapping between present behavior and future outcomes (self-efficacy).

In the first intervention session, participants were given an interactive lecture on thinking about the future. Participants were asked to think about the effect of small everyday behaviors (such as spending their leftover budget on snacks) on future outcomes. The intervention carefully avoided changing participants' beliefs about which present behavior would entail which future outcome - it merely encouraged them to make the connection themselves. Instead of pre-scribing a list of everyday behaviors, facilitators largely relied on examples brought up by the participants. The session then moved on to several silent visualization exercises, with prompts including "Close your eyes for one minute. Imagine the person you will be in one year. Imagine your family in one year." and "Imagine that your future self can now talk to you. How does she feel? What does she want you to do?" In the second part of the session, participants listened to a story of

\footnotetext{
${ }^{18}$ Both "as-if discounting" à la Gabaix and Laibson (2017) and quasi-hyperbolic discounting generate dynamic preference reversals, but only quasi-hyperbolic discounting generates self-control problems and commitment demand. Since there is no commitment in our study, the models are observationally equivalent for our purposes.
} 
a woman whose daily life is full of tasks and worries, and who consequently focuses only on what is necessary right now. Using examples of water chlorination and antenatal care visits, she learns over time that thinking about the future in her everyday actions helps her and her family to have a better life. The story was followed by a group discussion on behaviors from the participants' own lives, and visualizing alternative realizations of their own future, depending on present behavior. The session finished by asking participants to draw one these "future realizations", and make notes on the corresponding present behavior. Unlike the Planning intervention, it focused on high-level behaviors and outcomes without implementation details. The first intervention session concluded with the information module described below. In the second Visualization intervention session, participants largely revisited the first session, albeit with increased emphasis on how future visualizations can be used to deal with temptations in the present.

\subsection{Treatment 2: Planning + Information module ("P+INF")}

The Planning intervention aimed to help participants to undertake activities that they had identified as important but were struggling to do regularly. The key idea was to make

concrete, specific plans, and approach them in a way that is informed by recent work in psychology. One approach to treating mild depression, known as behavioral activation, draws on literature on instrumental reinforcement and motivation (Lejuez et al. 2011). ${ }^{19}$ Depressed people often reduce their overall activity level and avoid even basic tasks. In turn, avoidance exacerbates negative moods, which further increase avoidance. Behavioral activation teaches participants to set short-term goals, make detailed plans, and systematically start with the easiest tasks to "get going." This breaks the cycle of avoidance, and harnesses self-reinforcing motivation cycles (Ekers et al. 2014; Weobong et al. 2017).

A second literature on "implementation intentions" (Gollwitzer and Sheeran 2006; Locke and Latham 2002) suggests that plans are more likely to be implemented if they are concrete and detailed, if they anticipate potential obstacles, and incorporate strategies to overcome them. Interventions encouraging individuals to make such plans have improved classroom behavior and test scores with school students (Duckworth et al. 2013; Morisano et al. 2010), and increased voter turnout (Nickerson and Rogers 2010). In the health domain, they increase take-up of vaccinations (Milkman et al. 2011), preventive screening (Milkman et al. 2013), and reported exercise (Stadler, Oettingen, and Gollwitzer 2009). Importantly, completing a particular action plan (in this case, to exercise) has been associated with an increase in self-efficacy (Lorig et al. 2014).

The first session began with a short lecture about how anyone can get stuck in cycles of inactivity, where they lack motivation to get things done and lose out on the sense of achievement

\footnotetext{
${ }^{19}$ Importantly, we do not screen for or target people with depression symptoms, or attempt to provide any treatment for depression. We use manuals by Richards and Whyte (2011) and Lejuez et al. (2011).
} 
of accomplishing what they intended to do. Participants then listened to a story of a woman very similar to them who was overwhelmed and struggling to organize her chores, including fetching water and chlorinating it. Once she fell out of the habit of doing routine tasks, she found it very hard to find the motivation to start again. This had negative consequences for herself and her family. Participants could then share experiences of similar situations from their lives.

In the second part of the first session, participants were asked to identify activities in their daily lives that they felt were important, but where they were struggling to "get going." In contrast to the Visualization intervention, they did not set long-term goals, but focused on activities they could do in the next week. With a partner, they completed a simple worksheet with two lists of activities: one set that they enjoyed doing, and one set that were necessary and important but they might not enjoy. They ranked the tasks on each list from most to least difficult. In the final part of the session, participants picked the easiest one or two activities from each of the "necessary" and "enjoyable" lists of activities, and scheduled them in a weekly diary. They then broke the task down into steps, visualized what they would need to do to complete the activity, anticipated potential obstacles, and made plans how to overcome them. The first intervention session concluded with the information module described below. In the second intervention session, they worked in the same group with the same partner where possible. They crossed off completed plans and circled uncompleted ones, discussed barriers they had faced to undertaking the activities, and brainstormed ways to overcome these barriers in the future.

\subsection{Treatment 3: Active Control exercise + Information Module ("AC+INF") and Pure Control ("PC")}

The "active control" intervention controls for any effects of simply attending a session and interacting with women from neighboring villages. The sessions followed the format of the two treatment interventions. The content of these sessions centered on the birds and plants of Kenya, topics chosen intentionally to be psychologically inactive. In the first session, participants listened to a short lecture on different kinds of birds that live in Kenya, followed by a short story about the daily routine of a woman similar to them. Participants discussed the birds they see in their village, and any birds they were particularly interested in. They wrote a list of all the birds they could think of, and then made some drawings of birds. The second session followed an identical structure, except that it did not include another short story about a woman, in line with the second sessions of the other treatment groups. The second session centered on plants in Kenya. In addition, participants in this group also received the same information module as the Visualization and Planning treatment groups described above.

All three intervention groups concluded with an information module about the benefits of 
chlorination. Participants were read information on chlorination, as well as on antenatal and postnatal care (ANC/PNC). The text on chlorination read: : "Not all "drinking water" is safe, even when it is sold as "treated". Only water properly treated with chlorine or boiled water is safe to drink. If you drink unsafe water you and your family may get dangerous diseases like diarrhea, typhoid and cholera. Children are the most seriously affected by diarrhea: children can quickly become dehydrated and very ill, and having diarrhea a lot can stop children from growing at a normal rate. But you can avoid one out of three times you or your children gets diarrhea simply by chlorinating your water with a product like WaterGuard, or chlorine from a dispenser. Chlorinating in this way takes 30 minutes and makes it unnecessary to boil the water. One capful of WaterGuard makes 201 of water clean. If you keep the water covered and in a closed container with a lid, and don't dip dirty cups back into the water, the drinking water can't get re-contaminated. The smell of chlorine is not harmful and reduces over time. Chlorine is much cheaper than firewood for boiling. At some water points it is even available for free from a dispenser."

The pure control group were recruited at the same time as other groups. They completed a brief demographic questionnaire household recruitment but received no contact prior to endline.

\section{Outcome measures}

\subsection{Behavioral outcomes}

Our main pre-specified outcome is an objective measure of whether households chlorinate their drinking water. Enumerators made unannounced visits to participants' homes to test the household's stored drinking water for the presence of chlorine to minimize experimenter demand effects in the survey (de Quidt, Haushofer, and Roth 2018).We pre-specified Total Chlorine Residual (TCR) as our main chlorination outcome measure of interest. . TCR indicates the presence of any chlorine in the water; i.e., that the household had at some point added some amount of chlorine to the drinking water, which is suitable if one's primary interest is whether households attempt to chlorinate their water at all. ${ }^{20}$ We note that our measure is a lower bound on actual usage. Chlorine decays over time after being added to water, and may be undetectable in water after 24 hours (Null and Lantagne 2012). Households who store water for two to three days may thus appear not to have treated water.

We follow the same chlorine testing procedure as Null et al. (2018) and Kremer et al. (2011a). To conduct the tests, enumerators filled vials with a sample of stored household drinking water and added DPD chlorine reagent powder, separately for total chlorine and free chlorine. Using

\footnotetext{
${ }^{20}$ This is also the outcome of interest in Kremer et al. (2011a) and Dupas et al. (2016). Null et al. (2018) and Ashraf, Berry, and Shapiro (2010) focus on Free Chlorine Residual (FCR), which indicates that not only has chlorine been added, but that there is still enough unreacted chlorine in the water to keep it sanitized; i.e., that the household added sufficient chlorine to the drinking water.
} 
color comparator boxes and DPD color discs, enumerators recorded the level of chlorine present in the water sample, between $0 \mathrm{mg} / \mathrm{l}$ and $3.4 \mathrm{mg} / \mathrm{l}$. The TCR variable is 1 if any total chlorine is present in the sample, and 0 otherwise. The FCR variable is 1 if any free chlorine is present in the sample, and zero otherwise (CDC 2010).

While chlorination is our primary outcome of interest, our interventions were intended to be domain-general. Visualizing future benefits, as well as planning skills, are relevant for many everyday behaviors, and in particular for future investments like savings, education, and agricultural investments. During the endline survey, participants therefore completed several modules on economic and health behaviors. We pre-specified secondary outcomes as the extensive margins for savings and labor supply, as well as an index of investment into children's education. We also specified exploratory outcomes related to health (diarrhea, vaccinations, and ante-natal care visits).

\subsection{Targeted psychological channels}

We hypothesized three key mechanisms for the effect of our interventions on behavior: the Visualization intervention targeted time preferences and self-efficacy, while the Planning intervention targeted planning skills and self-efficacy (see footnote 4). We use a combination of incentivized choice tasks and validated psychological scales to measure these constructs.

Planning skills: First, we measure whether people choose to make plans and follow through on them in their everyday lives, with a short form of the Behavioral Activation for Depression Scale (Kanter et al. 2007; Manos, Kanter, and Luo 2011). Participants are asked to identify how much statements were true for them in the past week, including both positive (e.g. "I was an active person and accomplished the goals I set out to do") and negative items (e.g. "There were certain things I needed to do that I didn't do"). Responses range from "not at all" (1) to "completely" (7). Some items are reversed before summing to generate a composite score. Second, we use an incentivized version of the Tower of London task (TOL; also known as the "Stockings of Cambridge" task when implemented electronically), which measures a participant's higher-order cognitive ability to plan ahead in sequential strategies (Shallice 1982; Phillips et al. 2001). Appendix D.1 provides further details. ${ }^{21}$

Time preferences over effort: Following recent innovations in the elicitation of time preferences (Andreoni and Sprenger 2012; Augenblick, Niederle, and Sprenger 2015), and noting that

\footnotetext{
${ }^{21}$ Some of the psychological measures - the Tower of London task, Monetary Price Lists for time preferences, and the General Self-Efficacy Scale - were validated in a previous study (Esopo et al. 2018). This study involved translation and back-translation of the measures into Kiswahili, cognitive interviewing to establish cultural acceptability of the measures, and tests of internal consistency, test-retest reliability, and construct validity.
} 
water chlorination is an effortful task, we estimate time preferences in the effort domain. We use the methodology of Augenblick (2017), and implement it with a newly developed effort task, adapted to a field setting without computer or smartphone access in a developing country: participants choose how many units of an effort task they want to complete at a time $t$ for a piece rate $w$, where $t$ is $0,1,7$, or 8 days from today, and the piece rate $w$ is $\operatorname{KES~2,~6,~or~10.~Each~effort~task~consisted~}$ of sending a 30-digit random number string by SMS to a toll-free number. ${ }^{22}$ Participants thus decided, for each combination of $t$ and $w$, how many such strings they wanted to send by SMS. One time and one piece rate are randomly implemented at the end, and enforced using a KES 100 completion bonus. Following Augenblick (2017) as well as DellaVigna and Pope (2017), we structurally identify a present bias parameter $(\beta)$ and an impatience parameter $(\delta)$ assuming quasi-linear utility and a power cost of effort function. Appendix D.2 provides full details on the estimation.

In addition to the effort discounting task, we included a conventional Multiple Price List (MPL) (see Andreoni and Sprenger 2012 for a discussion), to measure monetary discounting. Payments ranged from KES 100 to KES 300, and delays included today, four weeks, and eight weeks. See Appendix D.3 for details.

Self-Efficacy: Self-efficacy broadly captures whether individuals feel a sense of control over their life. More specifically, self-efficacy is defined as the belief that one is able to achieve desired outcomes, and overcome obstacles (Bandura 1977). Beliefs are more difficult to capture in incentivized choice tasks than preference parameters or cognitive skills. Consequently, we rely on a widely used and validated psychological scale, the Generalized Self-Efficacy (GSE) scale (Schwarzer and Jerusalem 2010). Participants are asked to rate the truthfulness of statements such as "I can always manage to solve difficult problems if I try hard enough" on a scale from "never true" $(0)$ to "always true" (5). Our version contains 12 statements, 10 from the generic version, and two which are repeated and reversed. Responses are aggregated into a summary score and z-scored.

\subsection{Alternative Mechanisms}

As far as possible, our design holds other mechanisms which may drive behavior constant across the three active arms. In particular, the addition of the information module to all active arms ensures that beliefs and knowledge about chlorination are held constant. We verify this using multiple-choice questions. In addition, we test for differential effects of our treatments on the salience of chlorination and other future-oriented behaviors, as well as on risk preferences.

\footnotetext{
${ }^{22}$ Although we did not screen on phone access, all participants in our sample have access to a mobile phone: 71 percent own one, 96 percent have one in their household, and the remainder shares the phone of friends or relatives. Since phones are often used by multiple individuals, phone access should be understood as continuous rather than binary.
} 
Beliefs and Knowledge: We measure participants' beliefs about the effectiveness of chlorination in preventing disease. In particular, we measure beliefs across treatment groups about the proportion of pediatric diarrhea cases which can be prevented through water chlorination. We also measure knowledge about how to properly use chlorine with two multiple-choice questions: 1. how much chlorine to add to water, and 2. the amount of time that needs to pass after adding chlorine for water to be safe to drink. We score each question as a binary measure of whether the participant answered correctly and create a composite value that ranges from 0 to 2 , which is then z-scored. ${ }^{23}$ All belief and knowledge questions refer to information which was provided in the information module (Section 3.3) ten weeks earlier.

Salience Task: We test whether our interventions differentially focus participants' attention on chlorination. Since chlorination is an investment good, an increased salience of chlorination may be expected directly as a result of becoming more focused on the future (especially in the Visualization treatment). In this case, the salience of all future-oriented behaviors should increase. To disentangle confounds from such intended treatment effects, we measure the salience of three future-oriented behaviors (chlorination, savings, and farm investment) compared to non-future oriented behaviors. Enumerators read out three lists of nine words each to every participant, and asked her to recall as many words as possible directly after reading each list (participants were paid KES 5 for every word they remembered). Each list contained three categories of future-related words (chlorine, savings, and farm investment), as well as non-future related filler words (see Table A.7 for the list of words). While the recall of words is clearly driven by memory, the recall of words conditional on the total number of words remembered captures whether a concept is "top-of-mind". We thus test whether our treatments differentially affect the probability to recall chlorine words, conditional on the total number of words remembered. If our treatments differentially affect the salience of chlorine, we further test whether this is due to increased salience of future-oriented behaviors in general, by asking whether the differential treatment effect also holds for saving and farm investment, which were not emphasized in the sessions (see Appendix D for the empirical specification).

Risk Preferences: Chlorination behavior may increase if our participants became more risk averse in response to one of our treatments. We measure risk aversion using a modified EckelGrossman task which offered a choice between one of three 50/50 lotteries, represented as bets on a coin flip (Charness, Gneezy, and Imas 2013). One participant per session (25 people) was paid their chosen lottery. We construct an ordinal measure of risk aversion with three levels, based on the expected payout the participant is willing to forgo for an increase in certainty of payout.

\footnotetext{
${ }^{23}$ We similarly check for differential knowledge of WHO-recommended antenatal and postnatal care. These questions were included to pilot them for a future study.
} 


\section{Econometric approach}

\section{$5.1 \quad$ Experimental integrity}

We test for balance across treatment groups in (1) demographic variables and key outcomes, (2) timing of the surveys relative to the intervention, (3) participation in the endline survey and the chlorination test at home, and (4) compliance with the assigned treatment (i.e., participation in the intervention sessions). We regress baseline demographics available for the entire recruited sample (age, years of education, marital status, and village, see Section 2.1) on indicators for all treatment groups. The reference group is either the active control $(\mathrm{AC}+\mathrm{INF})$ or the pure control group (PC). The specification is identical to that used for the estimation of treatment effects (described in Sections 5.2 and 5.3), leaving out controls $\mathbf{X}_{i}$ and lags $y_{i 0}$.

We further test for differences in the timing of the endline survey relative to the baseline survey and first intervention date, as well as the timing of the chlorine test relative to the baseline survey and first intervention date. The outcome variables are the number of days between the first intervention and the endline survey, and between the first intervention and the chlorine test. For participants in the pure control group, and those in the treatment groups who did not attend the interventions, we use predictive mean matching to simulate a proxy intervention date, based on the actual intervention dates of other participants from their village of residence.

We also test for selective attrition in attending the endline survey and the chlorination test at home, for both the active control group comparison and the pure control comparison. We define attrition in two ways: firstly, failure to attend endline conditional upon being recruited to the study; and secondly, failure to attend endline conditional upon completing the baseline and first intervention. The specification is identical to that used for the estimation of treatment effects. Additional checks assess whether attriting individuals are different from non-attriting individuals in terms of observed demographics.

Finally, although recruited participants did not know their treatment assignment prior to arriving for the first intervention session, we test for differential compliance across treatment groups - i.e., the decision to participate in the first and second intervention session. Again, the

specification is identical to that used for the estimation of treatment effects, except that the outcome variable is an indicator for session attendance. 


\subsection{Main specification: Planning and Visualization treatments com- pared to Active Control}

We employ the following main specification:

$$
y_{i 1}=\alpha_{0}+\alpha_{1} T_{1 i}+\alpha_{2} T_{2 i}+\boldsymbol{\Phi}^{\prime} \mathbf{X}_{i}+\delta y_{i 0}+\gamma_{v}+\theta_{w}+\eta_{i}
$$

Here, $y_{i 1}$ is the outcome of interest for respondent $i$ at time of endline. $T_{1 i}$ and $T_{2 i}$ are dummies equal to one if the respondent is assigned to the "Visualization" or "Planning" group, respectively. X is a vector of participant controls (year of birth, employment status, marital status, education level). $\gamma_{v}$ are village fixed effects, and $\theta_{w}$ is an indicator for household wealth greater than the sample median (which was used for stratification). Standard errors are clustered by intervention cohort (five participants) to account for within-group dynamics. Psychological scales, behavioral tasks, selfreported chlorination, and diarrhea incidence were the only outcomes collected at baseline. For these variables we include $y_{i 0}$, the same outcome variable at time of baseline, in the regressors. Where only some baseline observations of a variable are missing, we replace the missing values with zero and add a dummy variable indicating such cases, following Jones (1996). We remove outliers by winsorizing outcome variables which have no theoretical lower and upper bounds at the 1st and 99th percentile.

The sample excludes the PC group. Thus, the AC+INF group is the reference category. As pre-specified, the sample includes all participants who completed both the endline survey and at least the first intervention session. Note that selection into the sample based on treatment is not possible because the nature of the intervention was not revealed before the first intervention session.

The comparison between the two "psychological" treatment groups and the AC+INF group isolates the effects of the psychologically active elements of these treatments. It tests the effect of interventions specifically targeting the ability to visualize the future or to make and execute plans, respectively, over and above the effect of the $\mathrm{AC}+\mathrm{INF}$ intervention (which provided information about the benefits of chlorination and got participants to gather as a group).

\subsection{Comparison with pure control group}

We also report results from comparing the three active $(\mathrm{V}+\mathrm{INF}, \mathrm{P}+\mathrm{INF}$, and $\mathrm{AC}+\mathrm{INF})$ to a pure control group (PC). As pre-specified, the sample includes all recruited participants who completed the endline survey, including "non-compliers" who were assigned to the active treatment groups, but chose not to participate in the baseline survey or the interventions. The comparison between the three "active" treatment groups and the pure control group gives the policy-relevant effect: the total effect on targeted behaviors of providing interventions such as ours in other, similar settings.

The specification is identical to that in equation 1, except that there is a third treatment 
indicator $T_{3 i}$ for the active control group, and the pure control group is used as the reference category. Further, since the pure control group was not surveyed at baseline, the estimation does not control for the baseline outcome $y_{i 0}$. Finally, because the pure control completed the endline survey on average two days earlier than the active treatment groups, the specification includes fixed effects for i) the week of endline survey and ii) the day of the week of endline survey. ${ }^{24}$

\subsection{WASH Benefits cross-randomization}

To study differential effects of our treatments in villages which do and do not have free and convenient access to chlorine through dispensers, we separately estimate the same pure control specification for dispenser and control villages using seemingly unrelated regression (SUR). This approach allows coefficients on control variables to vary by village treatment status, and at the same time allows us to compare treatment coefficients across models. The primary outcome of interest is an indicator for objective chlorination (TCR).

Due to a coding error in sampling (see Section 2.1), some participants were drawn from treatment arms of the WASH Benefits study other than "Water Quality" or "Passive Comparison." As noted above, we include these participants in the main analysis of the cross-randomization, grouped by whether or not their village had a chlorine dispenser. We exclude them in a robustness check in Appendix F.

\subsection{Treatment-on-the-Treated (TOT) Effects}

As pre-specified, we also report "treatment-on-the-treated" effects from an instrumental variables specification in which treatment status is instrumented with treatment assignment. For this purpose, we consider all those in any "active" group, including the active control group, who attended at least the initial baseline session to be complying with treatment assignment, even if they didn't complete the second session. ${ }^{25}$ For the comparison of the V+INF and P+INF to the $\mathrm{AC}+\mathrm{INF}$ group, the sample is already restricted to compliers, so that the TOT effect is the same as the Average Treatment Effect (ATE). We therefore report the TOT only for the comparison of the three active treatments to the pure control group.

\footnotetext{
${ }^{24}$ The inclusion of these fixed effects was not pre-specified. We report results in Table A.20 and Table A.21 to demonstrate that our results are robust to excluding the fixed effects.

${ }^{25}$ All substantive content was covered in the first session: the second session was merely a reinforcement and a repetition of the first session.
} 


\subsection{Multiple hypothesis testing (MHT) correction}

We use a step-down procedure to adjust $p$-values for the false discovery rate (FDR) among groups of outcomes, and report the resulting " $q$-values" (Benjamini, Krieger, and Yekutieli 2006). We adjust for multiple hypothesis testing within outcome groups (behaviors and psychological mechanisms) and hierarchical categories (primary and secondary), but not across them. Similarly, we consider the effects of our two active interventions to be theoretically distinct and therefore do not correct across them. Indices are constructed following Anderson (2008).

\section{Results}

\subsection{Experimental integrity}

Table 1 provides results on baseline balance on demographic variables, timing of the endline surveys relative to the intervention, differential endline participation, and compliance with treatment. To test for baseline balance, we estimate a version of equation 1 with baseline demographics as the outcome variables. Each row shows baseline balance for one demographic variable. Columns (1)-(5) show the comparison of the Visualization $(\mathrm{V}+\mathrm{INF})$ and Planning $(\mathrm{P}+\mathrm{INF})$ treatments to the active control (AC+INF) treatment, and Columns (6)-(10) show the comparison of the V+INF, $\mathrm{P}+\mathrm{INF}$, and AC+INF groups to the pure control group. Columns (1) and (6) show the mean and standard deviation of the respective comparison groups. Columns (2) and (3) show the treatment effects for the $\mathrm{V}+\mathrm{INF}$ and $\mathrm{P}+\mathrm{INF}$ treatments, respectively, relative to the AC+INF treatment. Column (4) is a test of equality between these two coefficients, and Column (5) shows the sample size, which varies slightly across rows because some respondents did not answer a small number of questions, some questions are restricted to certain respondent groups, e.g. those with children. Our demographic variables are balanced across treatments on the whole, with only two out of 30 coefficients on pairwise comparisons reaching statistical significance, at the 10 percent level.

Table A.2 presents results from a test of equality of means of outcome measures collected at baseline between active treatment groups, including self-reported chlorination practices and knowledge of how to use chlorine. We see no statistically significant differences in outcome scores between the active treatment groups prior to the interventions. 65 percent of respondents reported adding chlorine to water at some point during the last month, and the variable is balanced across arms. ${ }^{26}$

\footnotetext{
${ }^{26}$ In contrast, only 22 percent of the pure control group at endline have chlorine present in their water. Self-reported chlorination may be inflated by social desirability bias. As discussed in Section, in some households chlorine may have been added but decayed. Alternatively, households may chlorinate, but irregularly, reflecting the exact behavioral barriers we seek to target. Dupas et al. (2016) also find that 3 months after a study providing free chlorine or vouchers, 73 percent of respondents had non-empty chlorine bottles in their homes, but only 34 percent had verified chlorine in their stored drinking water.
} 
The second panel in Table 1 shows results across treatment groups in terms of the number of days between the date of baseline and first treatment and the date of endline, and then between the date of baseline and first treatment to the date of the chlorine test at the household. Column (1) shows that the average delay between the beginning of the interventions and endline was 68 days, i.e. ten weeks, and the average delay to the chlorine test was 78 days. Relative to the AC+INF group, the $\mathrm{P}$ group on average completed the endline survey 2 days later, significant at the 10 percent level. Relative to the pure control group, we see that both the $\mathrm{V}+\mathrm{INF}$ group and the $\mathrm{P}+\mathrm{INF}$ group on average completed the endline survey 2 days later. Although this difference is small in magnitude, we include a fixed effect for i) the week of endline survey and ii) the day of the week of the endline survey to the specification described in Section 5.3 for all survey outcome measures.

The third panel in Table 1 shows results on participation in the endline survey as well as in the chlorination measure, for two alternate definitions of attrition. Where attrition is defined as failure to complete the endline among all those initially censused, average attrition in the AC+INF and pure control groups was 8 and 24 percent, respectively. This more conservative definition captures the extent to which our sample deviates from being representative of our population of interest. Average attrition from the chlorine measurement, conducted at people's houses, was 12 percent in the $\mathrm{AC}+\mathrm{INF}$ group and 26 percent in the pure control group. Where attrition is defined as failure to complete the endline among those recruited into the study who attended baseline (the standard definition of attrition for most experiments), average attrition in the AC+INF group was 8 percent; it is 0 percent by definition for the pure control group. Under this definition, average attrition from the chlorine measurement was 8 percent in the $\mathrm{AC}+\mathrm{INF}$ group and 0 percent by definition for the pure control group.

Using the more conservative definition, in comparison to the AC+INF group, we find no differential attrition from either the endline survey, or the chlorine measurement. However, in comparison to the pure control group, the $\mathrm{V}+\mathrm{INF}$ and $\mathrm{AC}+\mathrm{INF}$ treatment groups have a small but statistically significantly smaller likelihood of attriting ( -6 percentage points). ${ }^{27}$ In addition, both the $\mathrm{V}+\mathrm{INF}$ and $\mathrm{AC}+\mathrm{INF}$ groups are 4 percentage points less likely to attrit from the chlorine measure than the pure control group, although this effect is only significant at the 10 and 5 percent levels.

Importantly, Appendix Tables A.4 and A.5 show that we find little evidence that this differential attrition led to differences in sample composition that would complicate inference. Columns (3) and (4) show that demographic variables do predict attrition from either endline measurement, once treatment status is controlled for. However, the interaction terms between demographic variables and treatment status in Columns (5) and (6) show that participants with particular characteristics are no more or less likely to drop out of the study in any one of the treatment groups

\footnotetext{
${ }^{27}$ This is unsurprising: in the active arms, we contact people again fairly soon after recruitment. In the pure control arms, we contact them for the endline for the first time roughly twelve weeks after recruitment.
} 
compared to the pure control group. This result suggests that the composition of the sample is similar in all treatment groups, including in the pure control group, and that differences in sample composition are unlikely to be responsible for observed differences between treatment groups. ${ }^{28}$

To account for attrition, we conduct two additional analyses of our results. First, in Appendix Tables A.14 and A.15, we re-estimate our main results while restricting the sample in the active treatment groups to those who attended the baseline. ${ }^{29}$ Second, to account for the differential attrition, we include controls selected by LASSO in the specification, following Belloni, Chernozhukov, and Hansen (2014). We present these results in Appendix A.16 and A.17. Finally, we present results in Appendix A.18 and A.19 where we both limit the sample to those who attended baseline and include controls selected by LASSO. All of these robustness checks lead to very similar results as our main specification.

The final panel in Table 1 shows compliance rates across the treatment groups. After the census, all respondents in the treatment groups were invited to the baseline and first intervention session, which were held on the same day. 78 percent of respondents attended the baseline and completed the first session. Only respondents who attended the first intervention session were invited to the second session. 74 percent of respondents completed both sessions, while 4 percent did not complete the second session. Compliance is balanced across treatment groups.

\subsection{Behavioral outcomes}

We present three main sets of results: first, a comparison of the $\mathrm{V}+\mathrm{INF}$ and $\mathrm{P}+\mathrm{INF}$ treatments to the AC+INF group; second, a comparison of these three groups to the pure control group; and finally, separate analyses in villages with chlorine dispensers vs. villages without dispensers, and the corresponding interaction terms with our treatment groups. The raw means and standard deviations of all outcome measures that were z-scored are reported in Appendix Table A.8. Table 2 shows results on behavioral outcome variables. The different panels show impacts on different families of outcomes, namely health, savings, labor, and other outcomes. The table panels indicate the variables which were pre-specified as primary, secondary or exploratory in the pre-analysis plan.

Both the Visualization and the Planning interventions lead to significant increases in our primary behavioral outcome measure, the presence of chlorine in household drinking water, as measured with an objective chlorine test during an unannounced household visit. In comparison to the pure control

\footnotetext{
${ }^{28}$ Relative to the AC+INF group, we do see that married women in the V+INF group are slightly less likely to attrit, significant at the 10 percent level. However, given the number of comparisons made in our attrition analysis, without correction for multiple hypothesis testing, we are not concerned about this result.

${ }^{29}$ Under this definition, where the sample includes only those who attend baseline, there is also no differential attrition across the active treatment arms. Attrition from endline conditional on attending baseline is, of course, higher in the active treatment groups than the pure control group, which by definition has 0 percent attrition since the pure control was not invited to baseline.
} 
group, the $\mathrm{V}+\mathrm{INF}$ group shows a 6 percentage point increase in the presence of total chlorine, significant at the 1 percent level. The $\mathrm{P}+\mathrm{INF}$ group shows a 4 percentage point increase in the presence of total chlorine relative to the pure control group, significant at the 10 percent level. The treatment effects in the $\mathrm{V}+\mathrm{INF}$ and $\mathrm{P}+\mathrm{INF}$ groups relative to pure control correspond to 27 and 18 percent increases relative to the pure control group mean of 22 percent. The treatment effect in the $\mathrm{AC}+\mathrm{INF}$ group relative to the pure control group is small (3 percentage points) and not statistically significant. In line with this result, chlorination is significantly higher in the V+INF group (5 percentage points, significant at the 1 percent level) relative to the $\mathrm{AC}+\mathrm{INF}$ group; the effect is smaller and not significant in the $\mathrm{P}+\mathrm{INF}$ group relative to the $\mathrm{AC}+\mathrm{INF}$ group (2 percentage points).

The results for free chlorine (FCR, see Section 4.1), which we had not pre-specified as a primary outcome, are similar in magnitude and statistical significance. We find no evidence that the increase in chlorination is driven by a substitution away from boiling water - the only effective alternative for making water safe, which was also mentioned in our information module (Section 3.3, note boiling is more expensive in terms of firewood). On the contrary, self-reports indicate that our treatments also increased rates of water boiling (Appendix Table A.22), with significant effects in the $\mathrm{V}+\mathrm{INF}$ group. ${ }^{30}$

Note that our objective chlorination measures, obtained during unannounced household visits, leave little room for experimenter demand effects, such as social desirability bias in responding to survey questions. It is possible that households talked among themselves and anticipated our visits. However, the visits were concentrated in time within each village: 68 percent of chlorine tests were conducted on the first day that our team visited a given village (the remaining tests were spread out, with a median within-village range of 7 days). Appendix Table A.12 shows that the estimated treatment effects on chlorine are unaffected by including (i) a dummy for being tested on the first day within one's village, and (ii) the number of days elapsed since the first chlorination tests were conducted in the village. Furthermore, chlorination behavior is not predicted by the delay between the endline survey and the chlorine test, which may be expected if the endline acted as a reminder to chlorinate.

Importantly, given our goal of improving health outcomes through psychological interventions, the $\mathrm{V}+\mathrm{INF}$ and $\mathrm{P}+\mathrm{INF}$ treatments both generate large and statistically significant reductions in the incidence of diarrhea among children. We find significant reductions in diarrhea episodes in both of these groups relative to the pure control group, with a 39 percent (9 percentage point) reduction for $\mathrm{V}+\mathrm{INF}$ and a 30 percent (7 percentage point) reduction for $\mathrm{P}+\mathrm{INF}$. The effects of the $\mathrm{V}+\mathrm{INF}$ and $\mathrm{P}+\mathrm{INF}$ interventions are also significant relative to the $\mathrm{AC}+\mathrm{INF}$ group (V+INF: 38 percent (9

\footnotetext{
${ }^{30}$ Our self-report question on whether households treated their water in any way to make it safe to drink generated 97 percent affirmative responses in all groups (Appendix Table A.22), likely owing to experimenter demand effects. This result suggests that all treatments were equally informative about the objectives of the experimenter (de Quidt, Haushofer, and Roth 2018), leading to similar experimenter demand effects across groups.
} 
percentage point) reduction, significant at the 1 percent level using both naïve and FDR-corrected p-values; $\mathrm{P}+\mathrm{INF}$ : 21 percent (5 percentage point) reduction, significant at the 10 percent level using conventional $p$-values, but not significant using FDR-correction). We cannot reject that the $\mathrm{V}+\mathrm{INF}$ and $\mathrm{P}+\mathrm{INF}$ treatments are equally effective in reducing diarrhea. We find no strong effects on other health outcomes, with the exception of a small decrease in the number of children under the age of 15 who visited a healthcare provider in the last 3 months, potentially due to reduced diarrhea incidence.

We pre-specified diarrhea in children under 15 (as opposed to younger age groups) to maximize sample size, and because children in a wide age range suffer negative health effects from ongoing enteric dysfunction, such as stunting and impaired cognition. We additionally report treatment effects on diarrhea in children under 5 in Appendix Table A.22. We find large and significant diarrhea reductions (34 and 25 percent, respectively) in both $\mathrm{V}+\mathrm{INF}$ and $\mathrm{P}+\mathrm{INF}$ relative to the $\mathrm{AC}+\mathrm{INF}$ group, though the effect sizes are not significant relative to the pure control.

The treatment effects of our interventions on diarrhea are rather large in relation to the effects on chlorination; with an effect on diarrhea of -39 percent and an effect on the presence of any chlorine of +27 percent, a back-of-the-envelope calculation suggests an instrumental variable estimate of -1.4 percent, i.e. a 1 percent increase in chlorination leads to a 1.4 percent reduction in diarrhea. This estimate compares favorably to that of a recent meta-analysis, which finds across six randomized controlled trials that a 1 percent increase of detectable free chlorine results in a 1 percent reduction in child diarrhea (Arnold and Colford Jr 2007). There are a few possible reasons for our slightly larger effects. First, we measure increases in total chlorine rather than the presence of residual chlorine. Second, our interventions are domain-general trainings that may affect multiple behaviors related to child diarrhea, such as handwashing or open defecation, while dispensers are likely to only affect chlorination. Third, there may be dependencies with the treatment effects on non-health outcomes: for instance, the observed increases in savings (described below) may allow for more consumption smoothing and thereby more advantageous health outcomes.

The second panel of Table 2 shows effects on savings-related outcomes. The V+INF treatment leads to a significant increase in our main savings-related outcome variable, the amount of money saved regularly. This effect corresponds to a 26 percent (KES 25) increase relative to the active control group, significant at the 5 percent level; relative to the pure control group, it is smaller (20 percent; KES 18) and not statistically significant. In addition, we find a large and highly significant effect on savings on the extensive margin, with the share of respondents who save regularly increasing by 13 percentage points (36 percent) in the $\mathrm{V}+\mathrm{INF}$ group relative to AC+INF, and 12 percentage points (38 percent) relative to the pure control group. Similarly, we find increases in the $\mathrm{V}+\mathrm{INF}$ treatment on an indicator for whether the respondent saves for productive investments, 11 and 9 percentage points (65 and 53 percent) relative to the AC+INF and pure control groups, respectively. All of these effects are significant at the 1 percent level even after 
correcting for multiple comparisons. $\mathrm{V}+\mathrm{INF}$ participants are also more likely to have joined a new ROSCA relative to $\mathrm{AC}+\mathrm{INF}$ participants. The $\mathrm{P}+\mathrm{INF}$ and $\mathrm{AC}+\mathrm{INF}$ interventions did not show significant effects on savings-related outcomes, and most of the effects in the V+INF group described above are significantly larger than in those groups. Together, these results show that the $\mathrm{V}+\mathrm{INF}$ treatment strongly affected savings-related behaviors.

This finding has two important implications. First, it shows that our V+INF intervention, while unsuccessful in affecting time preferences measured with laboratory-like discounting tasks, nevertheless strongly affected future-oriented behaviors (see the results and discussion in Section 7.1). A possible explanation comes from the theoretical work of Gabaix and Laibson (2017): If the visualization intervention helped decision-makers to generate less noisy signals about the utility they will derive from future events, then more patient behavior would result even in absence of changes in the underlying discounting parameters. Second, it provides evidence against an experimenter demand-effect account of the impacts of our interventions: while the interventions mentioned chlorination and health-related topics, savings were discussed only to the extent that participants brought them up themselves in the discussions. The treatment effects we report here are thus more likely to result from an increased valuation of the future (via preferences or forecasting skills) rather than from a simple desire to please the experimenters.

The third panel of Table 2 reports effects on labor-related outcomes. Somewhat surprisingly, we find a reduction in the total number of hours worked in the last 3 months in the P+INF group, with a magnitude of 24 hours (22 percent) relative both to the $\mathrm{AC}+\mathrm{INF}$ group and to the pure control group. These effects are significant at the 1 percent and 5 percent level, respectively. A similar effect is observed in the total number of days worked, which is reduced by 4 days or 18 percent in the $\mathrm{P}+\mathrm{INF}$ group, relative both to the $\mathrm{AC}+\mathrm{INF}$ group and to the pure control group, significant at the 5 percent level, although the result does not survive correction for multiple hypothesis testing. One possible reason for this reduction is again that participants in the $\mathrm{P}+\mathrm{INF}$ group may have improved their planning and execution ability and therefore be more efficient in accomplishing tasks. Only 3 percent of our sample work for wages, with the rest divided between subsistence farming and self-employment, and thus their income is determined largely by their output rather than their work hours. In support of this hypothesis, we find no significant change in average monthly earnings, despite the shortened work hours. The $\mathrm{V}+\mathrm{INF}$ and AC+INF treatments do not show significant effects on labor outcomes.

Appendix Table A.10 presents treatment-on-the-treated (TOT) estimates, when compliance is defined as attending at least the first intervention session (which happened on the same day as the baseline survey). Since the sample in the AC+INF comparison is restricted to compliers, the TOT estimator is only defined for the comparison to the pure control group. In Appendix Tables A.14, A.16, and A.18, we re-estimate our results to account for differential endline participation, as 
described in Section 6.1. In Appendix Table A.20 we present our results excluding the endline week and day-of-week fixed effects described in Section 5.3, since the inclusion of these fixed effects was not pre-specified. The results are similar in magnitude and significance across all specifications.

\subsection{Are psychological treatments more effective when cost barriers are removed?}

We next ask whether our treatment effects differ by whether or not the village in which the interventions took place was randomly treated with a chlorine dispenser in the WASH Benefits study that preceded ours. Appendix Table A.3 shows that, at baseline, participants in villages with chlorine dispensers were comparable to participants in villages without chlorine dispensers in terms of wealth level, age, and marital status, but had a slightly higher level of education.

Table 3 shows results from the two main estimating equations, focusing on chlorination-related outcomes, separately for non-dispenser villages (Columns (1)-(5)) and dispenser villages (Columns (6)-(10)). The interaction terms on our two treatment groups with the randomized dispenser treatment are shown in Columns (11)-(13) for $\mathrm{V}+\mathrm{INF}, \mathrm{P}+\mathrm{INF}$, and $\mathrm{AC}+\mathrm{INF}$, respectively.

We find weak evidence of heterogeneity in the effects of the treatments on outcomes related to chlorination by village type. Specifically, the active treatment groups $\mathrm{P}+\mathrm{INF}, \mathrm{V}+\mathrm{INF}$, and $\mathrm{AC}+\mathrm{INF}$ show significant treatment effects on water chlorination in the dispenser villages, but not in the villages without dispensers. The interaction term is significant at the 5 percent level for the $\mathrm{AC}+\mathrm{INF}$ treatment, but not for the psychological interventions. A possible interpretation is that information is effective if and only if cost barriers are removed, while the psychological treatments have a positive effect even in the presence of cost barriers. The effects in the non-dispenser villages are not statistically significant, potentially due to the smaller sample size. However, treatment effects on diarrhea are concentrated in the non-dispenser villages. To explain these counterintuitive results, it is worth thinking about those at the margin of chlorination: Participants in non-dispenser villages face a higher cost of chlorination than those in dispenser villages. Using simple first-order conditions, marginal benefits from chlorination should be higher in non-dispenser villages. Thus, larger effects on diarrhea could result despite smaller effects on chlorination. The pure control means in Table 3 suggest that non-dispenser villages have higher diarrhea levels absent treatment. Nevertheless, this interpretation is speculative, and does not allow us to draw definitive conclusions. ${ }^{31}$ At any rate, the differences are small and require replication before being taken seriously.

\footnotetext{
${ }^{31}$ In Appendix Table A.13, we test the robustness of our results when restricting to villages from the Water Quality and Passive Comparison arms of the WASH Benefits study, as discussed in Section 2.1 and Appendix B. This analysis permits a cleaner distinction between dispenser- and non-dispenser villages in the absence of any other interventions, at the expense of a somewhat smaller sample. In this analysis, the interaction term for both chlorination measures is significant for the $\mathrm{V}+\mathrm{INF}$ intervention, suggesting that this intervention had significantly larger effects in dispenser villages.
} 


\section{Mechanisms}

Our interventions targeted three psychological mechanisms: First, the visualization intervention encouraged participants to connect everyday behaviors to distant future outcomes, and to make these future outcomes vivid and tangible in their minds. It thus aimed to increase patient behavior, both through valuation of the future (time preferences), and through strengthening the mapping between current behavior and future outcomes (captured in self-efficacy, or domain-general returns to effort, see footnote 4). Second, our planning intervention aimed to build planning skills by teaching participants to structure tasks, break them down into individual steps, and approach them in a way that induces self-reinforcing motivation cycles. By empowering participants to tackle activities that they were struggling with, the intervention may also build up their self-efficacy. To shed light on the mechanisms which may account for the observed behavioral effects, we now turn to the results on our pre-specified psychological outcomes, as well as measures of key potential alternative mechanisms.

\subsection{Targeted psychological mechanisms}

Table 4 shows results on psychological outcome variables, estimated using equation 1 . The top panels show results on planning skills, time preferences, and self-efficacy, subdivided into primary and secondary outcome measures according to our pre-analysis plan. Adjustment of $p$-values for multiple comparisons using FDR is done separately across all primary and all secondary psychological outcomes.

For mechanisms, the main comparison of interest is that of the psychologically active treatment groups to the $\mathrm{AC}+\mathrm{INF}$ control group. The information module, exposure to field staff and other participants, and experimental payments are held constant across these treatments. The restriction to baseline survey participants holds constant any practice effects from having completed the same tasks at baseline, and also ensures that each individual in the sample received at least the first intervention session. This comparison is also more precisely estimated than the pure control comparison due to the inclusion of baseline outcome levels as control variables where available (see Section 5.2).

We find no statistically significant effects of any treatment on planning skills compared to the Active Control, although the coefficients in the Planning treatment have the expected signs (positive for the Behavioral Activation Score, and negative for the number of moves required to complete the Tower of London task). In comparison to the pure control group, we observe a 0.11 SD increase in the Behavioral Activation Score, significant at the 10 percent level. $^{32}$

The next panel reports results on outcomes related to time preferences. Our primary outcome

\footnotetext{
${ }^{32}$ Performance on the Tower of London task is significantly improved in all active treatment groups relative to the pure control group, but this result is likely due to the fact that all active groups had performed this task previously at baseline, while the pure control group had not.
} 
is $\beta^{\text {Effort }}$, which captures present bias in our effort task (see Section 4.2 and Appendix D.2 for details of the structural estimation). Additional outcomes are the $\delta^{E f f o r t}$ parameter from the same task, and corresponding parameters from the monetary discounting task. We find no statistically significant effects of the Visualization treatment on the estimated time preference parameters, relative to the active control. Somewhat surprisingly, we find a reduction of the $\delta^{\text {Effort }}$ parameter in the Planning group, driven by an increased willingness to supply effort 7 and 8 days in the future, at constant willingness to supply effort today or tomorrow (see Figure A.3). This result is consistent with the Planning intervention helping participants to plan the logistics of future effort provision (SMS data entry), such as phone access or child care (which is possible for 7 or 8 days, but perhaps too short notice for 0 or 1 days). The effect is economically small $(-0.002)$. Relative to the pure control comparison, we observe a small increase in the monetary discount parameter $\delta^{M P L}$ in the $\mathrm{V}+\mathrm{INF}$ and $\mathrm{AC}+\mathrm{INF}$ groups, plausibly due to income effects from the higher experimental payments in the active arms.

The third panel of Table 4 shows the effect of our interventions on the General Self-Efficacy (GSE) scale (Section 4.2). Both the $\mathrm{V}+\mathrm{INF}$ and the $\mathrm{P}+\mathrm{INF}$ interventions generate statistically significant $0.16 \mathrm{SD}$ and $0.12 \mathrm{SD}$ increases, respectively, relative to the $\mathrm{AC}+\mathrm{INF}$ group. This finding suggests that our interventions affected "inward-looking" beliefs about one's ability to achieve desired outcomes. We find similarly large (0.18 SD) and significant differences in the V+INF and $\mathrm{P}+\mathrm{INF}$ groups relative to the pure control group. The effect seems to be driven by the psychological interventions - the AC+INF treatment by itself does not increase self-efficacy. All effects persist or get stronger when we consider TOT estimates (Appendix Table A.11), and when we re-estimate results accounting for attrition, or excluding endline week and day-of-week fixed effects (Appendix F).

Summing up the results on our pre-specified psychological mechanisms, we find strong evidence that both the Visualization and the Planning interventions increased participants' self-efficacy, roughly understood as their sense of control over their life, or their perception of (domain-general) returns to exerting effort. This may explain the observed effects on both chlorination and savings. We find a larger increase in self-efficacy in $\mathrm{V}+\mathrm{INF}$ than in $\mathrm{P}+\mathrm{INF}$, which may help explain the larger observed behavioral effects in the Visualization treatment. Notably, neither the self-efficacy difference between $\mathrm{V}+\mathrm{INF}$ and $\mathrm{P}+\mathrm{INF}$ nor their difference in most behavioral outcomes is statistically significant. In contrast to our predictions, our interventions do not significantly affect laboratory measures of time preferences, neither over effort nor over money, nor do they affect measures of cognitive planning skills. One possible interpretation is that deep underlying preferences and cognitive functions do not respond strongly to light-touch interventions. This contrasts the results of Alan and Ertac (2018), who find effects of a similar (though longer) educational intervention on incentivized intertemporal choices. A second interpretation is that preferences changed in a way that is not captured by our state-of-the-art (but conceptually conventional) choice tasks. For instance, Gabaix 
and Laibson (2017) provide an account of intertemporal choice in terms of individuals' ability to simulate future utility. The Visualization intervention may have helped participants to generate less noisy signals about the utility they will derive from future events, resulting in more patient behavior. If this effect applied to forecasting of future utility in general, we would expect to see an increased weight of the future relative to the present (captured in our estimate of $\beta$ ). Importantly, the intervention prompted participants to visualize alternative realizations of their future in one year - a time horizon where future utility is likely to feel vague and distant. In contrast, intuitively speaking, time preferences are estimated from participants' relative willingness to exert effort in 0 versus 1 days (for $\beta \delta$ ) and 7 versus 8 days (for $\delta$, see Section 4.2). It is plausible that the intervention made far-future utility (such as having healthy children in one year) more tangible and salient, while the disutility from near-future effort (SMS data entry within the next 8 days) was already tangible at baseline. This could explain the observed changes in chlorination and savings behavior without affecting our lab measures of $\beta$ and $\delta$. If true, it contributes to concerns of how suitable incentivized laboratory measures of time preferences are to capture intertemporal choice in real-life contexts.

\subsection{Beliefs, knowledge, and risk preferences}

The last panel of Table 4 suggests that the information module (Section 3.3) had a similar effect across the active treatment groups: $\mathrm{V}+\mathrm{INF}, \mathrm{P}+\mathrm{INF}$, and $\mathrm{AC}+\mathrm{INF}$ all significantly increase beliefs in the efficacy of chlorine in averting diarrhea relative to the pure control group, with similar effect sizes (0.13 SD, 0.16 SD, and 0.12 SD). Effects on knowledge about how to correctly chlorinate water are also statistically indistinguishable across the three active treatment groups. Compared to the pure control group, the $\mathrm{V}+\mathrm{INF}$ group shows a significant increase in knowledge of 0.12 $\mathrm{SD}$. Effects are similar in magnitude for the other groups (0.07 SD for P+INF and 0.09 SD for $\mathrm{AC}+\mathrm{INF}$ ), but do not reach statistical significance, and we cannot reject that effects in all groups are of the same magnitude. ${ }^{33}$ Importantly, we see effects on beliefs and knowledge in all three active arms, but we only see statistically significant effects on chlorination and diarrhea in the $\mathrm{V}+\mathrm{INF}$ and $\mathrm{P}+\mathrm{INF}$ arms. Thus, the Visualization and Planning treatments have additional effects on behavior compared to the effect of information on its own. These are likely due to changes in psychological outcomes, such as self-efficacy (discussed above), or alternatively changes in salience (discussed below).Both are affected only in the $\mathrm{V}+\mathrm{INF}$ and $\mathrm{P}+\mathrm{INF}$ groups.

Finally, we find no effects on risk aversion, suggesting that any behavioral effects are unlikely to result from changes in risk preferences induced by our treatments.

\footnotetext{
${ }^{33}$ We also find that all three interventions are effective in increasing knowledge of the correct schedule of antenatal and postnatal care visits a woman should attend before and after giving birth. We do not see an associated increase in the number of ANC visits attended by pregnant women in our sample, but our sample size for this analysis is less than 300 individuals. These questions were included for piloting purposes for a future study.
} 


\subsection{Salience}

Section 4.3 explains the design of a test for increased salience of chlorination, and Appendix D explains the econometric specification. Column (1) of Table 5 shows that participants who had received the $\mathrm{V}+\mathrm{INF}$ or $\mathrm{P}+\mathrm{INF}$ intervention found it easier to remember chlorine-related words, conditional on the total number of words remembered. This effect was specific to chlorine-related words, rather than to future-oriented behaviors in general: Column (3) interacts treatment indicators with chlorine word indicators, and shows that the salience of chlorination increases differentially to the salience of other future-oriented words (the base category is farm investment). Finally, Column (4) suggests that neither treatment group had an effect on total words remembered, and thus on participants' memory in general.

Thus, we find an increase in the salience of chlorine-related words, but not savings-related words, as a result of treatment. Taken together, it is thus plausible that salience was a contributing factor to the observed treatment effect on chlorination. However, the observed treatment effect on savings, as well as on various other non-chlorine measures, is difficult to explain through salience, as the salience of savings was unaffected by treatment. Salience effects thus do not provide a consistent explanation across our findings, unless the mapping from salience to behavior is both non-linear and differential across domains.

\section{Conclusion}

In this randomized field experiment, we study the effect of two light-touch interventions on behavioral and psychological outcomes among young women in Kenya. Specifically, we ask whether a "Visualization" and a "Planning" intervention increase take-up of drinking water chlorination. Both interventions increase chlorination of drinking water, and reduce the number of diarrhea episodes in children (relative to the pure control, and relative to the active control group for Visualization). Possible mechanisms include self-efficacy: the sessions likely strenghtened participants' beliefs in their capacity to control their own life and achieve desirable outcomes. A second potential mechanism is increased salience of chlorination, though this does not explain our results on savings. We rule out mechanisms related to increased information or changed beliefs about the effectiveness of chlorination. We also find little evidence of changes in laboratory measures of time preferences or planning skills. The fact that we found no changes in deeper underlying preferences and cognitive functions suggests that the latter may not respond strongly to light-touch interventions. In contrast, internal beliefs and attention appear more malleable.

We estimate high cost-effectiveness of the interventions: in terms of DALYs saved, our interventions are roughly comparable to highly effective interventions such as the provision of 
insecticide-treated bed nets, and deworming of school children. Importantly, we find impacts even in villages which have free chlorine dispensers at water sources, suggesting that these interventions are effective over and above existing infrastructural interventions. Future work may attempt to replicate these effects, and extend the use of our interventions to other settings and behaviors of interest.

\section{References}

Alan, Sule, and Seda Ertac. 2018. "Fostering Patience in the Classroom: Results from Randomized Educational Intervention." Journal of Political Economy 126 (5): 1865-1911.

Anderson, Michael L. 2008. "Multiple Inference and Gender Differences in the Effects of Early Intervention: a Reevaluation of the Abecedarian, Perry Preschool, and Early Training Projects." Journal of the American Statistical Association 103 (484): 1481-1495.

Andreoni, James, and Charles Sprenger. 2012. "Estimating Time Preferences from Convex Budgets." American Economic Review 102 (7): 3333-3356.

Arnold, Benjamin, and John Colford Jr. 2007. "Treating Water with Chlorine at Point-Of-Use to Improve Water Quality and Reduce Child Diarrhea in Developing Countries: A Systematic Review and Meta-Analysis." The American Journal of Tropical Medicine and Hygiene 76 (2): 354-364.

Ashraf, Nava, James Berry, and Jesse M Shapiro. 2010. "Can higher prices stimulate product use? Evidence from a field experiment in Zambia." American Economic Review 100 (5): 2383-2413.

Ashraf, Nava, Kelsey Jack, and Emir Kamenica. 2010. "Information and Subsidies: Complements or Substitutes?" Journal of Economic Behavior and Organization 88:133-139.

Augenblick, Ned. 2017. "Short-Term Time Discounting of Unpleasant Tasks." Working Paper, UC Berkeley.

Augenblick, Ned, Muriel Niederle, and Charles Sprenger. 2015. "Working Over Time: Dynamic Inconsistency in Real Effort Tasks." The Quarterly Journal of Economics 130 (3): 1067-1115.

Bai, Liang, Benjamin Handel, Edward Miguel, and Gautam Rao. 2017. "Self-Control and Demand for Preventive Health: Evidence from Hypertension in India." NBER Working Paper No. 2372\%.

Baird, Sarah, Joan Hamory Hicks, Michael Kremer, and Edward Miguel. 2016. "Worms at Work: Long-Run Impacts of a Child Health Investment." The Quarterly Journal of Economics 131 (4): 1637-1680.

Bandura, Albert. 1977. "Self-Efficacy: Toward a Unifying Theory of Behavioral Change." Psychological Review 84 (2): 191-215.

-1997. Self-Efficacy: The Exercise of Control. New York: W.H. Freeman.

Banerjee, Abhijit, Eliana la Ferrara, and Victor Orozco. 2018. "The Entertaining Way to Behavioral Change: Fighting HIV with MTV." Working Paper, Massachusetts Institute of Technology.

Baranov, Victoria, Sonia Bhalotra, Pietro Biroli, and Joanna Maselko. 2017. "Mental Health and Women's Choices. Experimental Evidence from a Randomized Control Trial." Working Paper, University of Melbourne.

Beaman, Lori, Jeremy Magruder, and Jonathan Robinson. 2014. "Minding Small Change Among Small Firms in Kenya." Journal of Development Economics 108:69-86.

Belloni, Alexandre, Victor Chernozhukov, and Christian Hansen. 2014. "High-Dimensional Methods and Inference on Structural and Treatment Effects." Journal of Economic Perspectives 28 (2): 29-50.

Benjamini, Yoav, Abba M Krieger, and Daniel Yekutieli. 2006. "Adaptive Linear Step-Up Procedures That Control the False Discovery Rate." Biometrika 93 (3): 491-507.

Bernard, Tanguy, Stefan Dercon, Kate Orkin, and Alemayehu Seyoum Taffesse. 2018. "The Future in Mind: Short and Long-Run Impact of an Aspirations Intervention in Rural Ethiopia." Working Paper, University of Oxford.

Blattman, Christopher, Julian Jamison, and Margaret Sheridan. 2017. "Reducing Crime and Violence: Experimental Evidence from Cognitive Behavioral Therapy in Liberia." American Economic Review 107 (4): 1165-1206. 
Bleakley, Hoyt. 2010. "Malaria Eradication in the Americas: A Retrospective Analysis of Childhood Exposure." American Economic Journal: Applied Economics 2 (2): 1-45.

Bobonis, Gustavo, Edward Miguel, and Charu Puri-Sharma. 2006. "Anemia and School Participation." Journal of Human Resources 41 (4): 692-721.

CDC. 2010. Chlorine Residual Testing Fact Sheet. Centers for Disease Control and Prevention SWS Project.

Charness, Gary, Uri Gneezy, and Alex Imas. 2013. "Experimental Methods: Eliciting Risk Preferences." Journal of Economic Behavior \& Organization 87:43-51.

Cohen, Jessica, and Pascaline Dupas. 2010. "Free Distribution or Cost-Sharing? Evidence from a Randomized Malaria Prevention Experiment." The Quarterly Journal of Economics 125 (1): 1-45.

Daniel, Tinuke, Christina Stanton, and Leonard Epstein. 2013. "The Future Is Now: Reducing Impulsivity And Energy Intake Using Episodic Future Thinking." Psychological Science 24 (11): 2339-2342.

DellaVigna, Stefano, and Ulrike Malmendier. 2006. "Paying Not to Go to the Gym." American Economic Review 96 (3): 694-719.

DellaVigna, Stefano, and Devin Pope. 2017. "What Motivates Effort? Evidence and Expert Forecasts." The Review of Economic Studies 85 (2): 1029-1069.

de Quidt, Jonathan, Johannes Haushofer, and Christopher Roth. 2018. "Measuring and Bounding Experimenter Demand." American Economic Review 108 (11): 3266-3302.

Dillon, Andrew, Jed Friedman, and Pieter Serneels. 2014. "Health Information, Treatment, and Worker Productivity: Experimental Evidence from Malaria Testing and Treatment among Nigerian Sugarcane Cutters." Policy Research Working Paper Series 7120, The World Bank.

Dinkelman, Taryn, and Claudia Martínez. 2014. "Investing in Schooling in Chile: The Role of Information about Financial Aid for Higher Education." Review of Economics and Statistics 96 (2): 244-257.

Duckworth, Angela, Heidi Grant, Benjamin Loew, Gabriele Oettingen, and Peter Gollwitzer. 2011. "SelfRegulation Strategies Improve Self-Discipline in Adolescents: Benefits of Mental Contrasting and Implementation Intentions." Educational Psychology 31 (1): 17-26.

Duckworth, Angela, Teri Kirby, Anton Gollwitzer, and Gabriele Oettingen. 2013. "From Fantasy to Action: Mental Contrasting with Implementation Intentions (MCII) Improves Academic Performance in Children." Social Psychological and Personality Science 4 (6): 745-753.

Duflo, Esther, Pascaline Dupas, and Michael Kremer. 2015. "Education, HIV, and Early Fertility: Experimental Evidence from Kenya." American Economic Review 105 (9): 2257-97.

Dupas, Pascaline. 2009. "What Matters (and What Does Not) in Households' Decision to Invest in Malaria Prevention?" American Economic Review 99 (2): 224-230.

— 2011. "Do Teenagers Respond to HIV Risk Information? Evidence from a Field Experiment in Kenya." American Economic Journal: Applied Economics 3 (1): 1-36.

. 2014a. "Getting Essential Health Products to Their End Users: Subsidize, but How Much?" Science 345 (6202): 1279-1281.

- 2014b. "Short-Run Subsidies and Long-Run Adoption of New Health Products: Evidence from a Field Experiment." Econometrica 82 (1): 197-228.

Dupas, Pascaline, Vivian Hoffmann, Michael Kremer, and Alix Peterson Zwane. 2016. "Targeting Health Subsidies through a Nonprice Mechanism: A Randomized Controlled Trial in Kenya." Science 353 (6302): 889-895.

Ekers, David, Lisa Webster, Annemieke Van Straten, Pim Cuijpers, David Richards, and Simon Gilbody. 2014. "Behavioural Activation for Depression; an Update of Meta-Analysis of Effectiveness and Sub Group Analysis." PloS one 9, no. 6.

Esopo, Kristina, Daniel Mellow, Catherine Thomas, Hannah Uckat, Justin Abraham, Prachi Jain, Chaning Jang, Nicholas Otis, Michala Riis-Vestergaard, Amanda Starcev, Kate Orkin, and Johannes Haushofer. 2018. "Measuring Self-Efficacy, Executive Function, and Temporal Discounting in Kenya." Behaviour Research and Therapy 101:30-45.

Fink, Günther, and Felix Masiye. 2015. "Health and Agricultural Productivity: Evidence from Zambia." Journal of Health Economics 42:151-164. 
Fischbacher, Urs. 2007. "z-Tree: Zurich Toolbox for Ready-Made Economic Experiments." Experimental Economics 10 (2): 171-178.

Gabaix, Xavier, and David Laibson. 2017. "Myopia and Discounting." NBER Working Paper No. 23254.

Ghosal, Sayantan, Smarajit Jana, Anandi Mani, Sandip Mitra, and Sanchari Roy. 2019. "Sex Workers, Stigma and Self-Image: Evidence from Kolkata Brothels." Working Paper, University of Glasgow.

Gilbert, Daniel, and Timothy Wilson. 2009. "Why the Brain Talks to Itself: Sources of Error in Emotional Prediction." Philosophical Transactions of the Royal Society of London B: Biological Sciences 364 (1521): 1335-1341.

Giné, Xavier, Dean Karlan, and Jonathan Zinman. 2010. "Put Your Money Where Your Butt Is: A Commitment Contract for Smoking Cessation." American Economic Journal: Applied Economics 2 (4): 213-35.

Gollwitzer, Peter M, and Paschal Sheeran. 2006. "Implementation Intentions and Goal Achievement: A Meta-Analysis of Effects and Processes." Advances in Experimental Social Psychology 38:69-119.

Hanna, Rema, Sendhil Mullainathan, and Joshua Schwartzstein. 2014. "Learning Through Noticing: Theory and Evidence From a Field Experiment." The Quarterly Journal of Economics 129 (3): 1311-1353.

Heller, Sara, Anuj Shah, Jonathan Guryan, Jens Ludwig, Sendhil Mullainathan, and Harold Pollack. 2017. "Thinking, Fast and Slow? Some Field Experiments to Reduce Crime and Dropout in Chicago." The Quarterly Journal of Economics 132 (1): 1-54.

Hershfield, Hal, Daniel Goldstein, William Sharpe, Jesse Fox, Leo Yeykelis, Laura Carstensen, and Jeremy Bailenson. 2011. "Increasing Saving Behavior Through Age-Progressed Renderings of the Future Self." Journal of Marketing Research 48 (SPL): S23-S37.

Jalan, Jyotsna, and E. Somanathan. 2008. "The importance of being informed: experimental evidence on demand for environmental quality." Journal of Development Economics 87 (1): 14-28.

Jensen, Robert. 2010. "The (Perceived) Returns to Education and the Demand for Schooling." The Quarterly Journal of Economics 125 (2): 515-548.

- 2012. "Do Labor Market Opportunities Affect Young Women's Work and Family Decisions? Experimental Evidence from India." The Quarterly Journal of Economics 127 (2): 753-792.

Jones, Michael. 1996. "Indicator and Stratification Methods for Missing Explanatory Variables in Multiple Linear Regression." Journal of the American Statistical Association 91 (433): 222-230.

Kahneman, Daniel, Alan Krueger, David Schkade, Norbert Schwarz, and Arthur Stone. 2004. "A Survey Method for Characterizing Daily Life Experience: The Day Reconstruction Method." Science 306 (5702): 1776-1780.

Kanter, Jonathan, Patrick Mulick, Andrew Busch, Kristoffer Berlin, and Christopher Martell. 2007. "The Behavioral Activation for Depression Scale (BADS): Psychometric Properties and Factor Structure." Journal of Psychopathology and Behavioral Assessment 29 (3): 191.

King, Laura. 2001. "The Health Benefits of Writing About Life Goals." Personality and Social Psychology Bulletin 27 (7): 798-807.

Kremer, Michael, and Edward Miguel. 2007. "The Illusion of Sustainability." The Quarterly Journal of Economics 122 (3): 1007-65.

Kremer, Michael, Edward Miguel, Sendhil Mullainathan, Clair Null, and Alix Peterson Zwane. 2011a. "Social Engineering: Evidence from a Suite of Take-Up Experiments in Kenya." Working Paper, Harvard University.

Kremer, Michael, Edward Miguel, Clair Null, and Alix Peterson Zwane. 2011b. "Sustainability of Long-Term Take-Up at Point-Of-Collection Chlorine Dispensers Provided Free of Charge in Rural Western Kenya." Proceedings of the Water Environment Federation 2011 (3): 249-250.

Laibson, David. 1997. "Golden Eggs and Hyperbolic Discounting." The Quarterly Journal of Economics 112 (2): 443-478.

Lantagne, D, K Preston, E Blanton, N Kotlarz, H Gezagehn, E Van Dusen, J Berens, and K Jellison. 2010. "Hypochlorite solution expiration and stability in household water treatment in developing countries." Journal of Environmental Engineering 137 (2): 131-136.

Lejuez, Carl, Derek Hopko, Ron Acierno, Stacey Daughters, and Sherry Pagoto. 2011. "Ten Year Revision of the Brief Behavioral Activation Treatment for Depression: Revised Treatment Manual." Behavior Modification 35 (2): 111-161. 
Locke, Edwin, and Gary Latham. 2002. "Building a Practically Useful Theory of Goal Setting and Task Motivation: A 35-year Odyssey." American Psychologist 57 (9): 705.

Lorig, Kate, Diana D Laurent, Kathryn Plant, Eswar Krishnan, and Philip L Ritter. 2014. "The Components of Action Planning and Their Associations With Behavior and Health Outcomes." Chronic Illness 10 (1): 50-59.

Luoto, Jill, David Levine, Jeff Albert, and Stephen Luby. 2014. "Nudging to Use: Achieving Safe Water Behaviors in Kenya and Bangladesh." Journal of Development Economics 110:13-21.

Luoto, Jill, Nusrat Najnin, Minhaj Mahmud, Jeff Albert, M Sirajul Islam, Stephen Luby, Leanne Unicomb, and David I Levine. 2011. "What Point-of-Use Water Treatment Products Do Consumers Use? Evidence from a Randomized Controlled Trial among the Urban Poor in Bangladesh." PloS one 6 (10): e26132.

Madajewicz, Malgosia, Alexander Pfaff, Alexander Van Geen, Joseph Graziano, Iftikhar Hussein, Hasina Momotaj, Roksana Sylvi, and Habibul Ahsan. 2007. "Can Information Alone Change Behavior? Response to Arsenic Contamination of Groundwater in Bangladesh." Journal of Development Economics 84 (2): 731-754.

Manos, Rachel, Jonathan Kanter, and Wen Luo. 2011. "The Behavioral Activation for Depression Scale-Short Form: Development and Validation." Behavior Therapy 42 (4): 726-739.

Markus, Hazel, and Paula Nurius. 1986. "Possible Selves." American Psychologist 41 (9): 954.

McKelway, Madeline. 2018. "Women's Self-Efficacy and Women's Employment: Experimental Evidence from India." Working Paper, Massachusetts Institute of Technology.

Miguel, Edward, and Michael Kremer. 2004. "Worms: Identifying Impacts on Education and Health in the Presence of Treatment Externalities." Econometrica 72 (1): 159-217.

Milkman, Katherine, John Beshears, James Choi, David Laibson, and Brigitte Madrian. 2011. "Using Implementation Intentions Prompts to Enhance Influenza Vaccination Rates." Proceedings of the National Academy of Sciences 108 (26): 10415-10420.

_ 2013. "Planning Prompts as a Means of Increasing Preventive Screening Rates." Preventive Medicine 56 (1): 92-93.

Morisano, Dominique, Jacob Hirsh, Jordan Peterson, Robert Pihl, and Bruce Shore. 2010. "Setting, Elaborating, and Reflecting on Personal Goals Improves Academic Performance." Journal of Applied Psychology 95 (2): 255-264.

Nickerson, David, and Todd Rogers. 2010. "Do You Have a Voting Plan? Implementation Intentions, Voter Turnout, and Organic Plan Making." Psychological Science 21 (2): 194-199.

Null, Clair, and Daniele Lantagne. 2012. "Microbiological quality of chlorinated water after storage in ceramic pots." Journal of Water, Sanitation and Hygiene for Development 2 (4): 250-253.

Null, Clair, Christine Stewart, Amy Pickering, Holly Dentz, Benjamin Arnold, Charles Arnold, Jade Benjamin-Chung, Thomas Clasen, Kathryn Dewey, Lia Fernald, et al. 2018. "Effects of Water Quality, Sanitation, Handwashing, and Nutritional Interventions on Diarrhoea and Child Growth in Rural Kenya: A Cluster-Randomised Controlled Trial." The Lancet Global Health 6 (3): e316-e329.

O’Donoghue, Ted, and Matthew Rabin. 1999. "Doing It Now Or Later." American Economic Review 89 (1): $103-124$.

Oettingen, Gabriele, Doris Mayer, and Jennifer Thorpe. 2010. "Self-Regulation of Commitment to Reduce Cigarette Consumption: Mental Contrasting of Future With Reality." Psychology and Health 25 (8): 961-977.

Oettingen, Gabriele, Hyeon-ju Pak, and Karoline Schnetter. 2001. "Self-Regulation of Goal-Setting: Turning Free Fantasies About the Future Into Binding Goals." Journal of Personality and Social Psychology 80 (5): 736.

Ozier, Owen. 2018. "Exploiting Externalities to Estimate the Long-Term Effects of Early Childhood Deworming." American Economic Journal: Applied Economics 10 (3): 235-62.

Phillips, Louise, Victor Wynn, Selwyn-Lloyd McPherson, and Ken Gilhooly. 2001. "Mental Planning and the Tower of London Task." The Quarterly Journal of Experimental Psychology Section A 54 (2): 579-597.

Pop-Eleches, Cristian, Harsha Thirumurthy, James Habyarimana, Joshua Graff Zivin, Markus Goldstein, Damien de Walque, Leslie Mackeen, Jessica Haberer, John Sidle, and Duncan Ngare. 2011. "Mobile Phone Technologies Improve Adherence to Antiretroviral Treatment in Resource-Limited Settings: A Randomized Controlled Trial of Text Message Reminders." AIDS 25 (6) (6): 825-34. 
Reich, John W, and Frank J Infurna. 2016. Perceived control: theory, research, and practice in the first 50 years. Oxford University Press.

Richard, Stephanie, Robert Black, Robert Gilman, Richard Guerrant, Gagandeep Kang, Claudio Lanata, Kåre Mølbak, Zeba Rasmussen, R. Bradley Sack, Palle Valentiner-Branth, et al. 2013. "Diarrhea in Early Childhood: Short-Term Association with Weight and Long-Term Association with Length." American Journal of Epidemiology 178 (7): 1129-1138.

Richards, David, and Mark Whyte. 2011. Reach Out: National Programme Student Materials to Support the Delivery of Training for Psychological Wellbeing Practitioners Delivering Low Intensity Interventions. Rethink Mental Illness.

Royer, Heather, Mark Stehr, and Justin Sydnor. 2015. "Incentives, Commitments, and Habit Formation in Exercise: Evidence from a Field Experiment with Workers at a Fortune-500 Company." American Economic Journal: Applied Economics 7 (3): 51-84.

Schilbach, Frank. 2018. "Alcohol and Self-Control: A Field Experiment in India." American Economic Review (Forthcoming).

Schwarzer, Ralf, and Matthias Jerusalem. 2010. "The General Self-Efficacy Scale (GSE)." Anxiety, Stress, and Coping 12:329-345.

Shallice, Tim. 1982. "Specific Impairments of Planning." Philosophical Transactions of the Royal Society of London B: Biological Sciences 298 (1089): 199-209.

Sheldon, Kennon, and Sonja Lyubomirsky. 2006. "How to Increase and Sustain Positive Emotion: The Effects of Expressing Gratitude and Visualizing Best Possible Selves." The Journal of Positive Psychology 1 (2): 73-82.

Stadler, Gertraud, Gabriele Oettingen, and Peter Gollwitzer. 2009. "Physical Activity in Women: Effects of a Self-Regulation Intervention." American Journal of Preventive Medicine 36 (1): 29-34.

Stein, Jeffrey, Allison Tegge, Jamie Turner, and Warren Bickel. 2018. "Episodic Future Thinking Reduces Delay Discounting and Cigarette Demand: An Investigation of the Good-Subject Effect." Journal of Behavioral Medicine 41 (2): 269-276.

Troeger, Christopher, Danny V Colombara, Puja C Rao, Ibrahim A Khalil, Alexandria Brown, Thomas G Brewer, Richard L Guerrant, Eric R Houpt, Karen L Kotloff, Kavita Misra, William A Petri, and Jam Platts-Mills. 2018. "Global Disability-Adjusted Life-Year Estimates of Long-Term Health Burden and Undernutrition Attributable to Diarrhoeal Diseases in Children Younger than 5 Years." The Lancet Global Health 6 (3): e255-e269 (March).

Wang, Haidong, Mohsen Naghavi, Christine Allen, Ryan Barber, Zulfiqar Bhutta, Austin Carter, Daniel Casey, Fiona Charlson, Alan Chen, Matthew Coates, et al. 2016. "Global, Regional, and National Life Expectancy, All-Cause Mortality, and Cause-Specific Mortality for 249 Causes of Death, 1980-2015: A Systematic Analysis for the Global Burden of Disease Study 2015." The Lancet 388 (10053): 1459-1544.

Weobong, Benedict, Helen A Weiss, David McDaid, Daisy R Singla, Steven D Hollon, Abhijit Nadkarni, A-La Park, Bhargav Bhat, Basavraj Katti, Arpita Anand, et al. 2017. "Sustained Effectiveness and Cost-Effectiveness of the Healthy Activity Programme, a Brief Psychological Treatment for Depression Delivered by Lay Counsellors in Primary Care: 12-month Follow-Up of a Randomised Controlled Trial." PLoS Medicine 14, no. 9.

Wilson, Timothy, Thalia Wheatley, Jonathan Meyers, Daniel Gilbert, and Danny Axsom. 2000. "Focalism: A Source of Durability Bias in Affective Forecasting." Journal of Personality and Social Psychology 78 (5): 821-836.

Zwane, Alix Peterson, Jonathan Zinman, Eric Van Dusen, William Pariente, Clair Null, Edward Miguel, Michael Kremer, Dean Karlan, Richard Hornbeck, Xavier Giné, et al. 2011. "Being Surveyed Can Change Later Behavior and Related Parameter Estimates." Proceedings of the National Academy of Sciences 108 (5): 1821-1826. 
Table 1: Experimental integrity

\begin{tabular}{|c|c|c|c|c|c|c|c|c|c|c|}
\hline & \multicolumn{5}{|c|}{ Comparison with active control (AC+INF) } & \multicolumn{5}{|c|}{ Comparison with pure control (PC) } \\
\hline & $(1)$ & $(2)$ & (3) & (4) & $(5)$ & (6) & (7) & (8) & (9) & $(10)$ \\
\hline & $\begin{array}{c}\text { Active } \\
\text { Control } \\
\text { Group } \\
\text { Mean (SD) }\end{array}$ & $\begin{array}{c}\text { Visualization } \\
\text { Treatment } \\
\text { Effect }\end{array}$ & $\begin{array}{c}\text { Planning } \\
\text { Treatment } \\
\text { Effect }\end{array}$ & $\begin{array}{c}\text { Column } 2 \text { vs. } \\
\text { Column } 3 \\
p \text {-value }\end{array}$ & $N$ & $\begin{array}{c}\text { Pure } \\
\text { Control } \\
\text { Mean (SD) }\end{array}$ & $\begin{array}{c}\text { V+INF } \\
\text { Treatment } \\
\text { Effect }\end{array}$ & $\begin{array}{c}\text { P+INF } \\
\text { Treatment } \\
\text { Effect }\end{array}$ & $\begin{array}{c}\text { AC+INF } \\
\text { Treatment } \\
\text { Effect }\end{array}$ & $N$ \\
\hline \multicolumn{11}{|l|}{ Balance on recruitment census variables } \\
\hline Age & $\begin{array}{l}26.73 \\
(4.50)\end{array}$ & $\begin{array}{c}-0.06 \\
(0.23)\end{array}$ & $\begin{array}{c}-0.01 \\
(0.24)\end{array}$ & 0.82 & 2116 & $\begin{array}{l}26.88 \\
(4.63)\end{array}$ & $\begin{array}{c}-0.36 \\
(0.25)\end{array}$ & $\begin{array}{c}-0.43 \\
(0.26)^{*}\end{array}$ & $\begin{array}{c}-0.33 \\
(0.25)\end{array}$ & 2984 \\
\hline Married or cohabiting & $\begin{array}{c}0.89 \\
(0.31)\end{array}$ & $\begin{array}{c}0.00 \\
(0.02)\end{array}$ & $\begin{array}{c}0.00 \\
(0.02)\end{array}$ & 0.88 & 2116 & $\begin{array}{c}0.91 \\
(0.28)\end{array}$ & $\begin{array}{c}-0.02 \\
(0.02)\end{array}$ & $\begin{array}{c}-0.02 \\
(0.02)\end{array}$ & $\begin{array}{c}-0.03 \\
(0.02)^{*}\end{array}$ & 2984 \\
\hline Education level & $\begin{array}{c}5.85 \\
(1.20)\end{array}$ & $\begin{array}{c}-0.01 \\
(0.06)\end{array}$ & $\begin{array}{c}0.07 \\
(0.06)\end{array}$ & 0.19 & 2116 & $\begin{array}{c}5.92 \\
(1.10)\end{array}$ & $\begin{array}{c}-0.06 \\
(0.06)\end{array}$ & $\begin{array}{c}0.03 \\
(0.06)\end{array}$ & $\begin{array}{c}-0.03 \\
(0.06)\end{array}$ & 2984 \\
\hline High wealth index & $\begin{array}{c}0.55 \\
(0.50)\end{array}$ & $\begin{array}{c}-0.01 \\
(0.03)\end{array}$ & $\begin{array}{c}-0.02 \\
(0.03)\end{array}$ & 0.75 & 2116 & $\begin{array}{c}0.53 \\
(0.50)\end{array}$ & $\begin{array}{c}0.01 \\
(0.03)\end{array}$ & $\begin{array}{c}-0.00 \\
(0.03)\end{array}$ & $\begin{array}{c}0.02 \\
(0.03)\end{array}$ & 2984 \\
\hline Village of residence & $\begin{array}{l}89.08 \\
(54.74)\end{array}$ & $\begin{array}{c}-0.06 \\
(6.30)\end{array}$ & $\begin{array}{c}0.50 \\
(6.30)\end{array}$ & 0.93 & 2116 & $\begin{array}{l}85.46 \\
(57.21)\end{array}$ & $\begin{array}{c}1.49 \\
(4.79)\end{array}$ & $\begin{array}{l}1.73 \\
(4.84)\end{array}$ & $\begin{array}{c}1.16 \\
(4.55)\end{array}$ & 2984 \\
\hline \multicolumn{11}{|l|}{ Delay variables } \\
\hline Days between endline and baseline & $\begin{array}{c}67.73 \\
(20.63)\end{array}$ & $\begin{array}{c}0.62 \\
(1.00)\end{array}$ & $\begin{array}{l}1.80 \\
(0.93)^{*}\end{array}$ & 0.23 & 2116 & $\begin{array}{c}68.73 \\
(24.07)\end{array}$ & $\begin{array}{c}1.82 \\
(1.06)^{*}\end{array}$ & $\begin{array}{l}2.12 \\
(1.01)^{* *}\end{array}$ & $\begin{array}{c}1.23 \\
(1.00)\end{array}$ & 2984 \\
\hline Days between chlorine test and baseline & $\begin{array}{l}78.11 \\
(26.65)\end{array}$ & $\begin{array}{c}0.57 \\
(1.37)\end{array}$ & $\begin{array}{l}2.52 \\
(1.31)^{*}\end{array}$ & 0.16 & 1868 & $\begin{array}{c}81.12 \\
(27.54)\end{array}$ & $\begin{array}{c}0.70 \\
(1.26)\end{array}$ & $\begin{array}{l}1.71 \\
(1.21)\end{array}$ & $\begin{array}{c}0.08 \\
(1.19)\end{array}$ & 2646 \\
\hline Chlorine test was conducted on the first day of village's tests & $\begin{array}{c}0.68 \\
(0.47)\end{array}$ & $\begin{array}{c}0.01 \\
(0.02)\end{array}$ & $\begin{array}{c}-0.00 \\
(0.02)\end{array}$ & 0.69 & 2009 & $\begin{array}{c}0.67 \\
(0.47)\end{array}$ & $\begin{array}{c}-0.01 \\
(0.02)\end{array}$ & $\begin{array}{c}-0.01 \\
(0.02)\end{array}$ & $\begin{array}{c}-0.01 \\
(0.02)\end{array}$ & 2839 \\
\hline \multicolumn{11}{|l|}{ Endline participation } \\
\hline Did not participate in endline & $\begin{array}{c}0.08 \\
(0.27)\end{array}$ & $\begin{array}{c}0.02 \\
(0.02)\end{array}$ & $\begin{array}{l}0.03 \\
(0.02)^{*}\end{array}$ & 0.39 & 2337 & $\begin{array}{c}0.24 \\
(0.43)\end{array}$ & $\begin{array}{l}-0.06 \\
(0.02)^{* * *}\end{array}$ & $\begin{array}{c}-0.04 \\
(0.02)^{*}\end{array}$ & $\begin{array}{l}-0.06 \\
(0.02)^{* * *}\end{array}$ & 3750 \\
\hline Did not participate in endline, conditional on attending baseline & $\begin{array}{c}0.08 \\
(0.27)\end{array}$ & $\begin{array}{c}0.02 \\
(0.02)\end{array}$ & $\begin{array}{l}0.03 \\
(0.02)^{*}\end{array}$ & 0.39 & 2337 & $\begin{array}{c}0.00 \\
(0.05)\end{array}$ & $\begin{array}{l}0.07 \\
(0.01)^{* * *}\end{array}$ & $\begin{array}{l}0.08 \\
(0.01)^{* * *}\end{array}$ & $\begin{array}{l}0.06 \\
(0.01)^{* * *}\end{array}$ & 3750 \\
\hline Did not participate in chlorine test & $\begin{array}{c}0.12 \\
(0.33)\end{array}$ & $\begin{array}{c}0.01 \\
(0.02)\end{array}$ & $\begin{array}{c}0.03 \\
(0.02)\end{array}$ & 0.33 & 2337 & $\begin{array}{c}0.26 \\
(0.44)\end{array}$ & $\begin{array}{c}-0.04 \\
(0.02)^{*}\end{array}$ & $\begin{array}{c}-0.02 \\
(0.02)\end{array}$ & $\begin{array}{l}-0.04 \\
(0.02)^{* *}\end{array}$ & 3750 \\
\hline Did not participate in chlorine test, conditional on attending baseline & $\begin{array}{c}0.12 \\
(0.33) \\
\end{array}$ & $\begin{array}{c}0.01 \\
(0.02) \\
\end{array}$ & $\begin{array}{c}0.03 \\
(0.02) \\
\end{array}$ & 0.33 & 2337 & $\begin{array}{c}0.00 \\
(0.05) \\
\end{array}$ & $\begin{array}{c}0.10 \\
(0.01)^{* * *}\end{array}$ & $\begin{array}{l}0.12 \\
(0.01)^{* * *}\end{array}$ & $\begin{array}{l}0.09 \\
(0.01)^{* * *}\end{array}$ & 3750 \\
\hline \multicolumn{11}{|l|}{ Compliance } \\
\hline Completed both first and second intervention & $\begin{array}{c}0.74 \\
(0.44)\end{array}$ & $\begin{array}{c}0.01 \\
(0.02)\end{array}$ & $\begin{array}{c}-0.02 \\
(0.02)\end{array}$ & 0.35 & 2975 & $\begin{array}{l}- \\
-\end{array}$ & $\begin{array}{l}- \\
-\end{array}$ & $\begin{array}{l}- \\
-\end{array}$ & - & - \\
\hline Completed first intervention & $\begin{array}{c}0.78 \\
(0.41)\end{array}$ & $\begin{array}{c}0.01 \\
(0.02)\end{array}$ & $\begin{array}{c}0.01 \\
(0.02)\end{array}$ & 0.85 & 2975 & $\begin{array}{l}- \\
-\end{array}$ & $\begin{array}{l}- \\
-\end{array}$ & $\begin{array}{l}- \\
-\end{array}$ & $\begin{array}{l}- \\
-\end{array}$ & - \\
\hline Completed no intervention & $\begin{array}{c}0.22 \\
(0.41)\end{array}$ & $\begin{array}{c}-0.01 \\
(0.02)\end{array}$ & $\begin{array}{c}-0.01 \\
(0.02)\end{array}$ & 0.85 & 2975 & - & - & - & - & - \\
\hline
\end{tabular}

Notes: OLS estimates of balance across treatment groups. For each variable, we report the mean of the comparison group, the coefficients of interest, and standard errors in parentheses. Delay, attrition, and compliance specifications control for a vector of observed characteristics; baseline balance specifications do not. All specifications cluster standard errors at the level of intervention cohort. The "Balance on recruitment census variables" and "Delay variables" samples are restricted to those who attended endline, and for the AC+INF comparison additionally restricted to those who completed baseline and the first intervention session, since these are the samples used for the primary analyses. * denotes significance at 10 pct., $* *$ at 5 pct., and $*^{*}$ at 1 pct. level. Balance variables were collected at point of recruitment into the study, approximately four weeks before the first intervention. 'High wealth index denotes participants who scored above the median in a measure of the value of their holdings of a limited list of common household assets. Delay variables measure the number of days elapsed from when an individual participated in the first intervention session until i) the endline measures in the laboratory, and ii) the test in their home for the presence of chlorine in stored drinking water. The third delay variable indicates the proportion of study participants who had their drinking water tested for chlorine on the

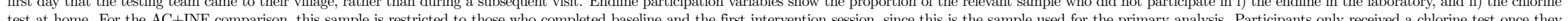

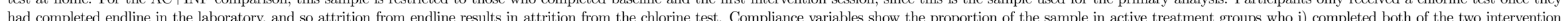
sessions, ii) completed only the first and did not return for the second, iii) failed to complete any of the interventions. A comparison is not shown relative to the pure control group since that group was not invited to intervention sessions. 
Table 2: Behavioral outcomes

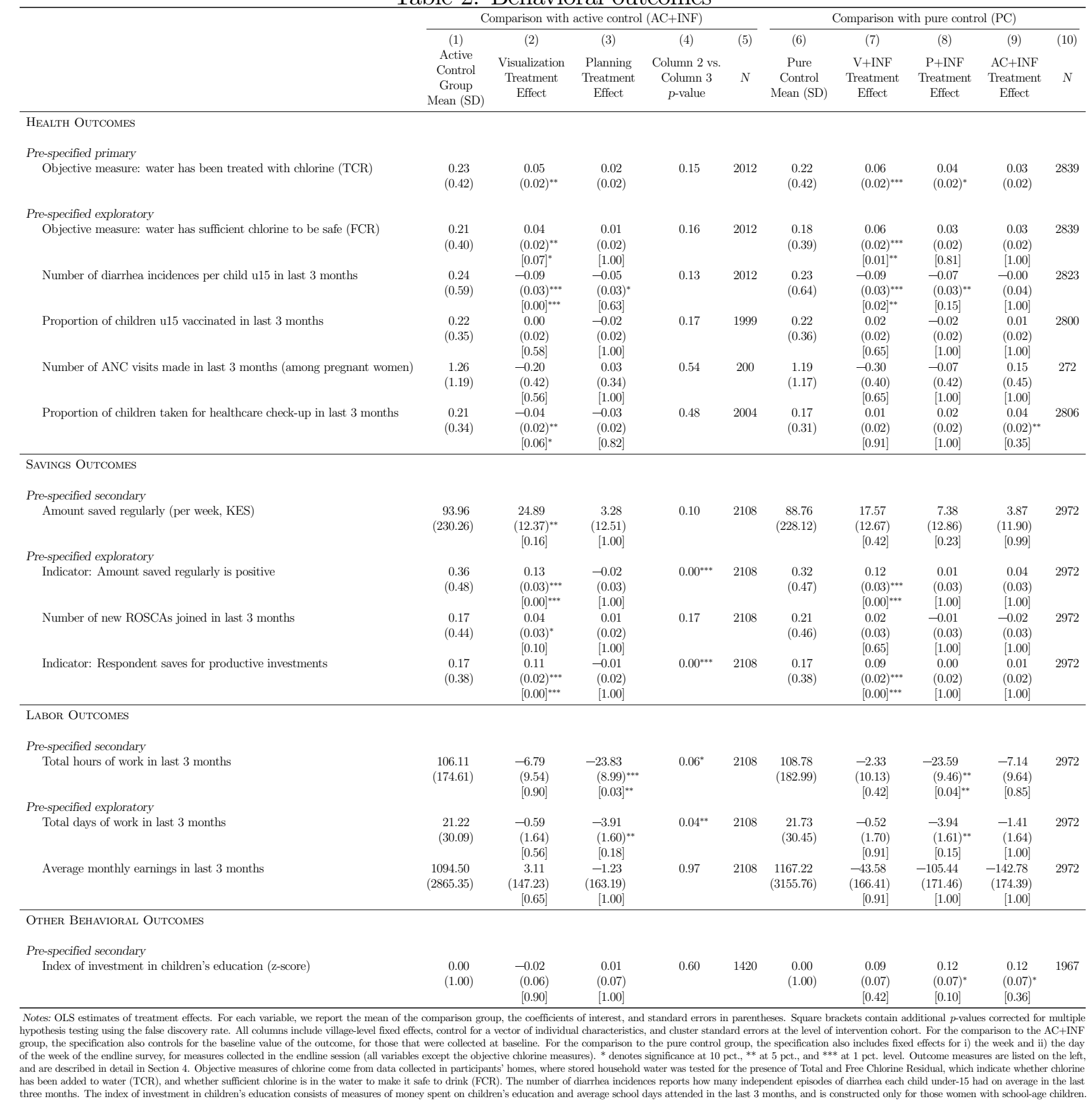


Table 3: Chlorine-related outcomes in dispenser vs. non-dispenser villages

\begin{tabular}{|c|c|c|c|c|c|c|c|c|c|c|c|c|c|}
\hline & \multicolumn{5}{|c|}{ Village has no chlorine dispenser } & \multicolumn{5}{|c|}{ Village has chlorine dispenser } & \multicolumn{3}{|c|}{ Comparison } \\
\hline & $\begin{array}{c}(1) \\
\text { Pure } \\
\text { Control } \\
\text { Mean (SD) }\end{array}$ & $\begin{array}{c}(2) \\
\text { V+INF } \\
\text { Treatment } \\
\text { Effect }\end{array}$ & $\begin{array}{c}(3) \\
\text { P+INF } \\
\text { Treatment } \\
\text { Effect }\end{array}$ & $\begin{array}{c}(4) \\
\text { AC+INF } \\
\text { Treatment } \\
\text { Effect }\end{array}$ & $\begin{array}{l}(5) \\
N\end{array}$ & $\begin{array}{c}(6) \\
\text { Pure } \\
\text { Control } \\
\text { Mean (SD) }\end{array}$ & $\begin{array}{c}(7) \\
\text { V+INF } \\
\text { Treatment } \\
\text { Effect }\end{array}$ & $\begin{array}{c}(8) \\
\text { P+INF } \\
\text { Treatment } \\
\text { Effect }\end{array}$ & $\begin{array}{c}(9) \\
\text { AC+INF } \\
\text { Treatment } \\
\text { Effect }\end{array}$ & $\begin{array}{c}(10) \\
N\end{array}$ & $\begin{array}{c}(11) \\
\text { V+INF } \\
\text { Interaction } \\
p \text {-value }\end{array}$ & $\begin{array}{c}(12) \\
\mathrm{P}+\mathrm{INF} \\
\text { Interaction } \\
p \text {-value }\end{array}$ & $\begin{array}{c}(13) \\
\text { AC+INF } \\
\text { Interaction } \\
p \text {-value }\end{array}$ \\
\hline Objective measure: water has been treated with chlorine (TCR) & $\begin{array}{c}0.23 \\
(0.42)\end{array}$ & $\begin{array}{c}0.04 \\
(0.03)\end{array}$ & $\begin{array}{c}0.02 \\
(0.03)\end{array}$ & $\begin{array}{c}-0.01 \\
(0.03)\end{array}$ & 1534 & $\begin{array}{c}0.21 \\
(0.41)\end{array}$ & $\begin{array}{l}0.08 \\
(0.03)^{* *}\end{array}$ & $\begin{array}{l}0.05 \\
(0.03)^{*}\end{array}$ & $\begin{array}{l}0.07 \\
(0.03)^{* *}\end{array}$ & 1305 & {$[0.31]$} & {$[0.42]$} & {$[0.04]^{* *}$} \\
\hline Objective measure: water has sufficient chlorine to be safe (FCR) & $\begin{array}{c}0.17 \\
(0.37)\end{array}$ & $\begin{array}{c}0.05 \\
(0.03)^{*}\end{array}$ & $\begin{array}{c}0.02 \\
(0.03)\end{array}$ & $\begin{array}{c}0.00 \\
(0.03)\end{array}$ & 1534 & $\begin{array}{c}0.20 \\
(0.40)\end{array}$ & $\begin{array}{c}0.06 \\
(0.03)^{*}\end{array}$ & $\begin{array}{c}0.03 \\
(0.03)\end{array}$ & $\begin{array}{c}0.05 \\
(0.03)\end{array}$ & 1305 & {$[0.81]$} & {$[0.80]$} & {$[0.24]$} \\
\hline Number of diarrhea incidences per child u15 in last 3 months & $\begin{array}{c}0.26 \\
(0.66)\end{array}$ & $\begin{array}{c}-0.09 \\
(0.05)^{* *}\end{array}$ & $\begin{array}{c}-0.08 \\
(0.05)^{*}\end{array}$ & $\begin{array}{c}-0.02 \\
(0.05)\end{array}$ & 1502 & $\begin{array}{c}0.20 \\
(0.61)\end{array}$ & $\begin{array}{c}-0.08 \\
(0.05)\end{array}$ & $\begin{array}{c}-0.07 \\
(0.05)\end{array}$ & $\begin{array}{c}0.03 \\
(0.05)\end{array}$ & 1321 & {$[0.82]$} & {$[0.87]$} & {$[0.48]$} \\
\hline Belief: Proportion of diarrhea incidences avoided through chlorination (z-score) & $\begin{array}{c}0.00 \\
(1.00)\end{array}$ & $\begin{array}{l}0.16 \\
(0.07)^{* *}\end{array}$ & $\begin{array}{l}0.17 \\
(0.07)^{* *}\end{array}$ & $\begin{array}{l}0.08 \\
(0.08)\end{array}$ & 1573 & $\begin{array}{l}0.00 \\
(1.00)\end{array}$ & $\begin{array}{c}0.08 \\
(0.08)\end{array}$ & $\begin{array}{c}0.13 \\
(0.08)\end{array}$ & $\begin{array}{c}0.16 \\
(0.08)^{*}\end{array}$ & 1382 & {$[0.37]$} & {$[0.60]$} & {$[0.56]$} \\
\hline Chlorine knowledge score (z-score) & $\begin{array}{c}0.00 \\
(1.00)\end{array}$ & $\begin{array}{l}0.16 \\
(0.08)^{* *}\end{array}$ & $\begin{array}{c}0.06 \\
(0.08)\end{array}$ & $\begin{array}{c}0.05 \\
(0.08)\end{array}$ & 1573 & $\begin{array}{c}0.00 \\
(1.00)\end{array}$ & $\begin{array}{c}0.05 \\
(0.08)\end{array}$ & $\begin{array}{c}0.06 \\
(0.08)\end{array}$ & $\begin{array}{c}0.12 \\
(0.08)\end{array}$ & 1382 & {$[0.29]$} & {$[1.00]$} & {$[0.57]$} \\
\hline
\end{tabular}

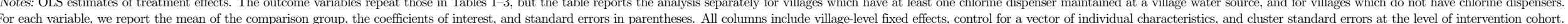

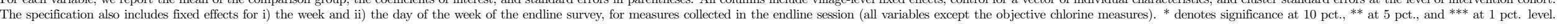
Outcome measures are listed on the left, and are described in detail in Section 4. Columns (11)-(13) report the $p$-values on the differential effect of the treatments in villages with vs. without chlorine dispensers using SUR. 
Table 4: Psychological outcomes

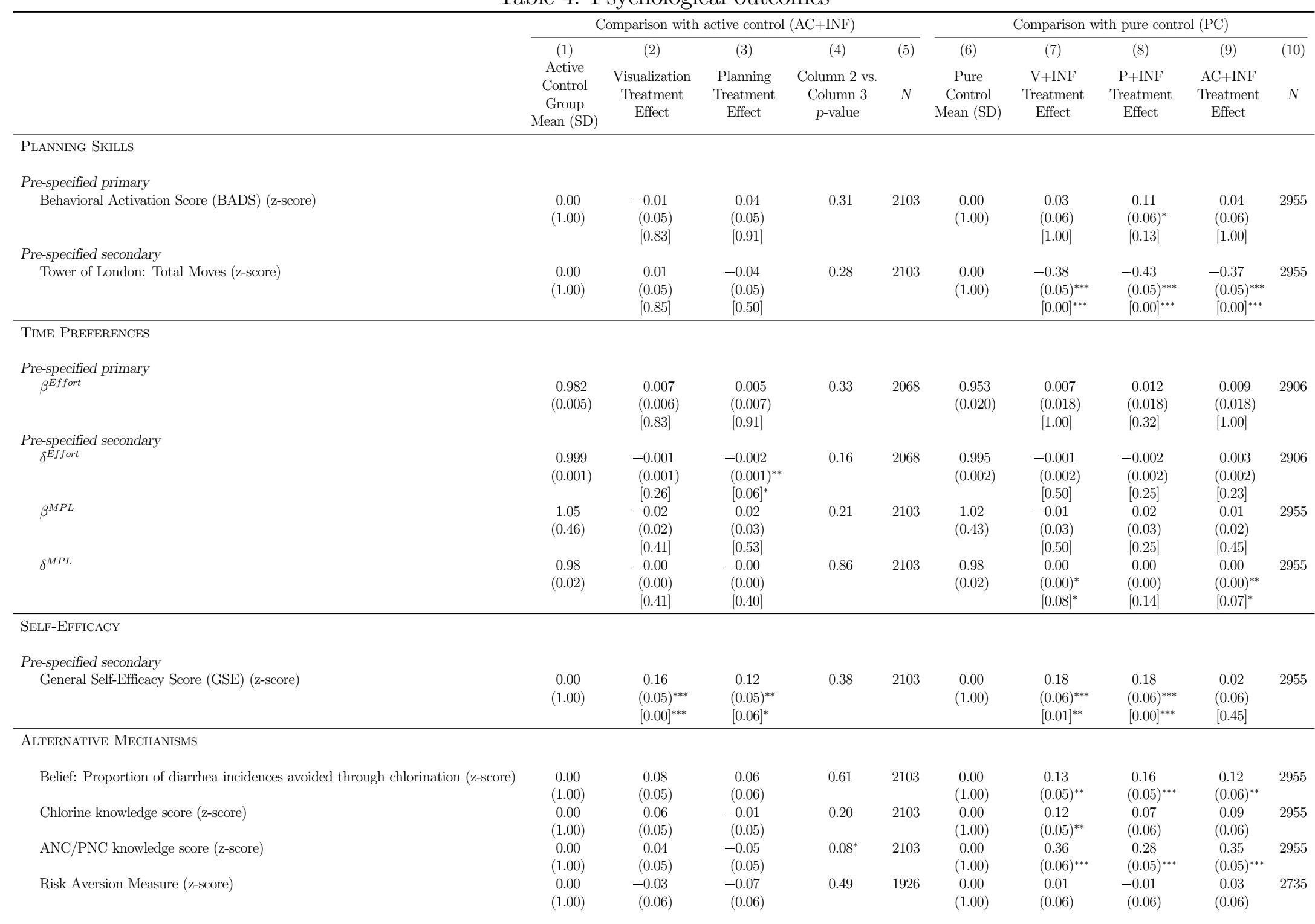

Notes: OLS estimates of treatment effects. For each variable, we report the mean of the comparison group, the coefficients of interest, and standard errors in parentheses. Square brackets contain additional $p$-values corrected for multiple hypothesi testing using the false discovery rate. All columns include village-level fixed effects, control for a vector of individual characteristics, and cluster standard errors at the level of the intervention cohort. For the comparison to the AC+INF group, the
specification also controls for the baseline value of the outcome, for those that were collected at baseline. For the comparison to the pure control group, the specification also includes fixed effects for i) the week and ii) the day of the week of the endline survey, for measures collected in the endline session. * denotes significance at 10 pct., ** at 5 pct., and *** at 1 pct. level. Outcome measures are listed on the left, and are described in detail in Section 4 . The BADS score measures a participant's ability and motivation to follow through on plans they make in their life. Tower of London is a lab game that measures a participant's ability to plan ahead. Time preferences over effort are estimated structurally from a real effort task involving data entry by SMSs. Time preferences over money are measured using Multiple Price Lists (MPL). The risk aversion measure is derived from responses to a coin flip for various monetary rewards. The General Self-Efficacy score measures a participant' belief in their own ability to achieve the outcomes they desire. The mechanisms variables check if the interventions differentially affected i) a participant's belief in the efficacy of chlorine to prevent diarrhea, and ii) their knowledge of how to correctly
chlorinate water, to assess whether changes in beliefs or knowledge could have been the cause of changes in chlorination behavior. 
Table 5: Salience \& memory test outcomes

(1)

(3)

(4)

Chlorine word Saving word Future word Total words remembered remembered remembered remembered

\begin{tabular}{|c|c|c|c|c|}
\hline Visualization & $\begin{array}{c}0.08 \\
(0.01)^{* * *}\end{array}$ & $\begin{array}{c}0.00 \\
(0.01)\end{array}$ & $\begin{array}{l}-0.01 \\
(0.01)\end{array}$ & $\begin{array}{l}-0.37 \\
(0.23)\end{array}$ \\
\hline Planning & $\begin{array}{c}0.05 \\
(0.01)^{* * *}\end{array}$ & $\begin{array}{c}0.02 \\
(0.01)\end{array}$ & $\begin{array}{l}-0.01 \\
(0.01)\end{array}$ & $\begin{array}{l}-0.03 \\
(0.24)\end{array}$ \\
\hline Active Control & $\begin{array}{c}0.02 \\
(0.01)\end{array}$ & $\begin{array}{c}0.01 \\
(0.01)\end{array}$ & $\begin{array}{c}-0.03 \\
(0.01)^{*}\end{array}$ & $\begin{array}{l}-0.12 \\
(0.22)\end{array}$ \\
\hline V x Chlorine Word Interaction & & & $\begin{array}{c}0.09 \\
(0.02)^{* * *}\end{array}$ & \\
\hline $\mathrm{P} \times \mathrm{x}$ Chlorine Word Interaction & & & $\begin{array}{c}0.06 \\
(0.02)^{* *}\end{array}$ & \\
\hline AC x Chlorine Word Interaction & & & $\begin{array}{c}0.05 \\
(0.02)^{*}\end{array}$ & \\
\hline V x Saving Word Interaction & & & $\begin{array}{c}0.02 \\
(0.02)\end{array}$ & \\
\hline P x Saving Word Interaction & & & $\begin{array}{c}0.03 \\
(0.02)\end{array}$ & \\
\hline AC x Saving Word Interaction & & & $\begin{array}{c}0.04 \\
(0.02)^{*}\end{array}$ & \\
\hline Constant & $\begin{array}{c}5.15 \\
(2.24)^{*}\end{array}$ & $\begin{array}{c}2.27 \\
(2.09)\end{array}$ & $\begin{array}{c}3.36 \\
(1.09)^{* *}\end{array}$ & $\begin{array}{l}-31.30 \\
(34.04)\end{array}$ \\
\hline
\end{tabular}

Notes: The table reports the probability in the salience test of remembering a chlorine-related word, or a savings-related word. The OLS specifications control for the total number of words the participant remembered in each list and include a 'chlorine word' fixed effect. The coefficients of the interaction terms show the differential probability of remembering a 'future-related' word if that word is related to chlorine or saving. * denotes significance at 10 pct., ${ }^{* *}$ at 5 pct., and ${ }^{* * *}$ at 1 pct. level. 


\section{Online Appendix}

\section{A. Cost-effectiveness per disability-adjusted life year saved}

To compute the disability-adjusted life years saved with our interventions, we proceed as follows. First, the cost of our interventions was USD 4 per household, or USD 1.33 per child because households have three children on average. This includes the costs relevant to a potential scale-up, i.e. the cost of running the sessions including overheads, but not our incentivized surveys. Troeger et al. (2018) estimate the DALYs lost per child in Kenya due to diarrhea in 2016, the year our study was conducted, to be 0.127 . Our region is one of the poorer ones in Kenya and has worse health outcomes than others, so using this figure will lead to a conservative estimate. We next assume that the treatment effects of our interventions on diarrhea relative to the active control group ( -38 percent for visualization and -21 percent for planning) were never higher during the study period of 3 months than what we measured at the 3-month endline, and then immediately went to zero. This, too, is a conservative assumption and will lead to a lower-bound estimate. Together, these figures suggest that DALYs saved per child due to the visualization intervention are $0.127 \times 38 \% \times \frac{3}{12}=0.012065$, and of the planning intervention 0.0066675 . Combined with an intervention cost of USD 1.33 per child for both interventions, this implies that the cost of one DALY saved is $\frac{\text { USD } 1.33}{0.012065}=$ USD110 for the visualization intervention and $\frac{\text { USD1.33 }}{0.0066675}=$ USD199 for the planning intervention. Notably, Troeger et al. (2018) estimate DALYs lost to diarrhea in children under 5, while our pre-specified outcome is diarrhea in children under 15. Our data allows us to re-run the estimation for diarrhea in children under 5: Appendix Table A.22 shows reductions in under-5 diarrhea of 34 and 25 percent in the visualization and planning groups, respectively, relative to the active control. Using these estimates instead of the under-15 ones, we obtain a cost per DALY

saved of $\frac{\text { USD } 1.33}{0.010795}=$ USD123 for the visualization intervention, and $\frac{\text { USD1.33 }}{0.0079375}=$ USD168 for planning.

\section{B. Description of WASH Benefits Kenya}

The WASH Benefits Kenya study is a cluster-randomized controlled trial testing the effects of six "water, sanitation and handwashing" (WASH) interventions on childhood development (Null et al. 2018). Villages were eligible if they were rural, most of the population relied on communal water sources and had unimproved sanitation facilities, and there were no other ongoing water, sanitation, handwashing, or nutrition programs. Between 2012 and 2014, 8,246 pregnant women were enrolled from three counties in western Kenya: Bungoma, Kakamega and Vihiga. The six interventions were (W) improved water quality ("Water Quality"); (S) improved sanitation; (H) handwashing with 
soap; (WSH) combined water, sanitation and handwashing; (N) improved nutrition; (WSH+N) combined water, sanitation, handwashing and nutrition. The study also included two control arms: (A) an active control arm, who received monthly visits to measure children's arm circumferences; and $(\mathrm{P})$ a passive comparison arm, who received no visits. The villages in our sample primarily came from either $(\mathrm{W})$ improved water quality or $(\mathrm{P})$ passive comparison arm.

In all Villages in Arm W, "Water Quality", chlorine dispensers were installed at public water sources used by study participants. All community members were able to use the dispensers free of charge. After filling water carrying containers, usually a 201 jerrycan, users turn the knob on the dispenser to add $3 \mathrm{ml}$ of 1.25 percent sodium hypochlorite (chlorine), which yields $2.5 \mathrm{ml} / \mathrm{l}$ of free chlorine residual after 30 mins for $20 \mathrm{l}$ of water (Kremer et al. 2011a). This is sufficient chlorine to sanitize the water for drinking. Community promoters encouraged use of the chlorine dispensers, which to this date are monitored and maintained by Evidence Action's "Dispensers for Safe Water" program. Sample households additionally received a six-month supply of bottled chlorine every six months, to be used for sanitizing water at home, in case the household drank harvested rainwater or chose not to use the water source with the installed dispenser.

About 20 percent of our sample was recruited uniformly from 71 villages in the remaining six WASH Benefits treatment arms in Mumias district, Kakamega county. The inclusion of participants from villages treated by the remaining six arms of the WASH intervention was not planned but occurred as a result of a coding error at the sampling stage. During the WASH Benefits study, 48 of these 71 villages received one of sanitation, handwashing or nutrition interventions, but no dispensers. We group these 48 villages with the passive comparison villages in our analysis. First, these additional interventions all took place at the household level. We exclude households which participated directly in the original WASH study from participation in the present study. Second, all interventions other than dispensers finished three to four years before our study. The other 23 villages received dispensers, as well as combinations of sanitation, handwashing or nutrition interventions. We group these villages with dispenser villages, as Evidence Action continued to maintain dispensers in these villages.

We include these villages in our main estimation of treatment effects, grouping treatment arms by whether or not they received the water quality interventions. As a robustness check, we exclude these 71 villages from the heterogeneity analysis by "Water Quality" assignment in Appendix F. We find little difference in the sign or magnitude of coefficients, and small differences in statistical significance, likely driven by reduced power from the smaller sample size. 


\section{Experimental integrity}

Table A.1: Summary of participation

\begin{tabular}{lccccc}
\hline & Pure Control & Active Control & Visualization & Planning & Total \\
\hline Recruited & 775 & 992 & 992 & 991 & 3,750 \\
Completed baseline & - & 777 & 783 & 777 & 2,337 \\
Completed baseline \& Intervention 1 & - & 777 & 783 & 777 & 2,337 \\
Completed baseline \& Intervention 1 \& Intervention 2 & - & 736 & 734 & 711 & 2,181 \\
Completed baseline \& endline & - & 716 & 708 & 692 & 2,116 \\
Completed endline & 588 & 811 & 800 & 785 & 2,984 \\
Completed baseline \& endline \& chlorine test & - & 662 & 647 & 641 & 1,950 \\
Completed endline \& chlorine test & 568 & 771 & 754 & 738 & 2,831 \\
Completed chlorine test & 571 & 771 & 756 & 741 & 2,839 \\
\hline
\end{tabular}


Table A.2: Baseline balance: main outcomes

\begin{tabular}{|c|c|c|c|c|c|}
\hline & \multicolumn{5}{|c|}{ Comparison with active control $(\mathrm{AC}+\mathrm{INF})$} \\
\hline & $\begin{array}{c}(1) \\
\text { Active } \\
\text { Control } \\
\text { Group } \\
\text { Mean (SD) }\end{array}$ & $\begin{array}{c}(2) \\
\text { Visualization } \\
\text { Treatment } \\
\text { Effect }\end{array}$ & $\begin{array}{c}(3) \\
\text { Planning } \\
\text { Treatment } \\
\text { Effect }\end{array}$ & $\begin{array}{c}(4) \\
\text { Column } 2 \text { vs. } \\
\text { Column } 3 \\
p \text {-value }\end{array}$ & (5) \\
\hline \multicolumn{6}{|l|}{ Baseline score } \\
\hline Tower of London: Total Moves & $\begin{array}{c}23.32 \\
(6.83)\end{array}$ & $\begin{array}{c}-0.48 \\
(0.46) \\
{[0.98]}\end{array}$ & $\begin{array}{c}-0.30 \\
(0.42) \\
{[1.00]}\end{array}$ & 0.70 & 2197 \\
\hline General Self-Efficacy Score (GSE) & $\begin{array}{c}42.84 \\
(11.59)\end{array}$ & $\begin{array}{c}-0.07 \\
(0.68) \\
{[1.00]}\end{array}$ & $\begin{array}{c}0.90 \\
(0.74) \\
{[1.00]}\end{array}$ & 0.19 & 2175 \\
\hline$\beta^{M P L}$ & $\begin{array}{c}0.99 \\
(0.37)\end{array}$ & $\begin{array}{c}0.01 \\
(0.02) \\
{[1.00]}\end{array}$ & $\begin{array}{c}0.00 \\
(0.02) \\
{[1.00]}\end{array}$ & 0.64 & 2142 \\
\hline$\delta^{M P L}$ & $\begin{array}{c}0.98 \\
(0.02)\end{array}$ & $\begin{array}{c}0.00 \\
(0.00) \\
{[1.00]}\end{array}$ & $\begin{array}{c}0.00 \\
(0.00) \\
{[1.00]}\end{array}$ & 0.52 & 2142 \\
\hline Self report: added chlorine in last month & $\begin{array}{c}0.65 \\
(0.48)\end{array}$ & $\begin{array}{r}-0.04 \\
(0.03) \\
{[0.56]}\end{array}$ & $\begin{array}{c}-0.04 \\
(0.03) \\
{[1.00]}\end{array}$ & 0.82 & 2184 \\
\hline Chlorine knowledge score (z-score) & $\begin{array}{c}0.00 \\
(1.00)\end{array}$ & $\begin{array}{c}0.09 \\
(0.05) \\
{[0.56]}\end{array}$ & $\begin{array}{c}0.01 \\
(0.05) \\
{[1.00]}\end{array}$ & 0.18 & 2337 \\
\hline Number of diarrhea incidences per child u15 in last 3 months & $\begin{array}{c}0.10 \\
(0.25)\end{array}$ & $\begin{array}{c}0.00 \\
(0.01) \\
{[1.00]}\end{array}$ & $\begin{array}{c}-0.00 \\
(0.01) \\
{[1.00]}\end{array}$ & 0.55 & 2084 \\
\hline
\end{tabular}

Notes: OLS estimates of baseline values of main outcomes. For each variable, we report the mean of the comparison group, the coefficients of interest, and standard errors in parentheses. Square brackets contain additional $p$-values corrected for multiple hypothesis testing using the false discovery rate. All columns include village-level fixed effects, control for a vector of individual characteristics, and cluster standard errors at the level of the intervention cohort. $*$ denotes significance at 10 pct., ${ }^{* *}$ at 5 pct., and ${ }^{* * *}$ at 1 pct. level. Outcome measures are listed on the left, and are described in detail in Section 4 . The Tower of London is a lab game that measures a participant's ability to plan ahead. The General Self-Efficacy score measures a participant's belief in their own ability to achieve the outcomes they desire. Time preference parameters $\beta$ and $\delta$ measured over money are derived from responses to Multiple Price Lists (MPL). 
Table A.3: Baseline balance: dispenser vs. non-dispenser villages

\begin{tabular}{lccc}
\hline & $(1)$ & $(2)$ & $(3)$ \\
& $\begin{array}{c}\text { Village without } \\
\text { Chlorine Dispenser } \\
\text { Mean (SD) }\end{array}$ & $\begin{array}{c}\text { Village with } \\
\text { Chlorine Dispenser } \\
\text { Difference }\end{array}$ & $N$ \\
\hline Observables & 26.25 & & \\
Age & $(4.68)$ & 0.21 & 3750 \\
Married/ Cohabiting & 0.89 & $(0.15)$ & \\
& $(0.31)$ & -0.01 & 3750 \\
Education Level & 5.84 & $(0.01)$ & 3750 \\
High Wealth Index & $(1.18)$ & 0.10 & $370.04)^{* * *}$ \\
& 0.51 & 0.01 & 3750 \\
\hline
\end{tabular}

Notes: OLS estimates of baseline balance on observed characteristics for villages with and without chlorine dispensers. For each variable, we report the mean of villages without a chlorine dispenser, with the standard deviation in parentheses. Column 2 reports the difference for villages with a chlorine dispenser, with standard errors in parentheses. All standard errors are clustered at the level of intervention cohort. ${ }^{*}$ denotes significance at 10 pct., ${ }^{* *}$ at 5 pct., and ${ }^{* * *}$ at 1 pct. level. 
Table A.4: Attrition analysis: treatments vs. active control

\begin{tabular}{|c|c|c|c|c|c|c|}
\hline & $\begin{array}{c}(1) \\
\text { Did not participate in endline }\end{array}$ & $\begin{array}{c}(2) \\
\text { Did not participate in chlorine test }\end{array}$ & $\begin{array}{c}(3) \\
\text { Did not participate in endline }\end{array}$ & $\begin{array}{c}(4) \\
\text { Did not participate in chlorine test }\end{array}$ & $\begin{array}{c}(5) \\
\text { Did not participate in endline }\end{array}$ & $\begin{array}{c}(6) \\
\text { Did not participate in chlorine test }\end{array}$ \\
\hline Visualization & $\begin{array}{c}0.02 \\
(0.02)\end{array}$ & $\begin{array}{c}0.01 \\
(0.02)\end{array}$ & $\begin{array}{c}0.02 \\
(0.02)\end{array}$ & $\begin{array}{c}0.01 \\
(0.02)\end{array}$ & $\begin{array}{c}0.02 \\
(0.12)\end{array}$ & $\begin{array}{r}-0.05 \\
(0.14)\end{array}$ \\
\hline Planning & $\begin{array}{c}0.03 \\
(0.02)^{*}\end{array}$ & $\begin{array}{c}0.03 \\
(0.02)\end{array}$ & $\begin{array}{c}0.03 \\
(0.02)^{*}\end{array}$ & $\begin{array}{c}0.03 \\
(0.02)\end{array}$ & $\begin{array}{c}0.14 \\
(0.14)\end{array}$ & $\begin{array}{c}0.15 \\
(0.15)\end{array}$ \\
\hline Age & & & $\begin{array}{l}-0.01 \\
(0.00)^{* * *}\end{array}$ & $\begin{array}{l}-0.01 \\
(0.00)^{* * *}\end{array}$ & $\begin{array}{l}-0.01 \\
(0.00)^{* * *}\end{array}$ & $\begin{array}{l}-0.01 \\
(0.00)^{* *}\end{array}$ \\
\hline Married or cohabiting & & & $\begin{array}{c}-0.03 \\
(0.02)\end{array}$ & $\begin{array}{c}-0.02 \\
(0.02)\end{array}$ & $\begin{array}{c}0.00 \\
(0.03)\end{array}$ & $\begin{array}{c}0.01 \\
(0.04)\end{array}$ \\
\hline Education level & & & $\begin{array}{c}-0.00 \\
(0.01)\end{array}$ & $\begin{array}{c}-0.01 \\
(0.01)\end{array}$ & $\begin{array}{c}-0.00 \\
(0.01)\end{array}$ & $\begin{array}{c}-0.01 \\
(0.01)\end{array}$ \\
\hline $\mathrm{V} x$ Age Interaction & & & & & $\begin{array}{l}0.00 \\
(0.00)\end{array}$ & $\begin{array}{c}0.00 \\
(0.00)\end{array}$ \\
\hline P x Age Interaction & & & & & $\begin{array}{r}-0.00 \\
(0.00)\end{array}$ & $\begin{array}{c}-0.00 \\
(0.00)\end{array}$ \\
\hline V x Married Interaction & & & & & $\begin{array}{l}-0.09 \\
(0.05)^{*}\end{array}$ & $\begin{array}{c}-0.08 \\
(0.05)\end{array}$ \\
\hline P x Married Interaction & & & & & $\begin{array}{c}-0.01 \\
(0.06)\end{array}$ & $\begin{array}{r}-0.01 \\
(0.06)\end{array}$ \\
\hline V x Education Interaction & & & & & $\begin{array}{c}0.01 \\
(0.01)\end{array}$ & $\begin{array}{c}0.00 \\
(0.01)\end{array}$ \\
\hline P x Education Interaction & & & & & $\begin{array}{c}-0.01 \\
(0.01)\end{array}$ & $\begin{array}{r}-0.01 \\
(0.02)\end{array}$ \\
\hline V x Wealth Interaction & & & & & $\begin{array}{c}-0.01 \\
(0.03)\end{array}$ & $\begin{array}{l}0.00 \\
(0.04)\end{array}$ \\
\hline P x Wealth Interaction & & & & & $\begin{array}{c}-0.03 \\
(0.03)\end{array}$ & $\begin{array}{c}-0.01 \\
(0.04)\end{array}$ \\
\hline Constant & $\begin{array}{l}0.09 \\
(0.01)^{* * *}\end{array}$ & $\begin{array}{l}0.15 \\
(0.02)^{* * *}\end{array}$ & $\begin{array}{l}0.31 \\
(0.06)^{* * *}\end{array}$ & $\begin{array}{l}0.39 \\
(0.07)^{* * *}\end{array}$ & $\begin{array}{l}0.27 \\
(0.08)^{* * *}\end{array}$ & $\begin{array}{l}0.37 \\
(0.10)^{* * *}\end{array}$ \\
\hline
\end{tabular}


Table A.5: Attrition analysis: active treatments vs. pure control

\begin{tabular}{|c|c|c|c|c|c|c|}
\hline & $\begin{array}{c}\text { (1) } \\
\text { Did not participate in endline }\end{array}$ & $\begin{array}{c}(2) \\
\text { Did not participate in chlorine test }\end{array}$ & $\begin{array}{c}(3) \\
\text { Did not participate in endline }\end{array}$ & $\begin{array}{c}(4) \\
\text { Did not participate in chlorine test }\end{array}$ & $\begin{array}{c}(5) \\
\text { Did not participate in endline }\end{array}$ & $\begin{array}{c}(6) \\
\text { Did not participate in chlorine test }\end{array}$ \\
\hline $\mathrm{V}+\mathrm{INF}$ & $\begin{array}{l}-0.05 \\
(0.02)^{* * *}\end{array}$ & $\begin{array}{c}-0.04 \\
(0.02)^{*}\end{array}$ & $\begin{array}{l}-0.06 \\
(0.02)^{* * *}\end{array}$ & $\begin{array}{c}-0.04 \\
(0.02)^{*}\end{array}$ & $\begin{array}{r}-0.02 \\
(0.16)\end{array}$ & $\begin{array}{c}0.01 \\
(0.17)\end{array}$ \\
\hline $\mathrm{P}+\mathrm{INF}$ & $\begin{array}{l}-0.04 \\
(0.02)^{*}\end{array}$ & $\begin{array}{c}-0.02 \\
(0.02)\end{array}$ & $\begin{array}{l}-0.04 \\
(0.02)^{* *}\end{array}$ & $\begin{array}{r}-0.02 \\
(0.02)\end{array}$ & $\begin{array}{c}-0.04 \\
(0.18)\end{array}$ & $\begin{array}{c}0.01 \\
(0.18)\end{array}$ \\
\hline $\mathrm{AC}+\mathrm{INF}$ & $\begin{array}{l}-0.06 \\
(0.02)^{* * *}\end{array}$ & $\begin{array}{c}-0.04 \\
(0.02)^{*}\end{array}$ & $\begin{array}{l}-0.06 \\
(0.02)^{* * *}\end{array}$ & $\begin{array}{l}-0.04 \\
(0.02)^{* *}\end{array}$ & $\begin{array}{c}-0.16 \\
(0.17)\end{array}$ & $\begin{array}{c}-0.09 \\
(0.17)\end{array}$ \\
\hline Age & & & $\begin{array}{l}-0.01 \\
(0.00)^{* * *}\end{array}$ & $\begin{array}{l}-0.01 \\
(0.00)^{* * *}\end{array}$ & $\begin{array}{l}-0.01 \\
(0.00)^{* *}\end{array}$ & $\begin{array}{c}-0.01 \\
(0.00)^{*}\end{array}$ \\
\hline Married or cohabiting & & & $\begin{array}{l}-0.08 \\
(0.02)^{* * *}\end{array}$ & $\begin{array}{l}-0.08 \\
(0.02)^{* * *}\end{array}$ & $\begin{array}{c}-0.10 \\
(0.06)^{*}\end{array}$ & $\begin{array}{l}-0.13 \\
(0.06)^{* *}\end{array}$ \\
\hline Education level & & & $\begin{array}{l}-0.01 \\
(0.01)^{* *}\end{array}$ & $\begin{array}{l}-0.01 \\
(0.01)^{* *}\end{array}$ & $\begin{array}{c}-0.01 \\
(0.01)\end{array}$ & $\begin{array}{c}-0.01 \\
(0.01)\end{array}$ \\
\hline V+INF x Age Interaction & & & & & $\begin{array}{r}-0.00 \\
(0.00)\end{array}$ & $\begin{array}{c}-0.00 \\
(0.00)\end{array}$ \\
\hline P+INF x Age Interaction & & & & & $\begin{array}{c}0.00 \\
(0.00)\end{array}$ & $\begin{array}{c}0.00 \\
(0.00)\end{array}$ \\
\hline AC+INF x Age Interaction & & & & & $\begin{array}{c}0.00 \\
(0.00)\end{array}$ & $\begin{array}{c}-0.00 \\
(0.00)\end{array}$ \\
\hline V+INF x Married Interaction & & & & & $\begin{array}{c}0.01 \\
(0.07)\end{array}$ & $\begin{array}{c}0.03 \\
(0.08)\end{array}$ \\
\hline P+INF x Married Interaction & & & & & $\begin{array}{c}0.04 \\
(0.08)\end{array}$ & $\begin{array}{c}0.08 \\
(0.08)\end{array}$ \\
\hline AC+INF x Married Interaction & & & & & $\begin{array}{c}0.05 \\
(0.07)\end{array}$ & $\begin{array}{c}0.09 \\
(0.08)\end{array}$ \\
\hline V+INF x Education Interaction & & & & & $\begin{array}{c}0.00 \\
(0.02)\end{array}$ & $\begin{array}{c}-0.01 \\
(0.02)\end{array}$ \\
\hline P+INF x Education Interaction & & & & & $\begin{array}{c}-0.01 \\
(0.02)\end{array}$ & $\begin{array}{r}-0.02 \\
(0.02)\end{array}$ \\
\hline AC+INF x Education Interaction & & & & & $\begin{array}{c}0.00 \\
(0.02)\end{array}$ & $\begin{array}{r}-0.00 \\
(0.02)\end{array}$ \\
\hline V+INF $x$ Wealth Interaction & & & & & $\begin{array}{c}0.00 \\
(0.04)\end{array}$ & $\begin{array}{r}-0.00 \\
(0.04)\end{array}$ \\
\hline $\mathrm{P}+\mathrm{INF} \times \mathrm{x}$ Wealth Interaction & & & & & $\begin{array}{c}-0.02 \\
(0.04)\end{array}$ & $\begin{array}{c}-0.02 \\
(0.04)\end{array}$ \\
\hline $\mathrm{AC}+\mathrm{INF} \times \mathrm{x}$ Wealth Interaction & & & & & $\begin{array}{c}0.02 \\
(0.04)\end{array}$ & $\begin{array}{c}0.00 \\
(0.04)\end{array}$ \\
\hline Constant & $\begin{array}{l}0.26 \\
(0.02)^{* * *}\end{array}$ & $\begin{array}{l}0.29 \\
(0.02)^{* * *}\end{array}$ & $\begin{array}{l}0.59 \\
(0.06)^{* * *}\end{array}$ & $\begin{array}{l}0.62 \\
(0.06)^{* * *}\end{array}$ & $\begin{array}{l}0.61 \\
(0.13)^{* * * *}\end{array}$ & $\begin{array}{l}0.61 \\
(0.14)^{* * *}\end{array}$ \\
\hline
\end{tabular}

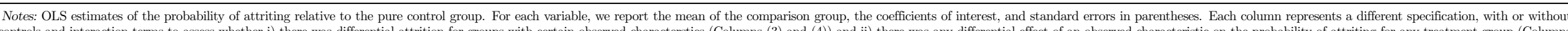

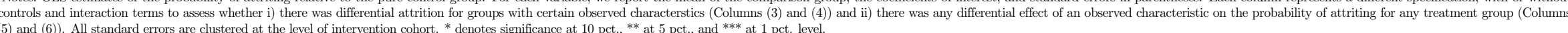




\section{Detailed descriptions of outcome measures}

\section{D.1 Tower of London planning task}

In our computerized version of the task, participants see a screen with two parts: on the left side is the word "start" with a picture of three "pegs" and various shapes positioned on the pegs; on the right side is the word "goal" with a similar picture of three "pegs" and the same shapes positioned differently on the pegs. To complete the task, participants must reposition the shapes underneath the "start" on the left to match the "goal" position on the right. They are instructed to complete each round in as few moves as possible, with the minimum number of moves shown as a number on the screen. In addition to a practice round, participants attempt four rounds of increasing complexity, beginning with one shape requiring only one move, and concluding with three shapes in a pattern that necessitates at least four moves. In all rounds, participants are limited to a maximum of 10 moves. If this occurs, the round ends and the participant is required to contact a staff member to ensure she understands the task before continuing to the next round. Therefore, the distribution of scores is censored at both ends. Performance on the Tower of London task is computed as the total number of moves used across the four rounds. An example of the participant's screen is shown in Figure A.1. Payment was based on a randomly selected round, with a payment of KES 250 for completing the task with the minimum number of moves, and a KES 50 deduction for each additional move.

\section{D.2 Effort discounting task}

Following recent innovations in the elicitation of time preferences (Andreoni and Sprenger 2012; Augenblick, Niederle, and Sprenger 2015), we estimate time preferences in the effort domain, using the methodology of Augenblick (2017): participants choose how many units of an effort task they want to complete at a time $t$ for a piece rate $w$, where $t$ is $0,1,7$, or 8 days from today, and the piece rate $w$ is KES 2, 6, or 10. Variation in time identifies the discount rate, while variation in piece rates identifies the curvature of the utility function. One time and one piece rate are randomly implemented at the end (described below). Figure A.2 provides an example of the participant interface for the task. ${ }^{34}$ In contrast to Augenblick (2017), we hold the time of decision constant and vary the time of effort provision, which requires us to control for weekday effects. All questions required a minimum effort allocation of one task at each time to control for the fixed costs of starting, and allow a maximum of 50 tasks.

Developing an effort task that is adapted to a field setting in a developing country, with low levels of literacy, was challenging: the required variation in timing meant that effort could not

\footnotetext{
${ }^{34}$ To consider the possibility that respondents feel obligated to carry out some effort regardless of the wage, a subsample of participants was also asked how many units of effort they would supply for a piece rate of KES 0 (but still receiving the KES 100 completion bonus explained below).
} 
be completed in the laboratory. We needed to monitor and enforce when participants supply effort, and how much, while they are in their homes, and do not have access to a computer. We thus developed a new effort task that is adapted to our setting: participants completed data entry tasks by SMS, using toll-free numbers administered by the Busara Center. ${ }^{35}$ Each SMS was supposed to contain a 30-digit random number string, which takes approximately two minutes to type. Participants were given a sheet with 50 such strings, including a counter to keep track. To ensure comprehension, participants completed one practice SMS during the survey. At the end of the survey, one decision (out of 12) was randomly selected to be the "decision that counts": at the selected piece rate and time horizon, participants had to send the exact number of SMS they chose. If they did, they received the full piece rate payment plus a KES 100 completion bonus. If they failed to implement the decision they made, they lost both the payment for this task and the completion bonus (see Augenblick 2017 for a full description of this method). ${ }^{36}$ Earnings from this task were paid 14 days from the survey date, regardless of the selected effort time horizon.

We estimate time preferences over effort following the approach of Augenblick (2017) by assuming quasi-linear utility (linear in money, convex in effort) and a power cost of effort function. We additionally assume quasi-hyperbolic discounting. Following DellaVigna and Pope (2017), we allow for a non-monetary reward $s$, which participants receive for each task in addition to the piece rate. The non-monetary reward captures a range of motives, from norm or sense of duty, to reciprocity towards the employer (for the flat payment), to intrinsic motivation and personal competitiveness. It was motivated by the observation that participants supply non-zero amounts of effort even for low piece rates (DellaVigna and Pope 2017). The optimal level of effort is thus given by

$$
e^{*}=\operatorname{argmax}\left(s+D_{m}(14) \cdot \phi \cdot w\right) \cdot e-\beta^{I(t>0)} \cdot \delta^{t} \cdot\left(\frac{1}{\gamma} e^{\gamma}+d_{w} \cdot e\right)
$$

where $\beta$ and $\delta$ capture (hyperbolic) temporal discounting of effort, $w$ is the piece rate, $D_{m}(14)$ captures monetary discounting of the payment in 14 days (this is constant for all questions, and thus allowed to differ from effort discounting), $t$ is the time of effort provision, $\gamma>1$ captures convex costs of effort, $\phi$ is a slope parameter, and $d_{w}$ are weekday indicators which allow the opportunity cost of time to vary across weekdays. Within the non-linear objective function above,

\footnotetext{
${ }^{35}$ Although we did not screen on phone access, all participants in our sample have access to a mobile phone: 71 percent own one, 96 percent have one in their household, and the remainder shares the phone of friends or relatives. Since phones are often used by multiple individuals, phone access should be understood as continuous rather than binary.

${ }^{36}$ The field setting with SMS required some tolerance: while a laboratory computer can confirm correct and incorrect entries, and display the number of tasks still to complete, we relied on participants to do this themselves. We thus allowed for 75 percent accuracy in entering the number strings, and a tolerance of 10 in the number of completed SMS (subject to positive completion). The permissible time window started on the calendar day before the task was due, and ended with the calendar day of the task itself. Participants were told that there would be some tolerance for mistakes, but not how much.
} 
we estimate additive treatment effects of $\mathrm{V}, \mathrm{P}$, and $\mathrm{AC}$ on the parameters $\beta, \delta, s$, and $\gamma \cdot{ }^{37}$

66 percent of participants identifiably sent at least one SMS (that was not a practice SMS during the session), 60 percent sent the correct number of SMS during the correct time window, and 41 percent additionally satisfied the required accuracy threshold (see footnote 36) and got paid. The key challenge for the verification of the effort task was matching SMS to participants: despite various safety provisions (including name and subject ID in each SMS, asking participants to report all phone numbers they might use), 59049 SMS from 3144 phone numbers could not be matched to any of our 2983 participants. This challenge arises from a field setting where individuals commonly share multiple phones within or across households (see footnote 35).

To test for difficulties in access to phones, we included a small module in the endline survey in which participants were asked about their access to a mobile phone, particularly at the times necessary to complete the SMS task. To alleviate the concern that respondents did not understand the payment scheme, we included three multiple-choice comprehension questions immediately before the task that asked participants to calculate the payout in different circumstances. Respondents could not participate in the task until they had answered the comprehension questions correctly.

Table A.9 shows phone access and task comprehension by treatment group. We find high rates of phone access and comprehension across all treatment groups, and no large differences across treatment groups. The exception is the pure control group, which showed lower comprehension at endline compared to the active treatment groups, presumably because it was their first time completing the task, while the other groups had already experienced it at baseline. We therefore interpret differences in time preferences between this group and the others with caution.

\section{D.3 Money discounting task}

In addition to the effort discounting task, we included a conventional Multiple Price List (MPL) task to measure monetary discounting. Participants were asked to make 10 choices between payments at earlier and later dates. The payment at the early date was always KES 100, while the payment at the later date increased gradually from KES 110 to KES 300, using gross interest rates 1.1, 1.25, 1.75, 2, and 3. Each decision was first made in a near time-frame (today vs. four weeks from today), and later in a future time-frame (four weeks vs. eight weeks from today). The list of decisions is presented in Table A.6. One decision was randomly selected to be paid out. As outcome measures from the MPL we estimate $\beta$ and $\delta$ in the quasi-hyperbolic discounting model of Laibson (1997), assuming linearity of utility in money.

\footnotetext{
${ }^{37}$ To control for the effect of introducing a 0 KES piece rate for a subsample of participants (Footnote 34), we additionally allow treatment effects of being exposed to the zero rate on the parameters $\gamma$ and $s$. These parameters measure the intercept and curvature of the effort supply function, and may thus be affected by variations in the set of wages. In contrast, time preferences are assumed to be orthogonal to wage variation effects.
} 


\section{D.4 Alternative mechanisms}

\section{D.4.1 Beliefs about effectiveness of chlorination}

We assess differential beliefs across treatment groups about the proportion of pediatric diarrhea cases which can be prevented by water chlorination. At baseline, all participants in the active treatment groups ("V+INF", "P+INF", and "AC+INF") are told that water chlorination reduces childhood diarrhea by approximately one third. At endline they are asked this question in a multiple-choice format. We take the proportion of cases the participant believes chlorine can avert as a measure of belief about chlorine effectiveness.

\section{D.4.2 Knowledge of how to use chlorine}

We assess differential knowledge across treatment groups of how to use chlorine to sanitize water. We ask two multiple-choice questions at endline, to which all three active treatment groups were told the correct answer at baseline: i) how much chlorine to add to water; ii) the amount of time that needs to pass after chlorine is added for water to be safe to drink.

\section{D.4.3 Risk Preferences}

We include a modified Eckel-Grossman task to account for changes in risk preferences (Charness, Gneezy, and Imas 2013). Participants choose between one of three 50/50 lotteries, represented as bets on a coin flip. We construct an ordinal measure of risk aversion based on the expected payout the participant is willing to forgo for an increase in certainty of payout.

\section{D.4.4 Salience of Chlorination}

We test for the possibility that our treatments differentially increased the salience of water chlorination. During the endline survey, enumerators read out three lists of nine words each to every participant, and asked her to recall as many words as possible directly after reading each list. Participants were paid KES 5 for every word they remembered. Each list contained three categories of future-related words (chlorine, savings, and farm investment), as well as non-future related filler words. The word lists are available in original Swahili and English translation in Table A.7. We estimate salience effects using equation 3:

$$
w_{i m}=a_{0}+\sum_{j=1}^{3} a_{j} T_{j i}+\psi_{0} X_{i m}+\delta_{m}+\theta_{i m}
$$

where $w_{i m}$ is an indicator for participant $i$ correctly recalling the word related to chlorine in list $m ; X_{i m}$ refers to the number of words that the individual correctly recounted from that list; $\delta_{m}$ is 
a fixed effect for list $m$; and $T_{j}$ are treatment indicators. We test $H_{0}: \alpha_{1}=\alpha_{2}=\alpha_{3}$, with the null hypothesis corresponding to no differential salience of chlorine across (active) treatment groups.

In case our treatments differentially affected the salience of chlorine, we further test whether this is due to an increased salience of future-oriented behaviors in general - which may result from our main psychological mechanisms of interest. To this end, we estimate whether the differential treatment effect on chlorine words also holds for two other future-oriented behaviors (saving and farm investment), which were not emphasized in the sessions. We estimate

$$
w_{i m n}=a_{0}+\sum_{j=1}^{3} a_{j} T_{j i}+\lambda \text { chlorine }_{n}+\psi X_{i m}+\sum_{k=1}^{3} b_{k} T_{k i} \cdot \text { chlorine }_{n}+\delta_{m}+\theta_{i m n}
$$

where $w_{i m n}$ is an indicator for participant $i$ correctly recalling the words in list $m$ from future oriented behavior $n$ (chlorination, savings or farm investment); and chlorine $e_{n}$ is a dummy for the word being related to chlorine. The $a_{j}$ coefficients capture increased future orientation due to treatment, while the $b_{j}$ coefficients indicate that salience increased differentially for chlorination. We test $H_{o}: b_{1}=b_{2}=b_{3}$, with the null hypothesis corresponding to no differential salience of chlorine across (active) treatments. 
Figure A.1: Tower of London Example Screen

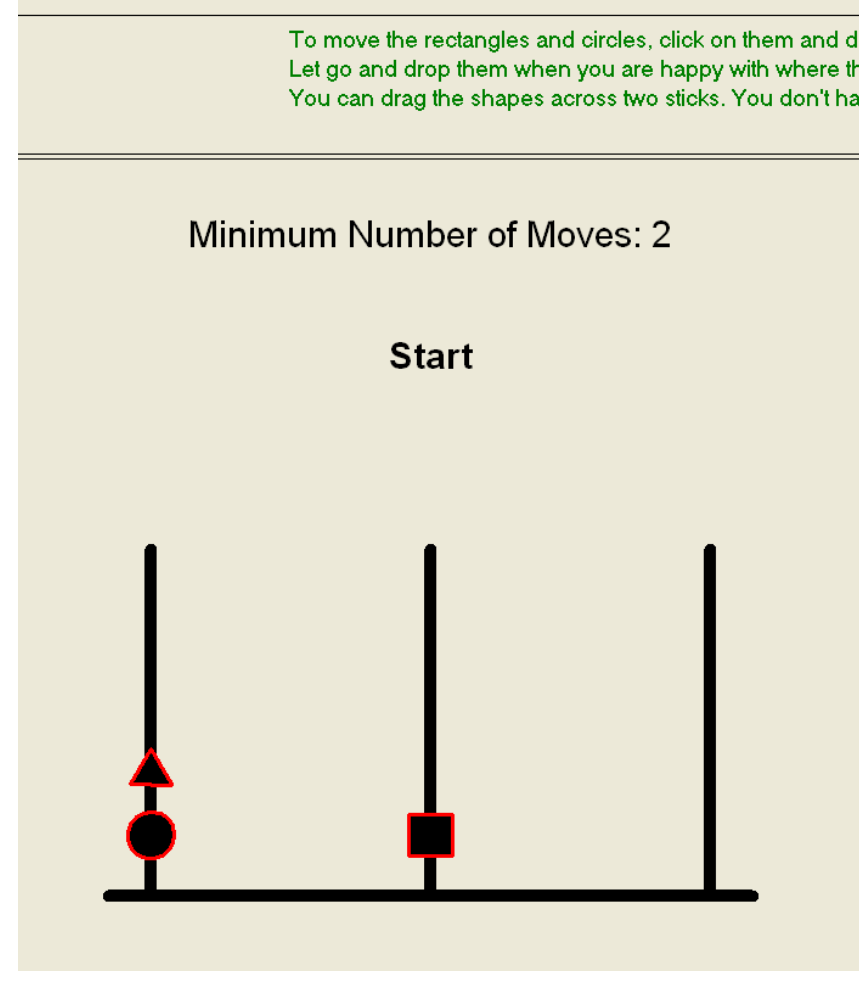

\section{The Goal}

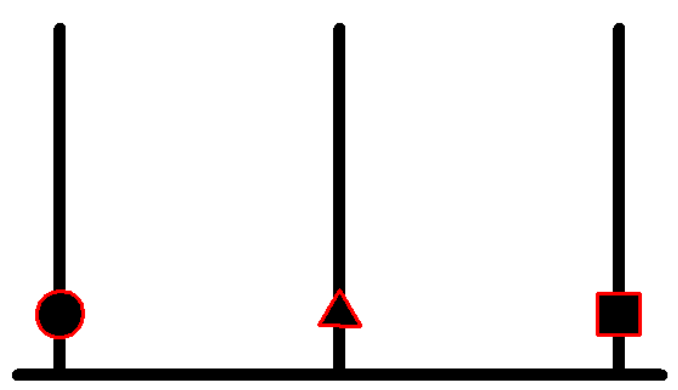

Table A.6: Monetary Discounting Decisions

\begin{tabular}{ccccc}
\hline $\begin{array}{c}\text { Front-end } \\
\text { delay }(t)\end{array}$ & $\begin{array}{c}\text { Delay between } \\
\text { payments }(k)\end{array}$ & $\begin{array}{c}\text { Early } \\
(m)\end{array}$ & $\begin{array}{c}\text { Maximum Late } \\
(m(1+r))\end{array}$ & $\begin{array}{c}\text { Implied interest } \\
\text { rate }(1+r)\end{array}$ \\
\hline Frame 1 & & & & \\
\hline 0 & 28 & 100 & 110 & 1.1 \\
0 & 28 & 100 & 125 & 1.25 \\
0 & 28 & 100 & 175 & 1.75 \\
0 & 28 & 100 & 200 & 2 \\
0 & 28 & 100 & 300 & 3 \\
\hline Frame 2 & & & & \\
\hline 28 & 28 & 100 & 110 & 1.1 \\
28 & 28 & 100 & 125 & 1.25 \\
28 & 28 & 100 & 175 & 1.75 \\
28 & 28 & 100 & 200 & 2 \\
28 & 28 & 100 & 300 & 3 \\
\hline
\end{tabular}


Figure A.2: Effort discounting task example screen

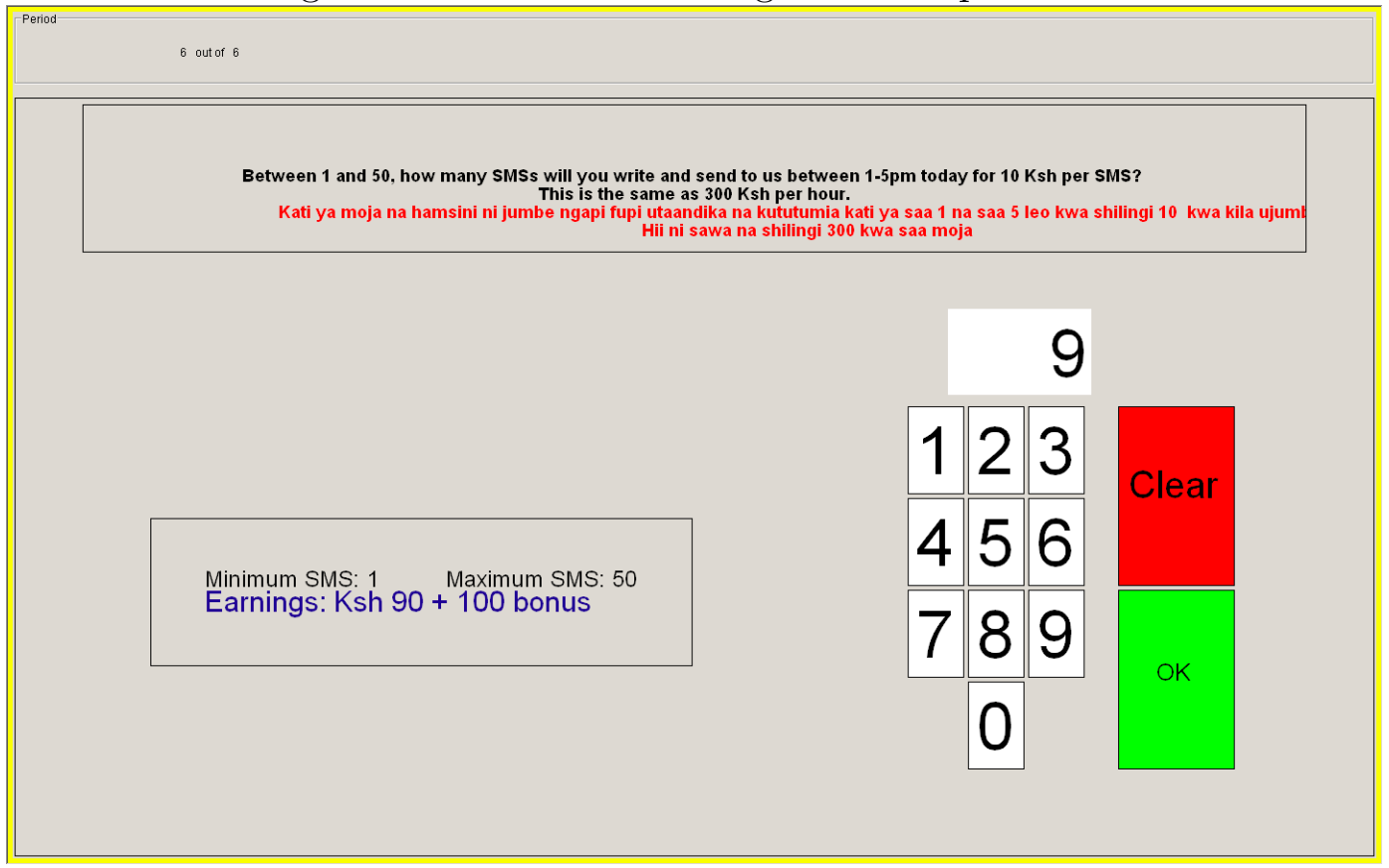

Figure A.3: Effort discounting: raw responses
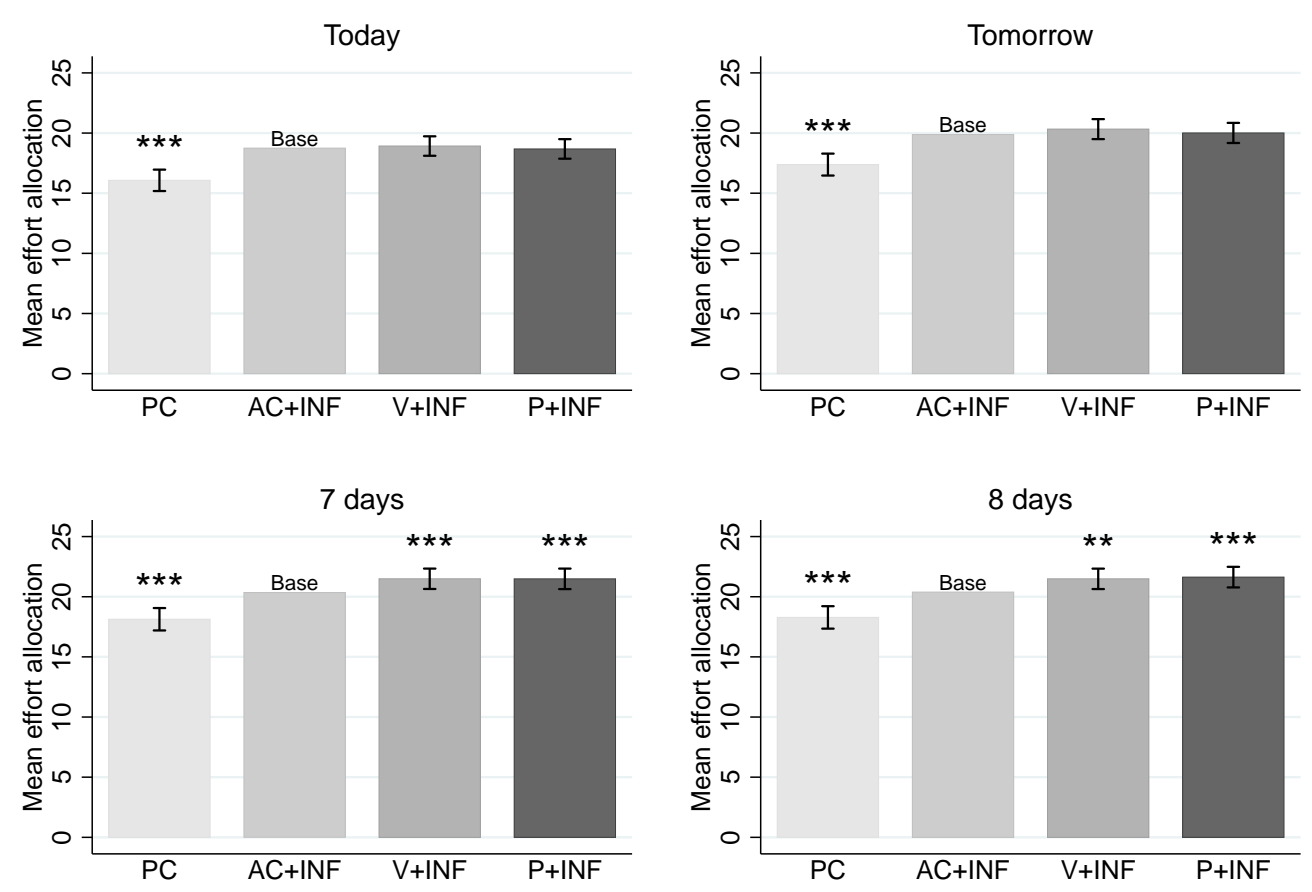

${ }^{*}$ denotes significance at 10 pct., ${ }^{* \star}$ at 5 pct., ${ }^{* * *}$ at 1 pct. level 
Table A.7: Word lists for salience test

\begin{tabular}{cclll}
\hline List & Position & English Translation & Swahili & Group \\
\hline A & 1 & Fence & Fence & Filler \\
A & 2 & Panadol & Panadol & Filler \\
A & 3 & WaterGuard & WaterGuard & Chlorine \\
A & 4 & Playing & Kucheza & Filler \\
A & 5 & Saving & Kuwekeza & Saving \\
A & 6 & Tarmac & Lami & Filler \\
A & 7 & Dairy Cow & Ng'ombe wa maziwa & Farm Investment \\
A & 8 & Safaricom & Safaricom & Filler \\
A & 9 & Resting & Kupumzika & Filler \\
B & 1 & Patterned Cloth & Kitenge & Filler \\
B & 2 & Thermos & Thermos & Filler \\
B & 3 & Savings Group & Chama & Savings \\
B & 4 & Baby Oil & Mafuta ya mtoto & Filler \\
B & 5 & Poultry Farming & Kilimo cha kuku & Farm investment \\
B & 6 & Petrol & Petroli & Filler \\
B & 7 & Chlorine & Klorini & Chlorine \\
B & 8 & Machete & Panga & Filler \\
B & 9 & Shoe Polish & Rangi ya viatu & Filler \\
C & 1 & Saucepan & Sufuria & Filler \\
C & 2 & Stool & Stool & Filler \\
C & 3 & Farm Lease & Kukodisha shamba & Farm investment \\
C & 4 & Transport & Transport & Filler \\
C & 5 & Dispenser & Dispensa & Chlorine \\
C & 6 & Photocopier & Photocopier & Filler \\
C & 7 & Piggybank & Benki ya nyumbani & Savings \\
C & 8 & Airtime & Airtime & Filler \\
C & 9 & Community Hall & Ukumbi wa jamii & Filler \\
\hline & & & &
\end{tabular}


Table A.8: Raw means of z-scored outcome variables

\begin{tabular}{lcc}
\hline & $(1)$ & $(2)$ \\
& Active & Pure \\
& Control & Control \\
& Group & Mean (SD) \\
Mean (SD) & \\
\hline & & \\
Behavioral Activation score (BADS) (9-63) & 29.38 & 28.90 \\
& $(5.90)$ & $(5.67)$ \\
Tower of London: Total moves (9-36) & 20.89 & 23.86 \\
& $(6.58)$ & $(6.79)$ \\
Risk aversion measure (1-3) & 1.74 & 1.70 \\
& $(0.82)$ & $(0.83)$ \\
General Self-Efficacy score (GSE) (0-72) & 43.35 & 43.32 \\
Belief: Proportion of diarrhea incidences avoided through chlorination $(0-1)$ & $(12.11)$ & $(9.83)$ \\
Chlorine knowledge score (0-2) & 0.74 & 0.71 \\
& $(0.39)$ & $(0.41)$ \\
ANC/PNC knowledge score (0-2) & 1.14 & 1.07 \\
& $(0.68)$ & $(0.69)$ \\
Index of investment in children's education (-3-3) & 1.25 & 0.93 \\
& $(0.84)$ & $(0.87)$ \\
& 0.03 & -0.07 \\
& $(1.14)$ & $(0.95)$ \\
\hline
\end{tabular}

Notes: Mean and standard deviation of the control group by which the z-scored outcome variables are standardized. 
Table A.9: Phone access \& task comprehension questions

\begin{tabular}{|c|c|c|c|c|c|c|c|c|c|c|}
\hline & \multicolumn{5}{|c|}{ Comparison with active control (AC+INF) } & \multicolumn{5}{|c|}{ Comparison with pure control (PC) } \\
\hline & $\begin{array}{c}(1) \\
\text { Active } \\
\text { Control } \\
\text { Group } \\
\text { Mean (SD) }\end{array}$ & $\begin{array}{c}(2) \\
\text { Visualization } \\
\text { Treatment } \\
\text { Effect }\end{array}$ & $\begin{array}{c}(3) \\
\text { Planning } \\
\text { Treatment } \\
\text { Effect }\end{array}$ & $\begin{array}{c}(4) \\
\text { Column } 2 \text { vs. } \\
\text { Column } 3 \\
p \text {-value }\end{array}$ & $\begin{array}{l}(5) \\
N\end{array}$ & $\begin{array}{c}(6) \\
\text { Pure } \\
\text { Control } \\
\text { Mean (SD) }\end{array}$ & $\begin{array}{c}(7) \\
\text { V+INF } \\
\text { Treatment } \\
\text { Effect }\end{array}$ & $\begin{array}{c}(8) \\
\text { P+INF } \\
\text { Treatment } \\
\text { Effect }\end{array}$ & $\begin{array}{c}(9) \\
\text { AC+INF } \\
\text { Treatment } \\
\text { Effect }\end{array}$ & $\begin{array}{l}(10) \\
N\end{array}$ \\
\hline $\begin{array}{l}\text { SMS Task Checks } \\
\text { Participant uses a phone she owns }\end{array}$ & $\begin{array}{c}0.71 \\
(0.45)\end{array}$ & $\begin{array}{c}0.01 \\
(0.02)\end{array}$ & $\begin{array}{c}-0.03 \\
(0.03)\end{array}$ & 0.15 & 2108 & $\begin{array}{c}0.70 \\
(0.46)\end{array}$ & $\begin{array}{c}0.00 \\
(0.02)\end{array}$ & $\begin{array}{c}-0.03 \\
(0.03)\end{array}$ & $\begin{array}{r}-0.00 \\
(0.03)\end{array}$ & 2972 \\
\hline Participant uses a phone belonging to her household & $\begin{array}{c}0.96 \\
(0.19)\end{array}$ & $\begin{array}{c}0.01 \\
(0.01)\end{array}$ & $\begin{array}{r}-0.00 \\
(0.01)\end{array}$ & 0.24 & 2108 & $\begin{array}{c}0.96 \\
(0.21)\end{array}$ & $\begin{array}{c}0.02 \\
(0.01)\end{array}$ & $\begin{array}{c}0.00 \\
(0.01)\end{array}$ & $\begin{array}{c}0.01 \\
(0.01)\end{array}$ & 2972 \\
\hline Proportion for whom accessing a phone for 30mins is very difficult or impossible & $\begin{array}{c}0.12 \\
(0.33)\end{array}$ & $\begin{array}{c}0.03 \\
(0.02)\end{array}$ & $\begin{array}{c}0.00 \\
(0.02)\end{array}$ & 0.21 & 2107 & $\begin{array}{c}0.13 \\
(0.33)\end{array}$ & $\begin{array}{c}0.02 \\
(0.02)\end{array}$ & $\begin{array}{r}-0.00 \\
(0.02)\end{array}$ & $\begin{array}{c}-0.01 \\
(0.02)\end{array}$ & 2970 \\
\hline Proportion for whom accessing a phone for $1 \mathrm{hr}$ is very difficult or impossible & $\begin{array}{c}0.17 \\
(0.37)\end{array}$ & $\begin{array}{l}0.04 \\
(0.02)^{*}\end{array}$ & $\begin{array}{c}0.03 \\
(0.02)\end{array}$ & 0.52 & 2107 & $\begin{array}{c}0.19 \\
(0.39)\end{array}$ & $\begin{array}{c}0.02 \\
(0.02)\end{array}$ & $\begin{array}{c}0.00 \\
(0.02)\end{array}$ & $\begin{array}{r}-0.03 \\
(0.02)\end{array}$ & 2970 \\
\hline Proportion for whom accessing a phone for $4 \mathrm{hrs}$ is very difficult or impossible & $\begin{array}{c}0.32 \\
(0.46)\end{array}$ & $\begin{array}{c}0.02 \\
(0.03)\end{array}$ & $\begin{array}{c}0.01 \\
(0.03)\end{array}$ & 0.54 & 2105 & $\begin{array}{c}0.35 \\
(0.48)\end{array}$ & $\begin{array}{c}-0.02 \\
(0.03)\end{array}$ & $\begin{array}{c}-0.03 \\
(0.03)\end{array}$ & $\begin{array}{c}-0.04 \\
(0.03)\end{array}$ & 2967 \\
\hline SMS Comprehension questions correct first time & $\begin{array}{c}0.81 \\
(0.39)\end{array}$ & $\begin{array}{c}-0.04 \\
(0.03)\end{array}$ & $\begin{array}{c}-0.01 \\
(0.03)\end{array}$ & 0.29 & 2103 & $\begin{array}{c}0.72 \\
(0.45)\end{array}$ & $\begin{array}{c}0.04 \\
(0.03)\end{array}$ & $\begin{array}{l}0.07 \\
(0.03)^{* * *}\end{array}$ & $\begin{array}{l}0.07 \\
(0.03)^{* * *}\end{array}$ & 2955 \\
\hline Number of attempts at SMS comprehension questions & $\begin{array}{c}0.78 \\
(1.89)\end{array}$ & $\begin{array}{l}0.23 \\
(0.12)^{*}\end{array}$ & $\begin{array}{c}0.14 \\
(0.12)\end{array}$ & 0.51 & 2103 & $\begin{array}{c}1.22 \\
(2.36)\end{array}$ & $\begin{array}{c}-0.21 \\
(0.13)\end{array}$ & $\begin{array}{l}-0.27 \\
(0.13)^{* *}\end{array}$ & $\begin{array}{l}-0.38 \\
(0.13)^{* * *}\end{array}$ & 2955 \\
\hline
\end{tabular}

Notes: OLS estimes of responses to questions asked as validation checks for the SMS effort task. For each variable, we report the mean of the comparison group, the coefficients of interest, and standard errors in parentheses. All columns include village-level fixed effects and a vector of individual characteristics, and cluster standard errors at the level of intervention cohort. $*$ denotes significance at 10 pct., $* *$ at 5 pct., and $* * *$ at 1 pct. level. 


\section{D.5 Schedule of tasks and treatments}

Participants were invited to a 7:30AM or 12:30PM session at a village hall in their area. Sessions

lasted between two and four hours. Participants received short breaks between each item on the agenda.

During zTree portions of the session, each participant sat in front of a Windows tablet computer, sufficiently spaced to prevent participants from seeing the answers of their neighbors. One enumerator read instructions and answer options aloud in Kiswahili from the center of the room, while several others were available to answer individual questions or assist with the technology.

During the SurveyCTO questionnaires at endline, five to eight enumerators went through questionnaires with participants individually, in the order that participants arrived.

Interventions were carried out in cohorts of approximately five, in a circle outside when weather permitted. Groups were physically separated to ensure participants could not be overheard. All participants received the same intervention on a given day.

Baseline and Intervention Session 1:

At baseline, the demographic questionnaire, behavioral tasks and psychological measures were carried out on the zTree experimental interface.

1. Welcome, identification and screening

2. Consent

3. Demographics questionnaire

(a) Marital status / household composition

(b) Assets module

(c) Water use

(d) Chlorination behavior

(e) Pregnancy health behaviors

4. Behavioral tasks and psychological scales

(a) Tower of London

(b) General Self-Efficacy scale

(c) Effort discounting measure

(d) Monetary discounting measure (Multiple Price List)

5. Administration of intervention: Part 1

6. Debrief

7. Payment 
Intervention Session 2:

1. Welcome, identification and screening

2. Administration of intervention: Part 2

3. Debrief

Endline:

At endline, the behavioral tasks and psychological measures were carried out on the zTree experimental interface, as at baseline. The salience task and individual survey were administered one-on-one with an enumerator.

1. Welcome, identification and screening

2. Consent

3. Salience task

4. Group tasks and measures

(a) Behavioral Activation for Depression Scale (BADS)

(b) General Self-Efficacy (GSE) scale

(c) Tower of London

(d) Risk measure

(e) Effort discounting measure

(f) Monetary discounting measure (Multiple Price Lists)

5. Individual Survey
(a) Savings
(b) Labor supply and search
(c) Fertility \& antenatal/postnatal care
(d) Child education \& health
(e) Participant education
(f) Phone access 


\section{E. Treatment effects on the treated}

Table A.10: Behavioral outcomes (TOT)

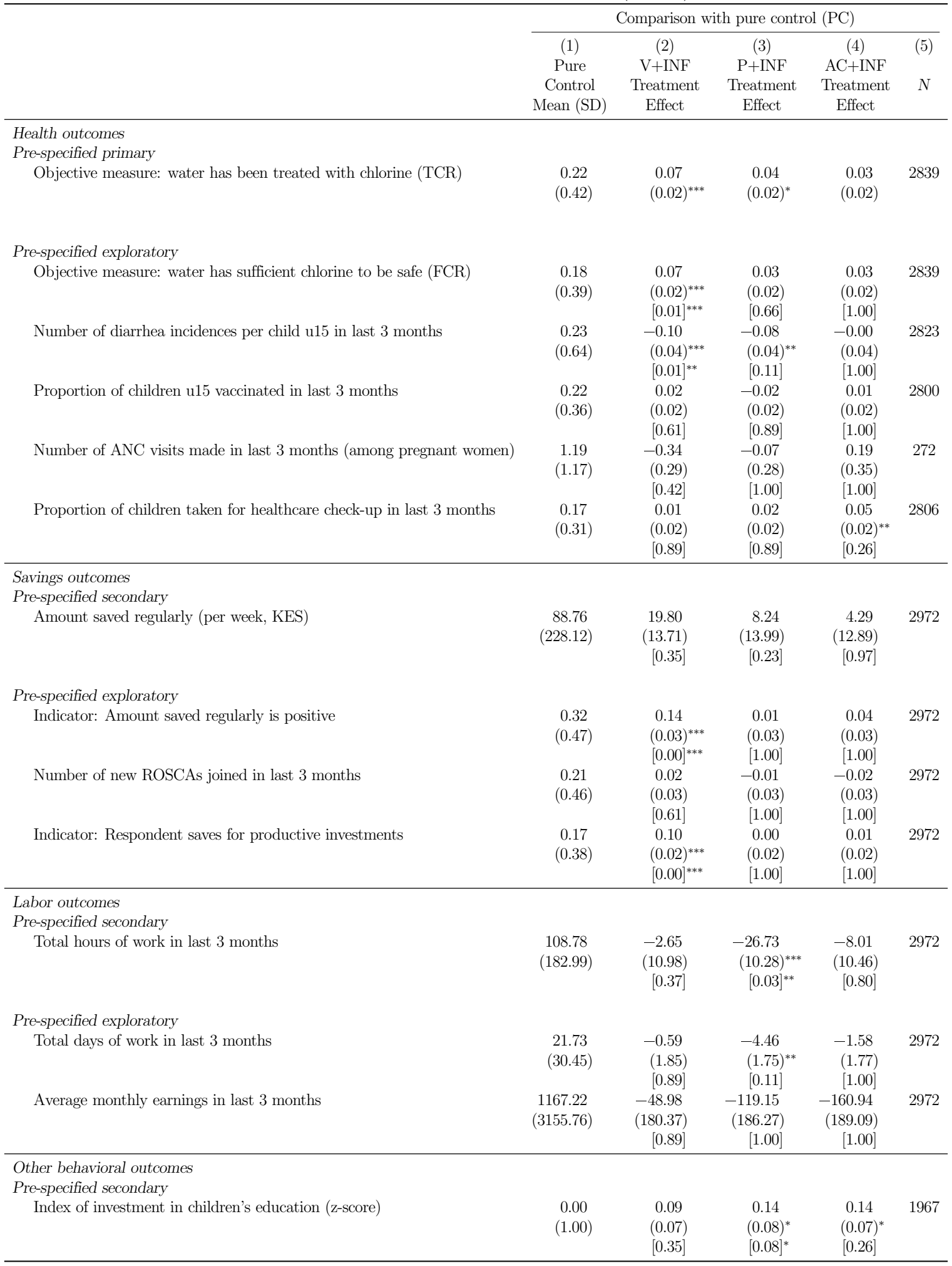

Notes: Treatment-on-the-treated estimates of treatment effects. For each variable, we report the mean of the comparison group, the coefficients of interest, and standard errors in parentheses. Square brackets contain additional $p$-values corrected for multiple hypothesis testing using the false discovery rate. All columns include village-level fixed effects, control for a vector of individual characteristics, and cluster standard errors at the level of intervention cohort. The specification also includes fixed effects for i) the week and ii) the day of the week of the endline survey, for measures collected in the endline session (all variables except the objective chlorine measures). * denotes significance at 10 pct., ${ }^{* *}$ at 5 pct., and ${ }^{* * *}$ at 1 pct. level. Outcome measures are listed on the left, and are described in detail in Section 4 . Objective measures of chlorine come from data collected in participants' homes, where stored househol 6ulater was tested for the presence of Total and Free Chlorine Residual, which indicate whether chlorine has been added to water (TCR), and whether sufficient chlorine is in the water to make it safe to drink (FCR). The number of diarrhea incidences reports how many independent episodes of diarrhea each child under- 15 had on average in the last three months. The index of investment in children's education consists of measures of money spent on children's education and average school days attended in the last 3 months, and is constructed only for those women with school-age children. 
Table A.11: Psychological outcomes (TOT)

\begin{tabular}{|c|c|c|c|c|c|}
\hline & \multicolumn{5}{|c|}{ Comparison with pure control (PC) } \\
\hline & $\begin{array}{c}(1) \\
\text { Pure } \\
\text { Control } \\
\text { Mean (SD) }\end{array}$ & $\begin{array}{c}(2) \\
\text { V+INF } \\
\text { Treatment } \\
\text { Effect }\end{array}$ & $\begin{array}{c}(3) \\
\text { P+INF } \\
\text { Treatment } \\
\text { Effect }\end{array}$ & $\begin{array}{c}(4) \\
\text { AC+INF } \\
\text { Treatment } \\
\text { Effect }\end{array}$ & $\begin{array}{l}(5) \\
N\end{array}$ \\
\hline \multicolumn{6}{|l|}{ Planning skills } \\
\hline $\begin{array}{l}\text { Pre-specified primary } \\
\quad \text { Behavioral Activation Score (BADS) (z-score) }\end{array}$ & $\begin{array}{c}0.00 \\
(1.00)\end{array}$ & $\begin{array}{l}0.03 \\
(0.06) \\
{[1.00]}\end{array}$ & $\begin{array}{l}0.12 \\
(0.06)^{* *} \\
{[0.10]}\end{array}$ & $\begin{array}{c}0.04 \\
(0.06) \\
{[1.00]}\end{array}$ & 2955 \\
\hline $\begin{array}{l}\text { Pre-specified secondary } \\
\text { Tower of London: Total Moves (z-score) }\end{array}$ & $\begin{array}{c}0.00 \\
(1.00)\end{array}$ & $\begin{array}{l}-0.43 \\
(0.06)^{* * *} \\
{[0.00]^{* * *}}\end{array}$ & $\begin{array}{l}-0.48 \\
(0.06)^{* * *} \\
{[0.00]^{* * *}}\end{array}$ & $\begin{array}{l}-0.41 \\
(0.06)^{* * *} \\
{[0.00]^{* * *}}\end{array}$ & 2955 \\
\hline $\begin{array}{l}\text { Time preferences } \\
\text { Pre-specified primary } \\
\quad \beta^{\text {Effort }}\end{array}$ & $\begin{array}{c}0.964 \\
(0.017)\end{array}$ & $\begin{array}{l}0.003 \\
(0.015) \\
{[1.00]}\end{array}$ & $\begin{array}{l}0.005 \\
(0.014) \\
{[0.54]}\end{array}$ & $\begin{array}{c}-0.004 \\
(0.013) \\
{[1.00]}\end{array}$ & 2906 \\
\hline $\begin{array}{l}\text { Pre-specified secondary } \\
\quad \delta^{\text {Effort }}\end{array}$ & $\begin{array}{c}0.995 \\
(0.002)\end{array}$ & $\begin{array}{c}-0.000 \\
(0.002) \\
{[0.60]}\end{array}$ & $\begin{array}{l}0.000 \\
(0.002) \\
{[0.67]}\end{array}$ & $\begin{array}{l}0.004 \\
(0.002)^{*} \\
{[0.09]^{*}}\end{array}$ & 2906 \\
\hline$\beta^{M P L}$ & $\begin{array}{c}1.02 \\
(0.43)\end{array}$ & $\begin{array}{c}-0.01 \\
(0.03) \\
{[0.60]}\end{array}$ & $\begin{array}{c}0.02 \\
(0.03) \\
{[0.26]}\end{array}$ & $\begin{array}{c}0.01 \\
(0.02) \\
{[0.40]}\end{array}$ & 2955 \\
\hline$\delta^{M P L}$ & $\begin{array}{c}0.98 \\
(0.02)\end{array}$ & $\begin{array}{c}0.00 \\
(0.00)^{*} \\
{[0.07]^{*}}\end{array}$ & $\begin{array}{c}0.00 \\
(0.00) \\
{[0.12]}\end{array}$ & $\begin{array}{l}0.00 \\
(0.00)^{* *} \\
{[0.06]^{*}}\end{array}$ & 2955 \\
\hline \multicolumn{6}{|l|}{ Self-efficacy } \\
\hline General Self-Efficacy Score (GSE) (z-score) & $\begin{array}{c}0.00 \\
(1.00)\end{array}$ & $\begin{array}{l}0.20 \\
(0.07)^{* * *} \\
{[0.01]^{* * *}}\end{array}$ & $\begin{array}{l}0.21 \\
(0.06)^{* * *} \\
{[0.00]^{* * *}}\end{array}$ & $\begin{array}{l}0.02 \\
(0.07) \\
{[0.40]}\end{array}$ & 2955 \\
\hline \multicolumn{6}{|l|}{ Alternative mechanisms } \\
\hline Belief: Proportion of diarrhea incidences avoided through chlorination (z-score) & $\begin{array}{c}0.00 \\
(1.00)\end{array}$ & $\begin{array}{l}0.14 \\
(0.06)^{* *}\end{array}$ & $\begin{array}{l}0.18 \\
(0.06)^{* * *}\end{array}$ & $\begin{array}{l}0.13 \\
(0.06)^{* *}\end{array}$ & 2955 \\
\hline Chlorine knowledge score (z-score) & $\begin{array}{c}0.00 \\
(1.00)\end{array}$ & $\begin{array}{l}0.13 \\
(0.06)^{* *}\end{array}$ & $\begin{array}{c}0.08 \\
(0.06)\end{array}$ & $\begin{array}{l}0.10 \\
(0.06)^{*}\end{array}$ & 2955 \\
\hline ANC/PNC knowledge score (z-score) & $\begin{array}{c}0.00 \\
(1.00)\end{array}$ & $\begin{array}{l}0.40 \\
(0.06)^{* * *}\end{array}$ & $\begin{array}{l}0.32 \\
(0.06)^{* * *}\end{array}$ & $\begin{array}{l}0.39 \\
(0.06)^{* * *}\end{array}$ & 2955 \\
\hline Risk Aversion Measure (z-score) & $\begin{array}{c}0.00 \\
(1.00)\end{array}$ & $\begin{array}{c}0.01 \\
(0.06)\end{array}$ & $\begin{array}{c}-0.01 \\
(0.06)\end{array}$ & $\begin{array}{c}0.04 \\
(0.06)\end{array}$ & 2735 \\
\hline
\end{tabular}

Notes: Treatment-on-the-treated estimates of treatment effects. For each variable, we report the mean of the comparison group, the coefficients of interest, and standard errors in parentheses. Square brackets contain additional $p$-values corrected for multiple hypothesis testing using the false discovery rate. All columns include village-level fixed effects, control for a vector of individual characteristics, and cluster standard errors at the level of the intervention cohort. The specification also includes fixed effects for i) the week and ii) the day of the week of the endline survey, for measures collected in the endline session. ${ }^{*}$ denotes significance at 10 pct., ${ }^{* *}$ at 5 pct., and ${ }^{* * *}$ at 1 pct. level. Outcome measures are listed on the left, and are described in detail in Section 4. The BADS score measures a participant's ability and motivation to follow through on plans they make in their life. Tower of London is a lab game that measures a participant's ability to plan ahead. Time preferences over effort $\left(\beta^{E f f o r t}\right.$ and $\left.\delta^{E f f o r t}\right)$ are estimated structurally, which makes a standard 2SLS approach infeasible. Instead, we report estimated treatment effects when the treatment indicator switches on for compliance with treatment, rather than assigned treatment. Due to the obvious selection issues, we prefer the estimates in Table 4. Time preferences over money are measured using Multiple Price Lists (MPL). The risk aversion measure is derived from responses to a coin flip for various monetary rewards. The General Self-Efficacy score measures a participant's belief in their own ability to achieve the outcomes they desire. The mechanisms variables check if the interventions differentially affected i) a participant's belief in the efficacy of chlorine to prevent diarrhea, and ii) their knowledge of how to correctly chlorinate water, to assess whether changes in beliefs or knowledge could have been the cause of changes in chlorination behavior. 


\section{F. Robustness checks}

Table A.12: Robustness of chlorination effects to within-village testing order

\begin{tabular}{|c|c|c|c|c|c|c|}
\hline & \multicolumn{3}{|c|}{ Comparison with active control $(\mathrm{AC}+\mathrm{INF})$} & \multicolumn{3}{|c|}{ Comparison with pure control (PC) } \\
\hline & $\begin{array}{c}(1) \\
\text { Chlorine } \\
\text { present } \\
\text { in water }\end{array}$ & $\begin{array}{c}(2) \\
\text { Chlorine } \\
\text { present } \\
\text { in water }\end{array}$ & $\begin{array}{c}(3) \\
\text { Chlorine } \\
\text { present } \\
\text { in water }\end{array}$ & $\begin{array}{c}(4) \\
\text { Chlorine } \\
\text { present } \\
\text { in water }\end{array}$ & $\begin{array}{c}(5) \\
\text { Chlorine } \\
\text { present } \\
\text { in water }\end{array}$ & $\begin{array}{c}(6) \\
\text { Chlorine } \\
\text { present } \\
\text { in water }\end{array}$ \\
\hline Visualization & $\begin{array}{l}0.05 \\
(0.02)^{* *}\end{array}$ & $\begin{array}{l}0.05 \\
(0.02)^{* *}\end{array}$ & $\begin{array}{l}0.05 \\
(0.02)^{* *}\end{array}$ & $\begin{array}{l}0.06 \\
(0.02)^{* * *}\end{array}$ & $\begin{array}{l}0.06 \\
(0.02)^{* * *}\end{array}$ & $\begin{array}{l}0.06 \\
(0.02)^{* * *}\end{array}$ \\
\hline Planning & $\begin{array}{c}0.02 \\
(0.02)\end{array}$ & $\begin{array}{c}0.02 \\
(0.02)\end{array}$ & $\begin{array}{c}0.02 \\
(0.02)\end{array}$ & $\begin{array}{c}0.04 \\
(0.02)^{*}\end{array}$ & $\begin{array}{c}0.04 \\
(0.02)^{*}\end{array}$ & $\begin{array}{l}0.04 \\
(0.02)^{*}\end{array}$ \\
\hline Active Control & & & & $\begin{array}{c}0.03 \\
(0.02)\end{array}$ & $\begin{array}{c}0.03 \\
(0.02)\end{array}$ & $\begin{array}{c}0.03 \\
(0.02)\end{array}$ \\
\hline $\begin{array}{l}\text { Days after first } \\
\text { day of testing } \\
\text { within village }\end{array}$ & & $\begin{array}{r}-0.00 \\
(0.00)\end{array}$ & & & $\begin{array}{r}-0.00 \\
(0.00)\end{array}$ & \\
\hline $\begin{array}{l}\text { Dummy: test done on } \\
\text { first day of testing } \\
\text { within village }\end{array}$ & & & $\begin{array}{c}0.02 \\
(0.03)\end{array}$ & & & $\begin{array}{c}0.02 \\
(0.02)\end{array}$ \\
\hline Observations & 2012 & 2012 & 2012 & 2839 & 2839 & 2839 \\
\hline
\end{tabular}

Notes: ${ }^{*}$ denotes significance at 10 pct., ${ }^{* *}$ at 5 pct., and ${ }^{* * *}$ at 1 pct. level. 
Table A.13: Chlorine-related outcomes in dispenser vs. non-dispenser villages: restricting to WASH villages in the Water Quality and Passive Comparison arms

\begin{tabular}{|c|c|c|c|c|c|c|c|c|c|c|c|c|c|}
\hline & \multicolumn{5}{|c|}{ Village has no chlorine dispenser } & \multicolumn{5}{|c|}{ Village has chlorine dispenser } & \multicolumn{3}{|c|}{ Comparison } \\
\hline & $\begin{array}{c}(1) \\
\text { Pure } \\
\text { Control } \\
\text { Mean (SD) }\end{array}$ & $\begin{array}{c}(2) \\
\text { V+INF } \\
\text { Treatment } \\
\text { Effect }\end{array}$ & $\begin{array}{c}(3) \\
\text { P+INF } \\
\text { Treatment } \\
\text { Effect }\end{array}$ & $\begin{array}{c}(4) \\
\text { AC+INF } \\
\text { Treatment } \\
\text { Effect }\end{array}$ & $\begin{array}{l}(5) \\
N\end{array}$ & $\begin{array}{c}(6) \\
\text { Pure } \\
\text { Control } \\
\text { Mean (SD) }\end{array}$ & $\begin{array}{c}(7) \\
\text { V+INF } \\
\text { Treatment } \\
\text { Effect }\end{array}$ & $\begin{array}{c}(8) \\
\text { P+INF } \\
\text { Treatment } \\
\text { Effect }\end{array}$ & $\begin{array}{c}(9) \\
\text { AC+INF } \\
\text { Treatment } \\
\text { Effect }\end{array}$ & $\begin{array}{c}(10) \\
N\end{array}$ & $\begin{array}{c}(11) \\
\text { V+INF } \\
\text { Interaction } \\
p \text {-value }\end{array}$ & $\begin{array}{c}(12) \\
\mathrm{P}+\mathrm{INF} \\
\text { Interaction } \\
p \text {-value }\end{array}$ & $\begin{array}{c}(13) \\
\mathrm{AC}+\mathrm{INF} \\
\text { Interaction } \\
p \text {-value }\end{array}$ \\
\hline Objective measure: water has been treated with chlorine (TCR) & $\begin{array}{c}0.26 \\
(0.44)\end{array}$ & $\begin{array}{c}-0.01 \\
(0.03)\end{array}$ & $\begin{array}{c}0.01 \\
(0.03)\end{array}$ & $\begin{array}{c}-0.04 \\
(0.03)\end{array}$ & 1066 & $\begin{array}{c}0.18 \\
(0.38)\end{array}$ & $\begin{array}{l}0.11 \\
\left(0.033^{* * * *}\right.\end{array}$ & $\begin{array}{l}0.07 \\
\left(0.033^{* *}\right.\end{array}$ & $\begin{array}{l}0.10 \\
(0.03)^{* * * *}\end{array}$ & 1091 & {$[0.01]^{* * *}$} & {$[0.15]$} & {$[0.00]^{* *-}$} \\
\hline Objective measure: water has sufficient chlorine to be safe (FCR) & $\begin{array}{c}0.16 \\
(0.37)\end{array}$ & $\begin{array}{c}0.01 \\
(0.03)\end{array}$ & $\begin{array}{c}0.02 \\
(0.03)\end{array}$ & $\begin{array}{c}-0.01 \\
(0.03)\end{array}$ & 1066 & $\begin{array}{c}0.17 \\
(0.38)\end{array}$ & $\begin{array}{c}0.09 \\
(0.04)^{* *}\end{array}$ & $\begin{array}{c}0.05 \\
(0.03)\end{array}$ & $\begin{array}{l}0.08 \\
(0.03)^{* *}\end{array}$ & 1091 & {$[0.07]^{*}$} & {$[0.58]$} & {$[0.04]^{* *}$} \\
\hline Number of diarrhea incidences per child u15 in last 3 months & $\begin{array}{c}0.26 \\
(0.69)\end{array}$ & $\begin{array}{c}-0.07 \\
(0.06)\end{array}$ & $\begin{array}{c}-0.07 \\
(0.06)\end{array}$ & $\begin{array}{c}-0.03 \\
(0.06)\end{array}$ & 1046 & $\begin{array}{c}0.21 \\
(0.64)\end{array}$ & $\begin{array}{c}-0.09 \\
(0.05)^{*}\end{array}$ & $\begin{array}{c}-0.06 \\
(0.05)\end{array}$ & $\begin{array}{c}-0.01 \\
(0.05)\end{array}$ & 1105 & [0.84] & [0.93] & {$[0.80]$} \\
\hline Belief: Proportion of diarrhea incidences avoided through chlorination (z-score) & $\begin{array}{c}-0.04 \\
(1.02)\end{array}$ & $\begin{array}{l}0.20 \\
(0.09)^{* *}\end{array}$ & $\begin{array}{c}0.19 \\
(0.09)^{* *}\end{array}$ & $\begin{array}{c}0.14 \\
(0.09)\end{array}$ & 1092 & $\begin{array}{c}0.01 \\
(1.01)\end{array}$ & $\begin{array}{c}0.07 \\
(0.09)\end{array}$ & $\begin{array}{c}0.09 \\
(0.09)\end{array}$ & $\begin{array}{c}0.11 \\
(0.09)\end{array}$ & 1160 & [0.32] & [0.48] & [0.87] \\
\hline Chlorine knowledge score (z-score) & $\begin{array}{c}0.08 \\
(1.02)\end{array}$ & $\begin{array}{c}0.16 \\
(0.09)^{*}\end{array}$ & $\begin{array}{c}0.03 \\
(0.09)\end{array}$ & $\begin{array}{c}0.01 \\
(0.09)\end{array}$ & 1092 & $\begin{array}{c}0.02 \\
(1.01)\end{array}$ & $\begin{array}{c}0.01 \\
(0.09)\end{array}$ & $\begin{array}{c}0.04 \\
(0.09)\end{array}$ & $\begin{array}{c}0.10 \\
(0.09)\end{array}$ & 1160 & [0.22] & [0.90] & {$[0.47]$} \\
\hline
\end{tabular}

Notes: Robustness check restricting the sample to individuals from villages in the Water Quality and Passive Comparison arms of the WASH Benefits study. The outcome variables repeat those in Tables 1-3, but the table reports the analysis separately for villages which have at least one chlorine dispenser

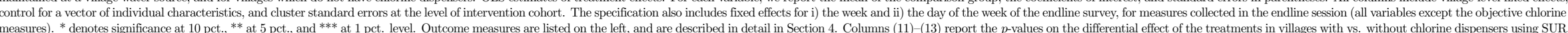


Table A.14: Behavioral outcomes for alternative attrition definition

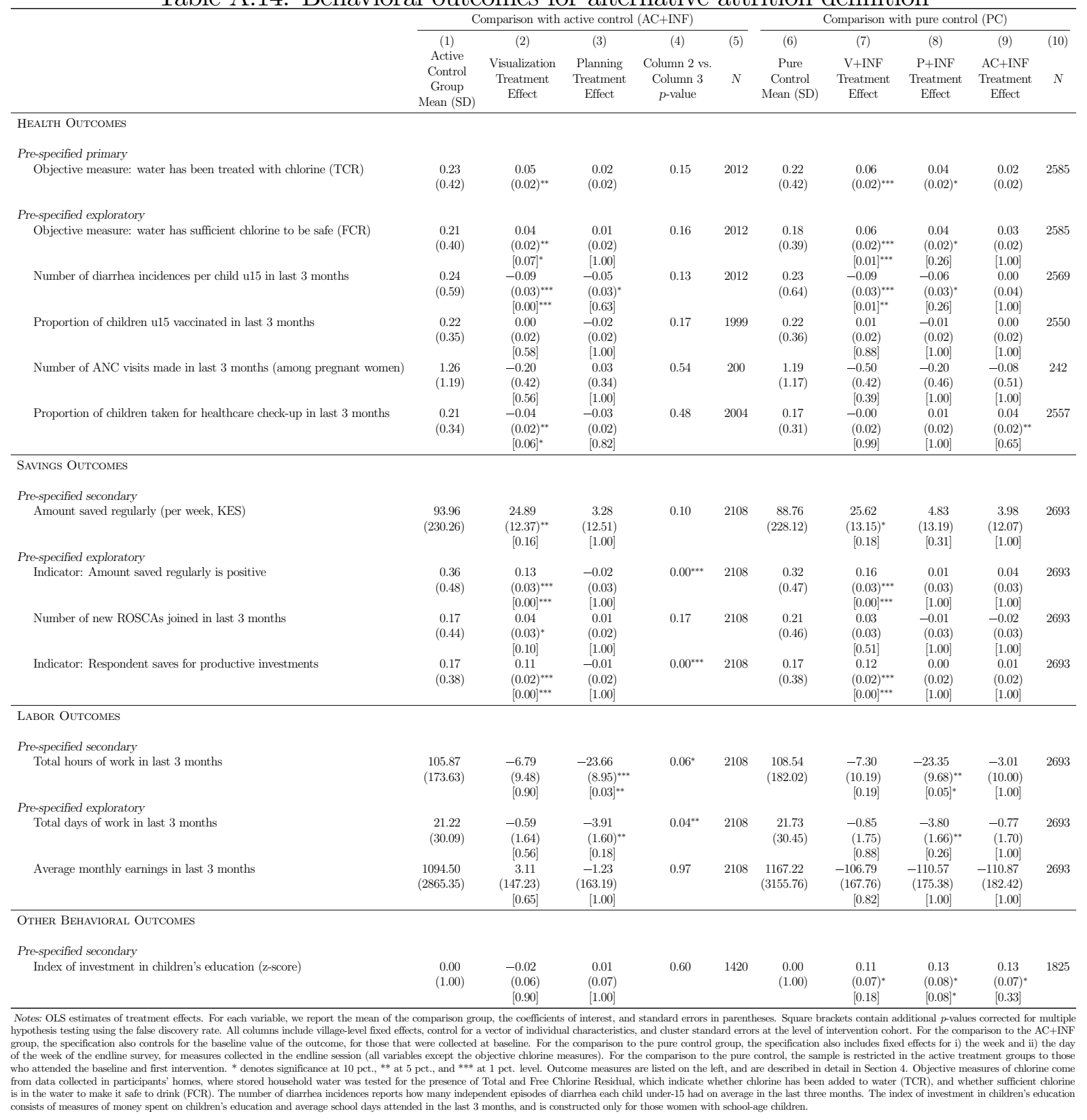


Table A.15: Psychological outcomes for alternative attrition definition

\begin{tabular}{|c|c|c|c|c|c|c|c|c|c|c|}
\hline & \multicolumn{5}{|c|}{ Comparison with active control (AC+INF) } & \multicolumn{5}{|c|}{ Comparison with pure control (PC) } \\
\hline & (1) & (2) & (3) & (4) & (5) & (6) & (7) & (8) & (9) & $(10)$ \\
\hline & $\begin{array}{c}\text { Active } \\
\text { Control } \\
\text { Group } \\
\text { Mean (SD) }\end{array}$ & $\begin{array}{c}\text { Visualization } \\
\text { Treatment } \\
\text { Effect }\end{array}$ & $\begin{array}{l}\text { Planning } \\
\text { Treatment } \\
\text { Effect }\end{array}$ & $\begin{array}{c}\text { Column } 2 \text { vs. } \\
\text { Column } 3 \\
p \text {-value }\end{array}$ & $N$ & $\begin{array}{c}\text { Pure } \\
\text { Control } \\
\text { Mean (SD) }\end{array}$ & $\begin{array}{c}\mathrm{V}+\mathrm{INF} \\
\text { Treatment } \\
\text { Effect }\end{array}$ & $\begin{array}{c}\text { P+INF } \\
\text { Treatment } \\
\text { Effect }\end{array}$ & $\begin{array}{c}\text { AC+INF } \\
\text { Treatment } \\
\text { Effect }\end{array}$ & $N$ \\
\hline \multicolumn{11}{|l|}{ PlanNing Skills } \\
\hline \multicolumn{11}{|l|}{ Pre-specified primary } \\
\hline Behavioral Activation Score (BADS) (z-score) & $\begin{array}{c}0.00 \\
(1.00)\end{array}$ & $\begin{array}{c}-0.01 \\
(0.05) \\
{[0.83]}\end{array}$ & $\begin{array}{c}0.04 \\
(0.05) \\
{[0.91]}\end{array}$ & 0.31 & 2103 & $\begin{array}{c}0.00 \\
(1.00)\end{array}$ & $\begin{array}{c}0.05 \\
(0.06) \\
{[1.00]}\end{array}$ & $\begin{array}{c}0.11 \\
(0.06)^{*} \\
{[0.15]}\end{array}$ & $\begin{array}{l}0.06 \\
(0.06) \\
{[1.00]}\end{array}$ & 2686 \\
\hline \multicolumn{11}{|l|}{ Pre-specified secondary } \\
\hline Tower of London: Total Moves (z-score) & $\begin{array}{c}0.00 \\
(1.00)\end{array}$ & $\begin{array}{l}0.01 \\
(0.05) \\
{[0.85]}\end{array}$ & $\begin{array}{c}-0.04 \\
(0.05) \\
{[0.50]}\end{array}$ & 0.28 & 2103 & $\begin{array}{c}0.00 \\
(1.00)\end{array}$ & $\begin{array}{l}-0.46 \\
(0.05)^{* * *} \\
{[0.00]^{* * *}}\end{array}$ & $\begin{array}{l}-0.48 \\
(0.05)^{* * *} \\
{[0.00]^{* * *}}\end{array}$ & $\begin{array}{l}-0.43 \\
(0.05)^{* * *} \\
{[0.00]^{* * *}}\end{array}$ & 2686 \\
\hline \multicolumn{11}{|l|}{ Time Preferences } \\
\hline \multicolumn{11}{|l|}{ Pre-specified primary } \\
\hline$\beta^{E \text { Effort }}$ & $\begin{array}{c}0.982 \\
(0.005)\end{array}$ & $\begin{array}{l}0.007 \\
(0.006) \\
{[0.83]}\end{array}$ & $\begin{array}{l}0.005 \\
(0.007) \\
{[0.91]}\end{array}$ & 0.33 & 2068 & $\begin{array}{c}0.953 \\
(0.020)\end{array}$ & $\begin{array}{l}0.007 \\
(0.018) \\
{[1.00]}\end{array}$ & $\begin{array}{l}0.012 \\
(0.018) \\
{[0.32]}\end{array}$ & $\begin{array}{l}0.009 \\
(0.018) \\
{[1.00]}\end{array}$ & 2906 \\
\hline \multicolumn{11}{|l|}{ Pre-specified secondary } \\
\hline$\delta^{E f f o r t}$ & $\begin{array}{c}0.999 \\
(0.001)\end{array}$ & $\begin{array}{c}-0.001 \\
(0.001) \\
{[0.26]}\end{array}$ & $\begin{array}{l}-0.002 \\
(0.001)^{* *} \\
{[0.06]^{*}}\end{array}$ & 0.16 & 2068 & $\begin{array}{c}0.995 \\
(0.002)\end{array}$ & $\begin{array}{c}-0.001 \\
(0.002) \\
{[0.46]}\end{array}$ & $\begin{array}{c}-0.002 \\
(0.002) \\
{[0.27]}\end{array}$ & $\begin{array}{c}0.003 \\
(0.002) \\
{[0.21]}\end{array}$ & 2906 \\
\hline$\beta^{M P L}$ & $\begin{array}{c}1.05 \\
(0.46)\end{array}$ & $\begin{array}{c}-0.02 \\
(0.02)\end{array}$ & $\begin{array}{c}0.02 \\
(0.03)\end{array}$ & 0.21 & 2103 & $\begin{array}{c}1.02 \\
(0.43)\end{array}$ & $\begin{array}{c}-0.01 \\
(0.03)\end{array}$ & $\begin{array}{c}0.03 \\
(0.03)\end{array}$ & $\begin{array}{c}0.02 \\
(0.02)\end{array}$ & 2686 \\
\hline & & {$[0.41]$} & {$[0.53]$} & & & & {$[0.46]$} & {$[0.17]$} & {$[0.40]$} & \\
\hline$\delta^{M P L}$ & 0.98 & -0.00 & -0.00 & 0.86 & 2103 & 0.98 & 0.00 & 0.00 & 0.00 & 2686 \\
\hline & $(0.02)$ & $(0.00)$ & $(0.00)$ & & & $(0.02)$ & $(0.00)^{* *}$ & $(0.00)$ & $(0.00)^{* *}$ & \\
\hline \multicolumn{11}{|l|}{ SElf-EFFicACY } \\
\hline \multicolumn{11}{|l|}{ Pre-specified secondary } \\
\hline General Self-Efficacy Score (GSE) (z-score) & $\begin{array}{c}0.00 \\
(1.00)\end{array}$ & $\begin{array}{l}0.16 \\
(0.05)^{* * *} \\
{[0.00]^{* * *}}\end{array}$ & $\begin{array}{l}0.12 \\
(0.05)^{* *} \\
{[0.06]^{*}}\end{array}$ & 0.38 & 2103 & $\begin{array}{c}0.00 \\
(1.00)\end{array}$ & $\begin{array}{l}0.21 \\
(0.07)^{* * *} \\
{[0.00]^{* * *}}\end{array}$ & $\begin{array}{l}0.19 \\
(0.06)^{* * *} \\
{[0.01]^{* * *}}\end{array}$ & $\begin{array}{c}0.01 \\
(0.06) \\
{[0.51]}\end{array}$ & 2686 \\
\hline \multicolumn{11}{|l|}{ Alternative Mechanisms } \\
\hline Belief: Proportion of diarrhea incidences avoided through chlorination (z-score) & $\begin{array}{c}0.00 \\
(1.00)\end{array}$ & $\begin{array}{c}0.08 \\
(0.05)\end{array}$ & $\begin{array}{c}0.06 \\
(0.06)\end{array}$ & 0.61 & 2103 & $\begin{array}{c}0.00 \\
(1.00)\end{array}$ & $\begin{array}{l}0.17 \\
(0.05)^{* * *}\end{array}$ & $\begin{array}{l}0.16 \\
(0.06)^{* * * *}\end{array}$ & $\begin{array}{c}0.10 \\
(0.06)^{*}\end{array}$ & 2686 \\
\hline Chlorine knowledge score (z-score) & $\begin{array}{c}0.00 \\
(1.00)\end{array}$ & $\begin{array}{c}0.06 \\
(0.05)\end{array}$ & $\begin{array}{c}-0.01 \\
(0.05)\end{array}$ & 0.20 & 2103 & $\begin{array}{c}0.00 \\
(1.00)\end{array}$ & $\begin{array}{l}0.18 \\
(0.05)^{* * *}\end{array}$ & $\begin{array}{c}0.10 \\
(0.06)^{*}\end{array}$ & $\begin{array}{l}0.12 \\
(0.06)^{* *}\end{array}$ & 2686 \\
\hline ANC/PNC knowledge score (z-score) & $\begin{array}{c}0.00 \\
(1.00)\end{array}$ & $\begin{array}{c}0.04 \\
(0.05)\end{array}$ & $\begin{array}{c}-0.05 \\
(0.05)\end{array}$ & $0.08^{*}$ & 2103 & $\begin{array}{c}0.00 \\
(1.00)\end{array}$ & $\begin{array}{l}0.43 \\
(0.06)^{* * *}\end{array}$ & $\begin{array}{l}0.35 \\
(0.05)^{* * * *}\end{array}$ & $\begin{array}{l}0.39 \\
(0.05)^{* * *}\end{array}$ & 2686 \\
\hline Risk Aversion Measure (z-score) & $\begin{array}{c}0.00 \\
(1.00)\end{array}$ & $\begin{array}{c}-0.03 \\
(0.06)\end{array}$ & $\begin{array}{c}-0.07 \\
(0.06)\end{array}$ & 0.49 & 1926 & $\begin{array}{c}0.00 \\
(1.00)\end{array}$ & $\begin{array}{c}0.01 \\
(0.06)\end{array}$ & $\begin{array}{c}-0.02 \\
(0.06)\end{array}$ & $\begin{array}{c}0.04 \\
(0.06)\end{array}$ & 2473 \\
\hline
\end{tabular}

Notes: OLS estimates of treatment effects. For each variable, we report the mean of the comparison group, the coefficients of interest, and standard errors in parentheses. Square brackets contain additional $p$-values corrected for multiple hypothesi testing using the false discovery rate. All columns include village-level fixed effects, control for a vector of individual characteristics, and cluster standard errors at the level of the intervention cohort. For the comparison to the AC+INF group, the specification also controls for the baseline value of the outcome, for those that were collected at baseline. For the comparison to the pure control group, the specification also includes fixed effects for i) the week and ii) the day of the week of the endline survey, lor measures collected in the endine session. For the comparison to the pure control, the sample is restricted in the active treatment groups to those who attended the baseline and first intervention. * a participant's ability to plan ahead. Time preferences over effort are estimated structurally from a real effort task involving data entry by SMSs. Time preferences over money are measured using Multiple Price Lists (MPL). The risk aversion measure is derived from responses to a coin flip for various monetary rewards. The General Self-Efficacy score measures a participant's belief in their own ability to achieve the outcomes they desire. The mechanisms variables check if the interventions differentially affected i) a participant's belief in the efficacy of chlorine to prevent diarrhea, and ii) their knowledge of how to correctly chlorinate water, to assess whether changes in beliefs or knowledge could have been the cause of changes in chlorination behavior. 
Table A.16: LASSO specification: behavioral outcomes

\begin{tabular}{|c|c|c|c|c|c|c|c|c|c|c|}
\hline & \multicolumn{5}{|c|}{$\begin{array}{l}\text { Comparison with active control }(\mathrm{AC}+\mathrm{INF}) \\
\end{array}$} & \multicolumn{5}{|c|}{ Comparison with pure control $(\mathrm{PC})$} \\
\hline & (1) & (2) & (3) & (4) & (5) & (6) & (7) & (8) & (9) & (10) \\
\hline & $\begin{array}{l}\text { Active } \\
\text { Control }\end{array}$ & Visualization & Planning & Column 2 vs. & & Pure & $\mathrm{V}+\mathrm{INF}$ & $\mathrm{P}+\mathrm{INF}$ & $\mathrm{AC}+\mathrm{INF}$ & \\
\hline & Group & $\begin{array}{l}\text { Treatment } \\
\text { Effect }\end{array}$ & $\begin{array}{l}\text { Treatment } \\
\text { Effect }\end{array}$ & $\begin{array}{l}\text { Column } 3 \\
p \text {-value }\end{array}$ & N & $\begin{array}{c}\text { Control } \\
\text { Mean (SD) }\end{array}$ & $\begin{array}{l}\text { Treatment } \\
\text { Effect }\end{array}$ & $\begin{array}{l}\text { Treatment } \\
\text { Effect }\end{array}$ & $\begin{array}{l}\text { Treatment } \\
\text { Effect }\end{array}$ & ${ }^{N}$ \\
\hline \multicolumn{11}{|l|}{ HEALTh Outcomes } \\
\hline \multirow{3}{*}{$\begin{array}{l}\text { Pre-specified primary } \\
\text { Objective measure: water has been treated with chlorine (TCR) }\end{array}$} & & & & & & & & & & \\
\hline & 0.23 & & & 0.15 & 2012 & & & & & \\
\hline & $(0.42)$ & $(0.02)^{* *}$ & $(0.02)$ & 0.11 & 2012 & $(0.42)$ & 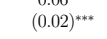 & $(0.02)^{*}$ & $(0.02)$ & 2000 \\
\hline \multicolumn{11}{|l|}{ Prespecified exploratory } \\
\hline \multirow{2}{*}{ Objective measure: water has sufficient chlorine to be safe (FCR) } & 0.21 & 0.04 & & 0.16 & 2012 & 0.18 & 0.06 & 0.03 & 0.03 & 2839 \\
\hline & $(0.40)$ & $\begin{array}{l}(0.02)^{* *} \\
{[0.07]^{*}}\end{array}$ & $(0.02)$ & & & $(0.399)$ & $(0.02)^{* * *}$ & $\begin{array}{l}(0.02) \\
{[0.81]}\end{array}$ & $(0.02)$ & \\
\hline \multirow[t]{2}{*}{ Number of diarrhea incidences per child u15 in last 3 months } & 0.24 & -0.09 & -0.05 & 0.13 & 2012 & 0.23 & -0.09 & -0.07 & -0.00 & 2823 \\
\hline & & $(0,03)^{*+\cdots *}$ & 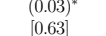 & & & & $\begin{array}{l}(0.0 .0)^{*+*} \\
{\left[0.2{ }^{* *}\right.}\end{array}$ & {$[0.03)^{* *}$} & $\begin{array}{l}(0.04) \\
{[1.00]}\end{array}$ & \\
\hline \multirow[t]{2}{*}{ Proportion of children u15 vaccinated in last 3 months } & $\begin{array}{c}0.22 \\
(0.35)\end{array}$ & $\begin{array}{l}0.000 \\
0.00 \\
(0.02)\end{array}$ & $\begin{array}{r}{[-0.03]} \\
(0.02)\end{array}$ & 0.17 & 1999 & $\begin{array}{c}0.22 \\
(0.36)\end{array}$ & $\begin{array}{l}{[0.02]^{2}} \\
0.01 \\
(0.02)\end{array}$ & $\begin{array}{r}{[0.1 .02} \\
-0.02 \\
(0.02)\end{array}$ & $\begin{array}{l}{[1.001} \\
0.01 \\
(0.02)\end{array}$ & 2800 \\
\hline & & {$[0.58]$} & {$[1.00]$} & & & & {$[0.83]$} & {$[1.00]$} & {$[1.00]$} & \\
\hline \multirow[t]{2}{*}{ Number of ANC visits made in last 3 months (among pregnant women) } & 1.26 & -0.20 & 0.03 & 0.54 & 200 & 1.19 & -0.25 & 0.03 & 0.16 & 272 \\
\hline & (1.19) & $(0.42)$ & $(0.34)$ & & & (1.17) & $(0.40)$ & $(0.41)$ & $(0.44)$ & \\
\hline \multirow[t]{2}{*}{ Proportion of children taken for healthcare check-up in last 3 months } & $\begin{array}{l}0.21 \\
(0.34)\end{array}$ & $\begin{array}{l}l_{0}^{2}-0.04 \\
(0.02)^{* * *}\end{array}$ & $\begin{array}{c}-0.03 \\
(0.02)\end{array}$ & 0.48 & 2004 & $\begin{array}{l}0.17 \\
(0.31)\end{array}$ & $\begin{array}{l}0.01 \\
(0.02)\end{array}$ & $\begin{array}{l}0.02 \\
(0.02)\end{array}$ & $\begin{array}{l}0.04 \\
(0.02)^{* *}\end{array}$ & 2806 \\
\hline & & & & & & & & & & \\
\hline \multicolumn{11}{|l|}{ SAVINGS OUtCOMES } \\
\hline \multirow{4}{*}{$\begin{array}{l}\text { Pre-specified secondary } \\
\text { Amount saved regularly (per week, KES) }\end{array}$} & & & & & & & & & & \\
\hline & 93.96 & 24.89 & 3.28 & 0.10 & 2108 & 88.76 & 17.71 & 7.55 & 4.03 & 2972 \\
\hline & $(230.26)$ & $(12.37)^{* *}$ & $(12.51)$ & & & $(228.12)$ & $(12.68)$ & $(12.87)$ & $(11.91)$ & \\
\hline & & & {$[1.00]$} & & & & {$[0.42]$} & {$[0.23]$} & {$[0.90]$} & \\
\hline \multirow{2}{*}{$\begin{array}{l}\text { Prespecified exploratory } \\
\text { Indicator: Amount saved regularly is positive }\end{array}$} & $\begin{array}{c}0.36 \\
(0.48)\end{array}$ & $\begin{array}{c}0.13 \\
(0.03)^{* * *}\end{array}$ & $\begin{array}{r}-0.02 \\
(0.03)\end{array}$ & $0.00^{* * *}$ & 2108 & $\begin{array}{c}0.32 \\
(0.47)\end{array}$ & $\begin{array}{l}0.12 \\
(0.03)^{* * *}\end{array}$ & $\begin{array}{c}0.02 \\
(0.03)\end{array}$ & 0.04 & 2972 \\
\hline & & {$[0.00)^{* \ldots}$} & {$\left[\begin{array}{l}0.003) \\
{[1.00]}\end{array}\right.$} & & & & {$[0.00]^{*+*}$} & {$[1.00]$} & {$[0.89]$} & \\
\hline \multirow[t]{2}{*}{ Number of new ROSCAs joined in last 3 months } & $\begin{array}{c}0.17 \\
(0.44)\end{array}$ & $\begin{array}{l}0.04 \\
(0.03)^{*}\end{array}$ & $\begin{array}{l}0.01 \\
(0.02)\end{array}$ & 0.17 & 2108 & $\begin{array}{c}0.21 \\
(0.46)\end{array}$ & $\begin{array}{l}0.02 \\
(0.03)\end{array}$ & $\begin{aligned}-0.01 \\
(0.03)\end{aligned}$ & $\begin{array}{r}-0.02 \\
(0.03)\end{array}$ & 2972 \\
\hline & & & {$[1.00]$} & & & & & & & \\
\hline \multirow[t]{2}{*}{ Indicator: Respondent saves for productive investments } & $\begin{array}{c}0.17 \\
(0.38)\end{array}$ & $\begin{array}{l}0.11 \\
(0.02)^{* \ldots *}\end{array}$ & $\begin{array}{r}-0.01 \\
(0.02)\end{array}$ & $0.00^{* * * *}$ & 2108 & $\begin{array}{c}0.17 \\
(0.38)\end{array}$ & $\begin{array}{ll}0.09 \\
(0.02)^{*+*}\end{array}$ & $\begin{array}{l}0.00 \\
(0.02)\end{array}$ & $\begin{array}{l}0.01 \\
(0.02)\end{array}$ & 2972 \\
\hline & & {$[0.00]^{3+*}$} & {$[1.00]$} & & & & {$[0.00]^{1+*+}$} & {$[1.00]$} & {$[1.00]$} & \\
\hline \multicolumn{11}{|l|}{ LABOR OUTCOMES } \\
\hline \\
\hline \multirow{2}{*}{$\begin{array}{l}\text { Pre-specified secondary } \\
\text { Total hours of work in last } 3 \text { months }\end{array}$} & $\begin{array}{c}106.11 \\
(174.61)\end{array}$ & $\begin{array}{r}-6.79 \\
(9.54)\end{array}$ & $\begin{aligned}-23.83 \\
(8.99) * * *\end{aligned}$ & $0.06^{*}$ & 2108 & $\begin{array}{c}108.78 \\
(182.99)\end{array}$ & $\begin{array}{l}-2.23 \\
(10.14)\end{array}$ & $\begin{array}{l}-23.47 \\
(9.45)^{* *}\end{array}$ & $\begin{array}{r}-7.00 \\
(9.64)\end{array}$ & 2972 \\
\hline & & {$[0.90]$} & {$[0.03]^{\omega *}$} & & & & {$[0.42]$} & {$[0.04]^{t *}$} & {$[0.88]$} & \\
\hline \multicolumn{11}{|l|}{ Pre-specified exploratory } \\
\hline \multirow[t]{2}{*}{ Total days of work in last 3 months } & $\begin{array}{l}21.22 \\
(30.09)\end{array}$ & $\begin{array}{c}-0.59 \\
(1.64)\end{array}$ & $\begin{array}{l}-3.91 \\
(1.60)^{* *}\end{array}$ & $0.04^{* *}$ & 2108 & $\begin{array}{c}21.73 \\
(30.45)\end{array}$ & $\begin{array}{c}-0.51 \\
(1.71)\end{array}$ & $\begin{array}{l}-4.01 \\
(1.60)^{* *}\end{array}$ & $\begin{array}{r}-1.45 \\
(1.64)\end{array}$ & 2972 \\
\hline & & {$[0.56]$} & {$[0.18]$} & & & & {$[0.91]$} & {$[0.14]$} & {$[1.00]$} & \\
\hline Average monthly earnings in last 3 months & 1094.50 & 3.11 & -1.23 & 0.97 & 2108 & 1167.22 & -43.58 & -105.44 & -142.78 & 2972 \\
\hline & $(2865.35)$ & $(147.23)$ & $(163.19)$ & & & $(3155.76)$ & $(166.41)$ & $(171.46)$ & $(174.39)$ & \\
\hline & & & {$[1.00]$} & & & & [0.91] & {$[1.00]$} & {$[1.00]$} & \\
\hline OTHER BEHAVIORAL OUTCOMES & & & & & & & & & & \\
\hline Prespec & & & & & & & & & & \\
\hline Index of investment in children's education (z-score) & $\begin{array}{l}0.00 \\
(1.00)\end{array}$ & $\begin{aligned}-0.02 \\
(0.06) \\
0.900\end{aligned}$ & $\begin{array}{c}0.01 \\
(0.07)\end{array}$ & 0.60 & 1420 & $\begin{array}{l}0.00 \\
(1.00)\end{array}$ & $\begin{array}{l}0.09 \\
(0.07) \\
0.42\end{array}$ & $\begin{array}{l}0.12 \\
(0.07)^{*} \\
{[0.101}\end{array}$ & $\begin{array}{l}0.12 \\
(0.07)^{*}\end{array}$ & 1967 \\
\hline & & & & & & & & & & \\
\hline sestima & & & & & & & ention & For the c & son to th & $\begin{array}{l}\text { Cling } \\
\text { the day }\end{array}$ \\
\hline & & & & & & & & & & \\
\hline & & & & & & & & & & \\
\hline
\end{tabular}


Table A.17: LASSO specification: psychological outcomes

\begin{tabular}{|c|c|c|c|c|c|c|c|c|c|c|}
\hline & \multicolumn{5}{|c|}{ Comparison with active control (AC+INF) } & \multicolumn{5}{|c|}{ Comparison with pure control (PC) } \\
\hline & (1) & (2) & (3) & (4) & (5) & (6) & (7) & (8) & (9) & $(10)$ \\
\hline & $\begin{array}{c}\text { Active } \\
\text { Control } \\
\text { Group } \\
\text { Mean (SD) }\end{array}$ & $\begin{array}{c}\text { Visualization } \\
\text { Treatment } \\
\text { Effect }\end{array}$ & $\begin{array}{c}\text { Planning } \\
\text { Treatment } \\
\text { Effect }\end{array}$ & $\begin{array}{l}\text { Column } 2 \text { vs. } \\
\text { Column } 3 \\
p \text {-value }\end{array}$ & N & $\begin{array}{c}\text { Pure } \\
\text { Control } \\
\text { Mean (SD) }\end{array}$ & $\begin{array}{c}\text { V+INF } \\
\text { Treatment } \\
\text { Effect }\end{array}$ & $\begin{array}{c}\mathrm{P}+\mathrm{INF} \\
\text { Treatment } \\
\text { Effect }\end{array}$ & $\begin{array}{c}\text { AC+INF } \\
\text { Treatment } \\
\text { Effect }\end{array}$ & $N$ \\
\hline \multicolumn{11}{|l|}{ PlanNing Skills } \\
\hline \multicolumn{11}{|l|}{ Pre-specified primary } \\
\hline Behavioral Activation Score (BADS) (z-score) & $\begin{array}{c}0.00 \\
(1.00)\end{array}$ & $\begin{array}{c}-0.01 \\
(0.05) \\
{[0.83]}\end{array}$ & $\begin{array}{c}0.04 \\
(0.05) \\
{[0.91]}\end{array}$ & 0.31 & 2103 & $\begin{array}{c}0.00 \\
(1.00)\end{array}$ & $\begin{array}{c}0.03 \\
(0.06) \\
{[1.00]}\end{array}$ & $\begin{array}{l}0.11 \\
(0.06)^{*} \\
{[0.13]^{2}}\end{array}$ & $\begin{array}{c}0.04 \\
(0.06) \\
{[1.00]}\end{array}$ & 2955 \\
\hline \multicolumn{11}{|l|}{ Pre-specified secondary } \\
\hline Tower of London: Total Moves (z-score) & $\begin{array}{c}0.00 \\
(1.00)\end{array}$ & $\begin{array}{c}0.01 \\
(0.05) \\
{[0.85]}\end{array}$ & $\begin{array}{c}-0.04 \\
(0.05) \\
{[0.50]} \\
\end{array}$ & 0.28 & 2103 & $\begin{array}{c}0.00 \\
(1.00)\end{array}$ & $\begin{array}{l}-0.38 \\
(0.05)^{* * *} \\
{[0.00]^{* * *}}\end{array}$ & $\begin{array}{l}-0.43 \\
(0.05)^{* * *} \\
{[0.00]^{* * *}}\end{array}$ & $\begin{array}{l}-0.37 \\
(0.05)^{* * * *} \\
{[0.00]^{* * * *}}\end{array}$ & 2955 \\
\hline \multicolumn{11}{|l|}{ Time Preferences } \\
\hline \multicolumn{11}{|l|}{ Pre-specified primary } \\
\hline$\beta^{\text {Effort }}$ & $\begin{array}{c}0.982 \\
(0.005)\end{array}$ & $\begin{array}{l}0.007 \\
(0.006) \\
{[0.83]}\end{array}$ & $\begin{array}{l}0.005 \\
(0.007) \\
{[0.91]}\end{array}$ & 0.33 & 2068 & $\begin{array}{c}0.953 \\
(0.020)\end{array}$ & $\begin{array}{l}0.007 \\
(0.018) \\
{[1.00]}\end{array}$ & $\begin{array}{l}0.012 \\
(0.018) \\
{[0.32]}\end{array}$ & $\begin{array}{l}0.009 \\
(0.018) \\
{[1.00]}\end{array}$ & 2906 \\
\hline \multicolumn{11}{|l|}{$\begin{array}{l}\text { Pre-specified secondary } \\
\text { SEffort }\end{array}$} \\
\hline & $(0.001)$ & $\begin{array}{c}-0.001 \\
(0.001) \\
{[0.26]}\end{array}$ & $\begin{array}{l}-0.002 \\
(0.001)^{* * *} \\
{[0.06]^{*}}\end{array}$ & 0.10 & 2008 & $(0.002)$ & $\begin{array}{c}-0.001 \\
(0.002) \\
{[0.50]}\end{array}$ & $\begin{array}{c}-0.002 \\
(0.002) \\
{[0.25]}\end{array}$ & $\begin{array}{l}0.003 \\
(0.002) \\
{[0.21]}\end{array}$ & 2900 \\
\hline$\beta^{M P L}$ & $\begin{array}{c}1.05 \\
(0.46)\end{array}$ & $\begin{array}{c}-0.02 \\
(0.02)\end{array}$ & $\begin{array}{l}0.02 \\
(0.03)\end{array}$ & 0.21 & 2103 & $\begin{array}{c}1.02 \\
(0.43)\end{array}$ & $\begin{array}{c}-0.01 \\
(0.03)\end{array}$ & $\begin{array}{c}0.02 \\
(0.03)\end{array}$ & $\begin{array}{c}0.01 \\
(0.02)\end{array}$ & 2955 \\
\hline & & {$[0.41]$} & {$[0.53]$} & & & & {$[0.50]$} & {$[0.25]$} & {$[0.40]$} & \\
\hline$\delta^{M P L}$ & 0.98 & -0.00 & -0.00 & 0.86 & 2103 & 0.98 & 0.00 & 0.00 & 0.00 & 2955 \\
\hline & $(0.02)$ & $(0.00)$ & $(0.00)$ & & & $(0.02)$ & $(0.00)^{*}$ & $(0.00)$ & $(0.00)^{* *}$ & \\
\hline & & {$[0.41]$} & {$[0.40]$} & & & & {$[0.08]^{*}$} & {$[0.14]$} & {$[0.07]^{*}$} & \\
\hline \multicolumn{11}{|l|}{ SELF-EFFicACY } \\
\hline \multicolumn{11}{|l|}{ Pre-specified secondary } \\
\hline General Self-Efficacy Score (GSE) (z-score) & $\begin{array}{c}0.00 \\
(1.00)\end{array}$ & $\begin{array}{l}0.16 \\
(0.05)^{* * *} \\
{[0.00]^{* * *}}\end{array}$ & $\begin{array}{l}0.12 \\
(0.05)^{* *} \\
{[0.06]^{*}}\end{array}$ & 0.38 & 2103 & $\begin{array}{c}0.00 \\
(1.00)\end{array}$ & $\begin{array}{l}0.18 \\
(0.06)^{* * *} \\
{[0.01]^{* *}}\end{array}$ & $\begin{array}{l}0.18 \\
(0.06)^{* * *} \\
{[0.00]^{* * *}}\end{array}$ & $\begin{array}{c}0.02 \\
(0.06) \\
{[0.40]} \\
\end{array}$ & 2955 \\
\hline \multicolumn{11}{|l|}{ Alternative Mechanisms } \\
\hline Belief: Proportion of diarrhea incidences avoided through chlorination (z-score) & $\begin{array}{c}0.00 \\
(1.00)\end{array}$ & $\begin{array}{c}0.08 \\
(0.05)\end{array}$ & $\begin{array}{c}0.06 \\
(0.06)\end{array}$ & 0.61 & 2103 & $\begin{array}{c}0.00 \\
(1.00)\end{array}$ & $\begin{array}{l}0.13 \\
(0.05)^{* *}\end{array}$ & $\begin{array}{l}0.16 \\
(0.05)^{* * * *}\end{array}$ & $\begin{array}{l}0.12 \\
(0.06)^{* *}\end{array}$ & 2955 \\
\hline Chlorine knowledge score (z-score) & $\begin{array}{c}0.00 \\
(1.00)\end{array}$ & $\begin{array}{c}0.06 \\
(0.05)\end{array}$ & $\begin{array}{c}-0.01 \\
(0.05)\end{array}$ & 0.20 & 2103 & $\begin{array}{c}0.00 \\
(1.00)\end{array}$ & $\begin{array}{l}0.12 \\
(0.05)^{* *}\end{array}$ & $\begin{array}{c}0.07 \\
(0.06)\end{array}$ & $\begin{array}{c}0.09 \\
(0.06)\end{array}$ & 2955 \\
\hline ANC/PNC knowledge score (z-score) & $\begin{array}{c}0.00 \\
(1.00)\end{array}$ & $\begin{array}{c}0.04 \\
(0.05)\end{array}$ & $\begin{array}{c}-0.05 \\
(0.05)\end{array}$ & $0.08^{*}$ & 2103 & $\begin{array}{c}0.00 \\
(1.00)\end{array}$ & $\begin{array}{l}0.36 \\
(0.06)^{* * *}\end{array}$ & $\begin{array}{l}0.28 \\
(0.05)^{* * * *}\end{array}$ & $\begin{array}{l}0.35 \\
(0.05)^{* * *}\end{array}$ & 2955 \\
\hline Risk Aversion Measure (z-score) & $\begin{array}{c}0.00 \\
(1.00)\end{array}$ & $\begin{array}{c}-0.03 \\
(0.06)\end{array}$ & $\begin{array}{c}-0.07 \\
(0.06)\end{array}$ & 0.49 & 1926 & $\begin{array}{c}0.00 \\
(1.00)\end{array}$ & $\begin{array}{c}0.01 \\
(0.06)\end{array}$ & $\begin{array}{c}-0.01 \\
(0.06)\end{array}$ & $\begin{array}{c}0.03 \\
(0.06)\end{array}$ & 2735 \\
\hline
\end{tabular}

Notes: OLS estimates of treatment effects. For each variable, we report the mean of the comparison group, the coefficients of interest, and standard errors in parentheses. Square brackets contain additional $p$-values corrected for multiple hypothesi testing using the false discovery rate. All columns include village-level fixed effects, control for a vector of individual characteristics, and cluster standard errors at the level of the intervention cohort. For the comparison to the AC+INF group, the specification also controls for the baseline value of the outcome, for those that were collected at baseline. For the comparison to the pure control group, the specification also includes fixed effects for i) the week and ii) the day of the week of the endline

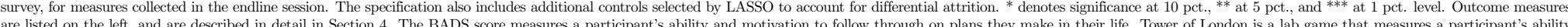
to plan ahead. Time preferences over effort are estimated structurally from a real effort task involving data entry by SMSs. Time preferences over money are measured using Multiple Price Lists (MPL). The risk aversion measure is derived from responses to a coin flip for various monetary rewards. The General Self-Efficacy score measures a participant's belief in their own ability to achieve the outcomes they desire. The mechanisms variables check if the interventions differentially affected i) a participant's belief in the efficacy of chlorine to prevent diarrhea, and ii) their knowledge of how to correctly chlorinate water, to assess whether changes in beliefs or knowledge could have been the cause of changes in chlorination behavior. 
Table A.18: LASSO specification: behavioral outcomes for alternative attrition definition

\begin{tabular}{|c|c|c|c|c|c|c|c|c|c|c|}
\hline & \multicolumn{5}{|c|}{ Comparison with active control $(\mathrm{AC}+\mathrm{INF})$} & \multicolumn{5}{|c|}{ Comparison with pure control (PC) } \\
\hline & $\begin{array}{c}\text { (1) } \\
\text { Active } \\
\text { Control } \\
\text { Group } \\
\text { Mean (SD) }\end{array}$ & $\begin{array}{c}(2) \\
\text { Visualization } \\
\text { Treatment } \\
\text { Effect }\end{array}$ & $\begin{array}{l}\stackrel{(3)}{ } \\
\text { Planning } \\
\text { Treatment } \\
\text { Effect }\end{array}$ & $\begin{array}{c}(4) \\
\text { Column } 2 \text { vs. } \\
\text { Column } 3 \\
p \text {-value }\end{array}$ & $\begin{array}{l}\text { (5) } \\
N\end{array}$ & $\begin{array}{c}\text { (6) } \\
\text { Pure } \\
\text { Control } \\
\text { Mean (SD) }\end{array}$ & $\begin{array}{c}(7) \\
\text { V+INF } \\
\text { Treatment } \\
\text { Effect }\end{array}$ & $\begin{array}{c}(8) \\
\text { P+INF } \\
\text { Treatment } \\
\text { Effect }\end{array}$ & $\begin{array}{c}(9) \\
\text { AC+INF } \\
\text { Treatment } \\
\text { Effect }\end{array}$ & $\begin{array}{l}(10) \\
N\end{array}$ \\
\hline \multicolumn{11}{|l|}{ HEALTH OUTCOMES } \\
\hline $\begin{array}{l}\text { Prespecified primary } \\
\text { Objective measure: water has been treated with chlorine (TCR) }\end{array}$ & $\begin{array}{l}0.23 \\
(0.42)\end{array}$ & $\begin{array}{l}0.05 \\
(0.02)^{* * *}\end{array}$ & $\begin{array}{l}0.02 \\
(0.02)\end{array}$ & 0.15 & 2012 & $\begin{array}{l}0.22 \\
(0.42)\end{array}$ & $\begin{array}{l}0.06 \\
(0.02)^{* * *}\end{array}$ & $\begin{array}{l}0.04 \\
(0.02)^{*}\end{array}$ & $\begin{array}{c}0.02 \\
(0.02)\end{array}$ & 2585 \\
\hline $\begin{array}{l}\text { Pre-specified exploratory } \\
\text { Objective measure: water has sufficient chlorine to be safe (FCR) }\end{array}$ & $\begin{array}{c}0.21 \\
(0.40)\end{array}$ & $\begin{array}{l}0.04 \\
(0.02)^{* * *} \\
{[0.7]^{*}}\end{array}$ & $\begin{array}{l}0.01 \\
(0.02)\end{array}$ & 0.16 & 2012 & $\begin{array}{c}0.18 \\
(0.39)\end{array}$ & $\begin{array}{l}0.06 \\
(0.02)^{*+* *} \\
0.01+* *+4\end{array}$ & $\begin{array}{l}0.04 \\
(0.02)^{*} \\
(0.25\end{array}$ & $\begin{array}{r}0.03 \\
(0.02)\end{array}$ & 2585 \\
\hline Number of diarrhea incidences per child u15 in last 3 months & $\begin{array}{c}0.24 \\
(0.59)\end{array}$ & $\begin{array}{c}-0.09 \\
(0.03)^{* * * *} \\
\left(0.00^{* * * *}\right.\end{array}$ & $\begin{array}{c}-0.05 \\
(0.03)^{*} \\
{[0.63]^{*}}\end{array}$ & 0.13 & 2012 & $\begin{array}{c}0.23 \\
(0.64)\end{array}$ & $\begin{array}{l}-0.09 \\
(0.03)^{*+* *} \\
{\left[0.011^{* *}\right.}\end{array}$ & $\begin{array}{c}-0.06 \\
(0.03)^{*} \\
{[0.25]}\end{array}$ & $\begin{array}{l}0.00 \\
(0.04) \\
{[1.00]}\end{array}$ & 2569 \\
\hline Proportion of children u15 vaccinated in last 3 months & $\begin{array}{l}0.22 \\
(0.35)\end{array}$ & $\begin{array}{l}0.00 \\
(0.02) \\
{[0.58]}\end{array}$ & $\begin{array}{r}-0.02 \\
(0.02) \\
{[1.00]}\end{array}$ & 0.17 & 1999 & $\begin{array}{c}0.22 \\
(0.36)\end{array}$ & $\begin{array}{l}0.00 \\
(0.02) \\
{[1.00]}\end{array}$ & $\begin{array}{c}-0.01 \\
(0.02) \\
{[1.00]}\end{array}$ & $\begin{array}{l}0.00 \\
(0.02) \\
{[1.00]}\end{array}$ & 2550 \\
\hline Number of ANC visits made in last 3 months (among pregnant women) & $\begin{array}{l}1.26 \\
(1.19)\end{array}$ & $\begin{array}{r}-0.20 \\
(0.42) \\
{[0.56]}\end{array}$ & $\begin{array}{c}0.03 \\
(0.34) \\
{[1.00]}\end{array}$ & 0.54 & 200 & $\begin{array}{l}1.19 \\
(1.17)\end{array}$ & $\begin{array}{c}-0.43 \\
(0.42) \\
{[0.51]}\end{array}$ & $\begin{array}{c}-0.14 \\
(0.44) \\
{[1.00]}\end{array}$ & $\begin{array}{l}0.00 \\
(0.50) \\
{[1.00]}\end{array}$ & 242 \\
\hline Proportion of children taken for healthcare check-up in last 3 months & $\begin{array}{l}0.21 \\
(0.34)\end{array}$ & $\begin{array}{c}-0.04 \\
(0.02)^{* * *} \\
{[0.06]^{*}}\end{array}$ & $\begin{array}{r}-0.03 \\
(0.02) \\
{[0.82]} \\
\end{array}$ & 0.48 & 2004 & $\begin{array}{c}0.17 \\
(0.31)\end{array}$ & $\begin{array}{r}-0.00 \\
(0.02) \\
{[1.00]} \\
\end{array}$ & $\left.\begin{array}{l}0.01 \\
(0.02) \\
{[1.00]}\end{array}\right]$ & $\begin{array}{l}0.04 \\
(0.02)^{* * *} \\
{[0.50]}\end{array}$ & 2557 \\
\hline \multicolumn{11}{|l|}{ SAVINGS OUTCOMES } \\
\hline $\begin{array}{l}\text { Pre-specified secondary } \\
\text { Amount saved regularly (per week, KES) }\end{array}$ & $\begin{array}{r}93.96 \\
(230.26)\end{array}$ & $\begin{array}{c}24.89 \\
(12.37)^{* *} \\
{[0.16]^{*}}\end{array}$ & $\begin{array}{r}3.28 \\
(12.51) \\
{[1.00]}\end{array}$ & 0.10 & 2108 & $\begin{array}{c}88.76 \\
(228.12)\end{array}$ & $\begin{array}{c}25.62 \\
(13.15)^{*} \\
{[0.18]}\end{array}$ & $\begin{array}{r}4.83 \\
(13.19) \\
{[0.31]}\end{array}$ & $\begin{array}{r}3.98 \\
(12.07) \\
{[1.00]}\end{array}$ & 2693 \\
\hline $\begin{array}{l}\text { Pre-specified exploratory } \\
\text { Indicator: Amount saved regularly is positive }\end{array}$ & $\begin{array}{l}0.36 \\
(0.48)\end{array}$ & $\begin{array}{l}0.13 \\
(0.03)^{*+*} \\
{[0.0+* *+}\end{array}$ & $\begin{array}{c}-0.02 \\
(0.03)\end{array}$ & $0.00^{* * *}$ & 2108 & $\begin{array}{l}0.32 \\
(0.47)\end{array}$ & $\begin{array}{l}0.16 \\
(0.03)^{*+*} \\
(500)^{*+* * *}\end{array}$ & $\begin{array}{l}0.02 \\
(0.03)\end{array}$ & $\begin{array}{l}0.04 \\
(0.03)\end{array}$ & 2693 \\
\hline Number of new ROSCAs joined in last 3 months & $\begin{array}{l}0.17 \\
(0.44)\end{array}$ & $\begin{array}{l}{[0.00]^{* * *}} \\
0.04 \\
(0.03)^{*} \\
{[0.10]}\end{array}$ & $\begin{array}{l}{[1.00]} \\
0.01 \\
(0.02) \\
11.00]\end{array}$ & 0.17 & 2108 & $\begin{array}{l}0.21 \\
(0.46)\end{array}$ & $\begin{array}{c}{[0.00]^{+* * *}} \\
0.03 \\
(0.03) \\
{[0.51]}\end{array}$ & $\begin{array}{c}{[1.00]} \\
-0.01 \\
(0.03) \\
{[1.00]}\end{array}$ & $\begin{array}{c}{[1.00]} \\
-0.02 \\
(0.03) \\
{[1.00]}\end{array}$ & 2693 \\
\hline Indicator: Respondent saves for productive investments & $\begin{array}{c}0.17 \\
(0.38)\end{array}$ & $\begin{array}{l}0.11 \\
(0.02)^{* * *} \\
{[0.0]^{* * *}}\end{array}$ & $\begin{array}{c}-0.01 \\
(0.02) \\
{[1.00]}\end{array}$ & $0.00^{* * *}$ & 2108 & $\begin{array}{c}0.17 \\
(0.38)\end{array}$ & $\begin{array}{l}0.12 \\
0.02)^{* * *} \\
{[0.0]^{* * *}} \\
{[0 .}\end{array}$ & $\begin{array}{l}0.00 \\
(0.02) \\
1.00] \\
\end{array}$ & $\begin{array}{l}0.01 \\
(0.02) \\
{[1.00]} \\
\end{array}$ & 2693 \\
\hline \multicolumn{11}{|l|}{ LABOR OUTCOMES } \\
\hline $\begin{array}{l}\text { Pre-specified secondary } \\
\text { Total hours of work in last } 3 \text { months }\end{array}$ & $\begin{array}{l}105.87 \\
(173.63)\end{array}$ & $\begin{array}{c}-6.79 \\
(9.48) \\
{[0.90]}\end{array}$ & $\begin{array}{c}-23.66 \\
(8.95)^{* * * *} \\
{[0.03]^{* * *}}\end{array}$ & $0.06^{*}$ & 2108 & $\begin{array}{r}108.54 \\
(182.02)\end{array}$ & $\begin{array}{r}-7.30 \\
(10.19) \\
{[0.19]}\end{array}$ & $\begin{array}{c}-23.35 \\
(9.68)^{* * *} \\
{[0.05]^{*}}\end{array}$ & $\begin{array}{c}-3.01 \\
(10.00) \\
{[1.00]}\end{array}$ & 2693 \\
\hline $\begin{array}{l}\text { Prespecified exploratory } \\
\quad \text { Total days of work in last } 3 \text { months }\end{array}$ & $\begin{array}{l}21.22 \\
(30.09)\end{array}$ & $\begin{array}{l}-0.59 \\
(1.64) \\
{[0.56]}\end{array}$ & $\begin{array}{l}-3.91 \\
(1.60)^{* *} \\
0.18\end{array}$ & $0.04^{* *}$ & 2108 & $\begin{array}{l}21.73 \\
(30.45)\end{array}$ & $\left.\begin{array}{rl}-0.84 \\
(1.76) \\
0.90\end{array}\right]$ & $\begin{array}{l}-3.92 \\
(1.66)^{* *} \\
(0.22\end{array}$ & $\begin{array}{c}-0.86 \\
(1.17) \\
1.00 \mid\end{array}$ & 2693 \\
\hline Average monthly earnings in last 3 months & $\begin{array}{l}1094.50 \\
(2865.35)\end{array}$ & $\begin{array}{r}3.11 \\
(147.23) \\
{[0.65]}\end{array}$ & $\begin{array}{r}-1.23 \\
(163.19) \\
{[1.00]}\end{array}$ & 0.97 & 2108 & $\begin{array}{l}1167.22 \\
(3155.76)\end{array}$ & $\begin{array}{r}-106.79 \\
(167.76) \\
{[0.82]}\end{array}$ & $\begin{array}{r}-110.57 \\
(175.38) \\
{[1.00]}\end{array}$ & $\begin{array}{r}-110.87 \\
(182.42) \\
{[1.00]}\end{array}$ & 2693 \\
\hline \multicolumn{11}{|l|}{ OTHER BEHAVIORAL OUTCOMES } \\
\hline $\begin{array}{l}\text { Prespecified secondary } \\
\text { Index of investment in children's education (z-score) }\end{array}$ & $\begin{array}{l}0.00 \\
(1.00)\end{array}$ & $\begin{array}{c}-0.02 \\
(0.06) \\
{[0.90]} \\
\end{array}$ & $\begin{array}{l}0.01 \\
(0.07) \\
{[1.00]}\end{array}$ & 0.60 & 1420 & $\begin{array}{l}0.00 \\
(1.00)\end{array}$ & $\begin{array}{l}0.11 \\
(0.07)^{*} \\
{[0.18]^{*}}\end{array}$ & $\begin{array}{c}0.13 \\
(0.08)^{*} \\
{[0.08]^{*}}\end{array}$ & $\begin{array}{l}0.13 \\
(0.07)^{*} \\
{[0.33]}\end{array}$ & 1825 \\
\hline
\end{tabular}


Table A.19: LASSO specification: psychological outcomes for alternative attrition definition

\begin{tabular}{|c|c|c|c|c|c|c|c|c|c|c|}
\hline & \multicolumn{5}{|c|}{ Comparison with active control (AC+INF) } & \multicolumn{5}{|c|}{ Comparison with pure control (PC) } \\
\hline & (1) & (2) & (3) & (4) & (5) & (6) & (7) & (8) & (9) & (10) \\
\hline & $\begin{array}{c}\text { Active } \\
\text { Control } \\
\text { Group } \\
\text { Mean (SD) }\end{array}$ & $\begin{array}{c}\text { Visualization } \\
\text { Treatment } \\
\text { Effect }\end{array}$ & $\begin{array}{l}\text { Planning } \\
\text { Treatment } \\
\text { Effect }\end{array}$ & $\begin{array}{c}\text { Column } 2 \text { vs. } \\
\text { Column } 3 \\
p \text {-value }\end{array}$ & N & $\begin{array}{c}\text { Pure } \\
\text { Control } \\
\text { Mean (SD) }\end{array}$ & $\begin{array}{c}\text { V+INF } \\
\text { Treatment } \\
\text { Effect }\end{array}$ & $\begin{array}{l}\text { P+INF } \\
\text { Treatment } \\
\text { Effect }\end{array}$ & $\begin{array}{c}\text { AC+INF } \\
\text { Treatment } \\
\text { Effect }\end{array}$ & N \\
\hline \multicolumn{11}{|l|}{ PLANNING SKILLS } \\
\hline \multicolumn{11}{|l|}{ Pre-specified primary } \\
\hline Behavioral Activation Score (BADS) (z-score) & $\begin{array}{c}0.00 \\
(1.00)\end{array}$ & $\begin{array}{c}-0.01 \\
(0.05) \\
{[0.83]}\end{array}$ & $\begin{array}{c}0.04 \\
(0.05) \\
{[0.91]}\end{array}$ & 0.31 & 2103 & $\begin{array}{c}0.00 \\
(1.00)\end{array}$ & $\begin{array}{l}0.05 \\
(0.06) \\
{[1.00]}\end{array}$ & $\begin{array}{l}0.11 \\
(0.06)^{*} \\
{[0.15]}\end{array}$ & $\begin{array}{c}0.06 \\
(0.06) \\
{[1.00]}\end{array}$ & 2686 \\
\hline \multicolumn{11}{|l|}{ Pre-specified secondary } \\
\hline Tower of London: Total Moves (z-score) & $\begin{array}{c}0.00 \\
(1.00)\end{array}$ & $\begin{array}{l}0.01 \\
(0.05) \\
{[0.85]}\end{array}$ & $\begin{array}{c}-0.04 \\
(0.05) \\
{[0.50]}\end{array}$ & 0.28 & 2103 & $\begin{array}{c}0.00 \\
(1.00)\end{array}$ & $\begin{array}{c}-0.46 \\
(0.05)^{* * *} \\
{[0.00]^{* * *}}\end{array}$ & $\begin{array}{c}-0.48 \\
(0.05)^{* * *} \\
{[0.00]^{* * * *}}\end{array}$ & $\begin{array}{c}-0.44 \\
(0.05)^{* * *} \\
{[0.00]^{* * *}}\end{array}$ & 2686 \\
\hline \multicolumn{11}{|l|}{ TIME PREFERENCES } \\
\hline \multicolumn{11}{|l|}{ Pre-specified primary } \\
\hline$\beta^{\text {Effort }}$ & $\begin{array}{c}0.982 \\
(0.005)\end{array}$ & $\begin{array}{l}0.007 \\
(0.006) \\
{[0.83]}\end{array}$ & $\begin{array}{l}0.005 \\
(0.007) \\
{[0.91]}\end{array}$ & 0.33 & 2068 & $\begin{array}{c}0.953 \\
(0.020)\end{array}$ & $\begin{array}{l}0.007 \\
(0.018) \\
{[1.00]}\end{array}$ & $\begin{array}{l}0.012 \\
(0.018) \\
{[0.32]}\end{array}$ & $\begin{array}{l}0.009 \\
(0.018) \\
{[1.00]}\end{array}$ & 2906 \\
\hline \multicolumn{11}{|l|}{ Pre-specified secondary } \\
\hline$\delta^{E f f o r t}$ & $\begin{array}{c}0.999 \\
(0.001)\end{array}$ & $\begin{array}{c}-0.001 \\
(0.001) \\
{[0.26]}\end{array}$ & $\begin{array}{c}-0.002 \\
(0.001)^{* *} \\
{\left[0.066^{*}\right.}\end{array}$ & 0.16 & 2068 & $\begin{array}{c}0.995 \\
(0.002)\end{array}$ & $\begin{array}{c}-0.001 \\
(0.002) \\
{[0.46]}\end{array}$ & $\begin{array}{c}-0.002 \\
(0.002) \\
{[0.27]}\end{array}$ & $\begin{array}{c}0.003 \\
(0.002) \\
{[0.21]}\end{array}$ & 2906 \\
\hline$\beta^{M P L}$ & $\begin{array}{l}1.05 \\
(0.46)\end{array}$ & $\begin{array}{c}-0.02 \\
(0.02)\end{array}$ & $\begin{array}{c}0.02 \\
(0.03)\end{array}$ & 0.21 & 2103 & $\begin{array}{c}1.02 \\
(0.43)\end{array}$ & $\begin{array}{r}-0.01 \\
(0.03)\end{array}$ & $\begin{array}{l}0.03 \\
(0.03)\end{array}$ & $\begin{array}{l}0.02 \\
(0.02)\end{array}$ & 2686 \\
\hline$\delta^{M P L}$ & $\begin{array}{c}0.98 \\
(0.02)\end{array}$ & $\begin{array}{c}{[0.41]} \\
-0.00 \\
(0.00) \\
{[0.41]}\end{array}$ & $\begin{array}{c}{[0.53]} \\
-0.00 \\
(0.00) \\
{[0.40]}\end{array}$ & 0.86 & 2103 & $\begin{array}{c}0.98 \\
(0.02)\end{array}$ & $\begin{array}{l}{[0.46]} \\
0.00 \\
(0.00)^{* *} \\
{[0.05]^{*}}\end{array}$ & $\begin{array}{c}{[0.17]} \\
0.00 \\
(0.00) \\
{[0.17]}\end{array}$ & $\begin{array}{l}{[0.40]} \\
0.00 \\
(0.00)^{* *} \\
{[0.02]^{* *}}\end{array}$ & 2686 \\
\hline \multicolumn{11}{|l|}{ SELF-EFFiCACY } \\
\hline \multicolumn{11}{|l|}{ Pre-specified secondary } \\
\hline General Self-Efficacy Score (GSE) (z-score) & $\begin{array}{c}0.00 \\
(1.00)\end{array}$ & $\begin{array}{l}0.16 \\
(0.05)^{* * *} \\
{[0.00]^{* * *}}\end{array}$ & $\begin{array}{l}0.12 \\
(0.05)^{* *} \\
{[0.06]^{*}}\end{array}$ & 0.38 & 2103 & $\begin{array}{c}0.00 \\
(1.00)\end{array}$ & $\begin{array}{l}0.21 \\
(0.07)^{* * *} \\
{[0.00]^{* * *}}\end{array}$ & $\begin{array}{l}0.19 \\
(0.06)^{* * *} \\
{[0.01]^{* * *}}\end{array}$ & $\begin{array}{c}0.01 \\
(0.06) \\
{[0.51]}\end{array}$ & 2686 \\
\hline \multicolumn{11}{|l|}{ ALTERNATIVE MECHANISMS } \\
\hline Belief: Proportion of diarrhea incidences avoided through chlorination (z-score) & $\begin{array}{c}0.00 \\
(1.00)\end{array}$ & $\begin{array}{c}0.08 \\
(0.05)\end{array}$ & $\begin{array}{c}0.06 \\
(0.06)\end{array}$ & 0.61 & 2103 & $\begin{array}{c}0.00 \\
(1.00)\end{array}$ & $\begin{array}{l}0.17 \\
(0.05)^{* * *}\end{array}$ & $\begin{array}{c}0.16 \\
(0.06)^{*+* *}\end{array}$ & $\begin{array}{c}0.10 \\
(0.06)^{*}\end{array}$ & 2686 \\
\hline Chlorine knowledge score (z-score) & $\begin{array}{l}0.00 \\
(1.00)\end{array}$ & $\begin{array}{l}0.06 \\
(0.05)\end{array}$ & $\begin{array}{c}-0.01 \\
(0.05)\end{array}$ & 0.20 & 2103 & $\begin{array}{l}0.00 \\
(1.00)\end{array}$ & $\begin{array}{l}0.18 \\
(0.05)^{* * *}\end{array}$ & $\begin{array}{l}0.11 \\
(0.06)^{*}\end{array}$ & $\begin{array}{l}0.13 \\
(0.06)^{* *}\end{array}$ & 2686 \\
\hline ANC/PNC knowledge score (z-score) & $\begin{array}{r}0.00 \\
(1.00)\end{array}$ & $\begin{array}{l}0.04 \\
(0.05)\end{array}$ & $\begin{array}{r}-0.05 \\
(0.05)\end{array}$ & $0.08^{*}$ & 2103 & $\begin{array}{l}0.00 \\
(1.00)\end{array}$ & $\begin{array}{l}0.43 \\
(0.06)^{* * *}\end{array}$ & 0.35 & 0.39 & 2686 \\
\hline Risk Aversion Measure (z-score) & $\begin{array}{c}0.00 \\
(1.00)\end{array}$ & $\begin{array}{c}-0.03 \\
(0.06)\end{array}$ & $\begin{array}{c}-0.07 \\
(0.06)\end{array}$ & 0.49 & 1926 & $\begin{array}{l}0.00 \\
(1.00)\end{array}$ & $\begin{array}{c}0.01 \\
(0.06)\end{array}$ & $\begin{array}{c}-0.02 \\
(0.06)\end{array}$ & $\begin{array}{c}0.04 \\
(0.06)\end{array}$ & 2473 \\
\hline
\end{tabular}

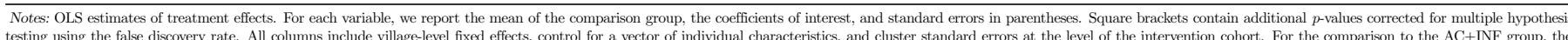
specification also controls for the baseline value of the outcome for those that were collected at baseline. For the comparison to the pure control groun the specification also includes fived effects for i) the week and ii) the day of the week of the endlise survey, for measures collected in the endline session. For the comparison to the pure control, the sample is restricted in the active treatment groups to those who attended the baseline and first intervention. The specification also includes additional controls selected by LASSO to account for differential attrition. * *enotes significcance at 10 pct., ** at 5 pct., and *** at 1 pect. level. Outcome measures are listed on the left, and are described in detail in Section 4 . The BADS score measures a

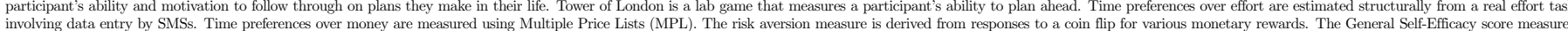
a participant's belief in their own ability to achieve the outcomes they desire. The mechanisms variables check if the interventions differentially affected i) a participant's belief in the efficacy of chlorine to prevent diarrhea, and ii) their knowledge 
Table A.20: Behavioral outcomes (without endline date fixed effects)

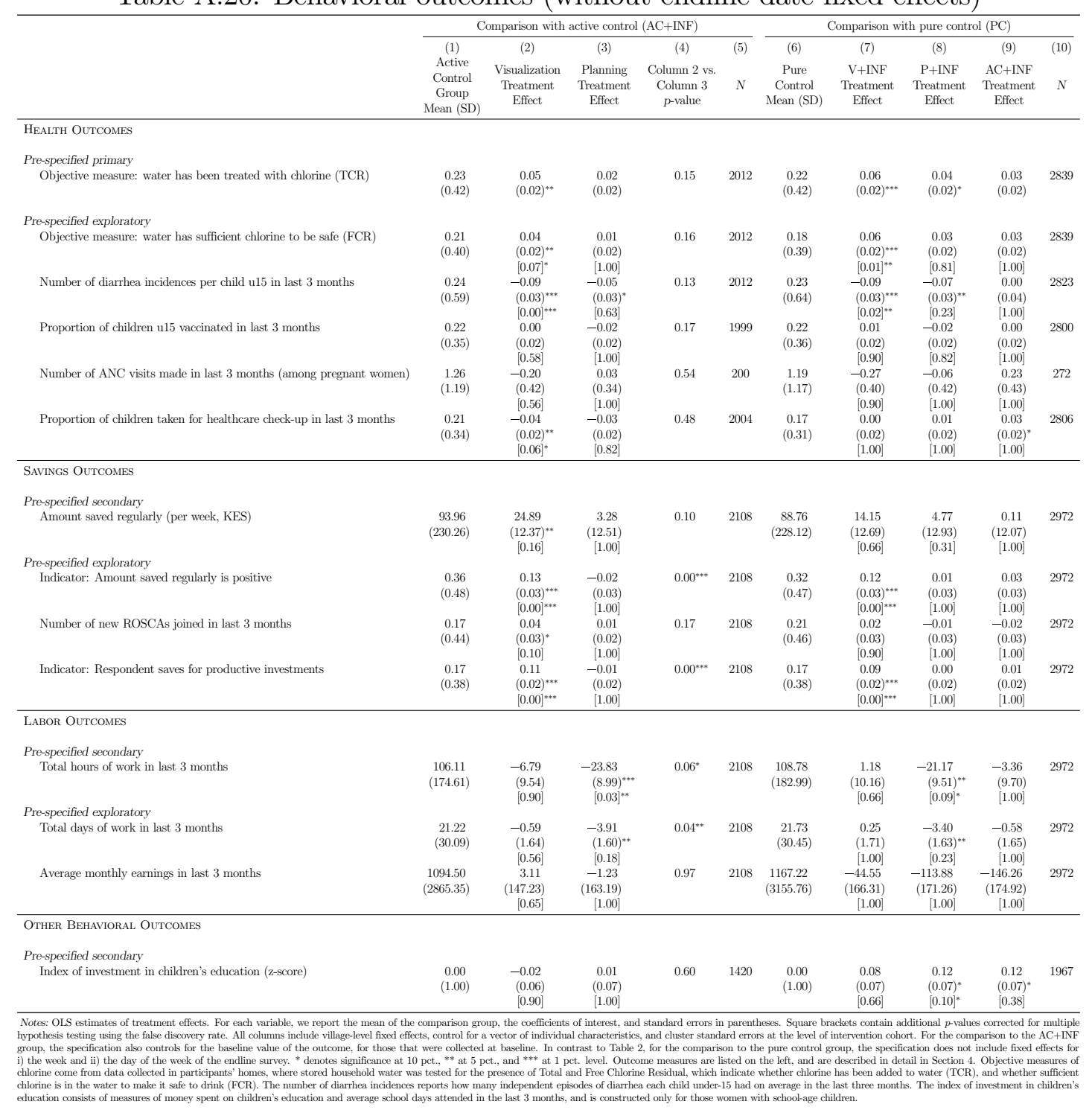


Table A.21: Psychological outcomes (without endline date fixed effects)

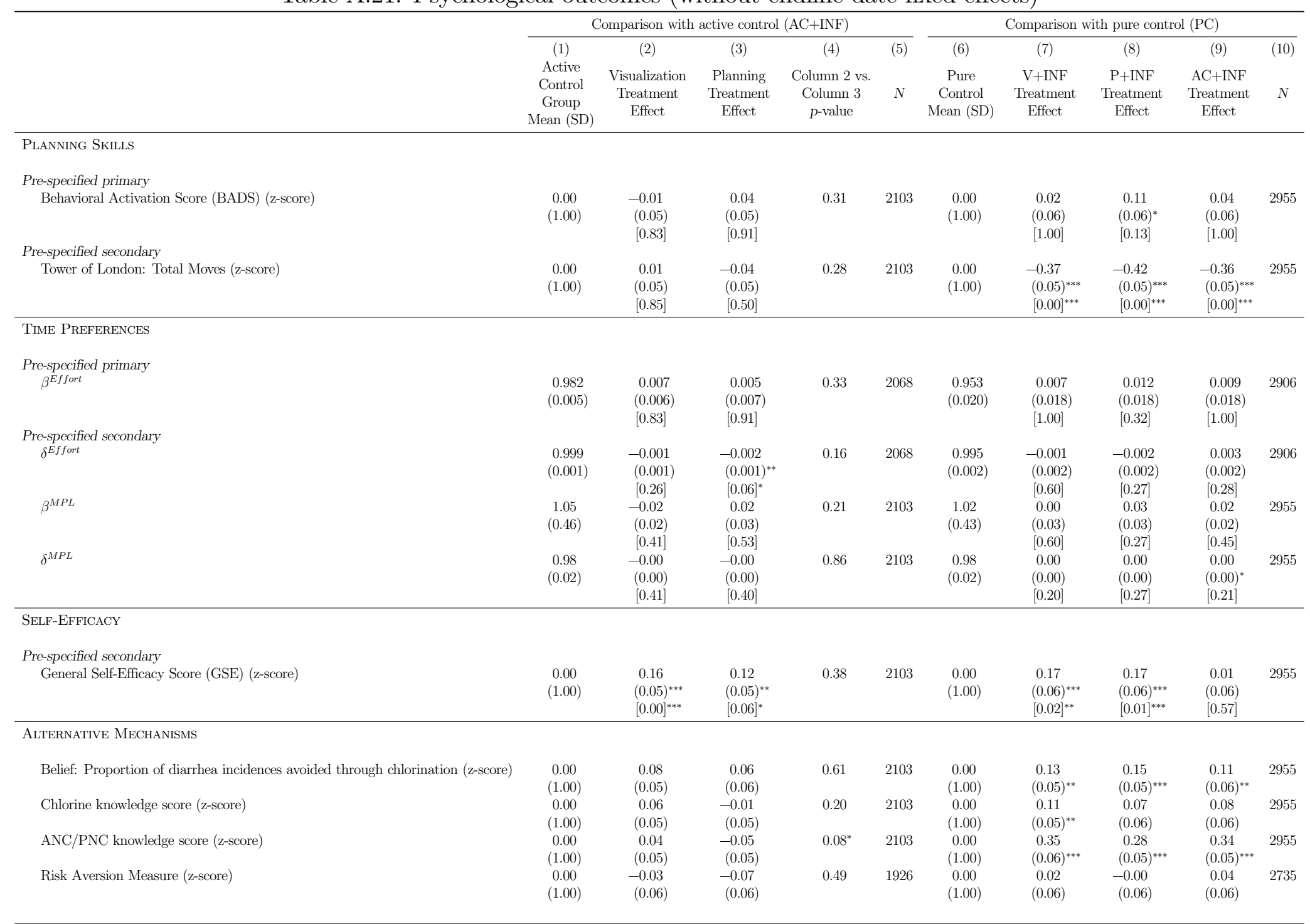

Notes: OLS estimates of treatment effects. For each variable, we report the mean of the comparison group, the coefficients of interest, and standard errors in parentheses. Square brackets contain additional $p$-values corrected for multiple hypothesis testing using the false discovery rate. All columns include village-level fixed effects, control for a vector of individual characteristics, and cluster standard errors at the level of the intervention cohort. For the comparison to the AC+INF group, the specification also controls for the baseline value of the outcome, for those that were collected at baseline. In contrast to Table 4, for the comparison to the pure control group, the specification does not include fixed effects for 1) the week and iil) the day of the week of the endline survey. $*$ denotes significance at $10 \mathrm{pct.},{ }^{* *}$ at $5 \mathrm{pct.}$, and ${ }^{* * *}$ at $1 \mathrm{pct}$. level. Outcome measures are listed on the left, and are described in detail in Section 4 . The BADS score measures a participant's ability and motivation to follow through on plans they make in their life. Tower of
London is a lab game that measures a participant's ability to plan ahead. Time preferences over effort are estimated structurally from a real effort task involving data entry by SMSs. Time preferences over money are measured using Multiple Price Lists (MPI). The risk aversion measure is derived from responses to a coin flip for various monetary rewards. The General Self-Efficacy score measures a participant's belief in their own ability to achieve the outcomes they desire. The mechanisms variables check if the interventions differentially affected i) a participant's belief in the efficacy of chlorine to prevent diarrhea, and ii) their knowledge of how to correctly chlorinate water, to assess whether changes in beliefs or knowledge could have been the cause of changes in chlorination behavior. 
Table A.22: Other health outcomes (not pre-specified)

\begin{tabular}{|c|c|c|c|c|c|c|c|c|c|c|}
\hline & \multicolumn{5}{|c|}{ Comparison with active control $(\mathrm{AC}+\mathrm{INF})$} & \multicolumn{5}{|c|}{ Comparison with pure control (PC) } \\
\hline & $\begin{array}{c}(1) \\
\text { Active } \\
\text { Control } \\
\text { Group } \\
\text { Mean (SD) }\end{array}$ & $\begin{array}{c}\text { (2) } \\
\text { Visualization } \\
\text { Treatment } \\
\text { Effect }\end{array}$ & $\begin{array}{c}(3) \\
\text { Planning } \\
\text { Treatment } \\
\text { Effect }\end{array}$ & $\begin{array}{c}\text { (4) } \\
\text { Column } 2 \text { vs. } \\
\text { Column } 3 \\
p \text {-value }\end{array}$ & $(5)$ & $\begin{array}{c}(6) \\
\text { Pure } \\
\text { Control } \\
\text { Mean (SD) }\end{array}$ & $\begin{array}{c}(7) \\
\text { V+INF } \\
\text { Treatment } \\
\text { Effect }\end{array}$ & $\begin{array}{c}(8) \\
\text { P+INF } \\
\text { Treatment } \\
\text { Effect }\end{array}$ & $\begin{array}{c}(9) \\
\text { AC+INF } \\
\text { Treatment } \\
\text { Effect }\end{array}$ & $\begin{array}{c}(10) \\
N\end{array}$ \\
\hline \multicolumn{11}{|l|}{ SELF-REPORTED WATER TREATMENT } \\
\hline $\begin{array}{l}\text { How do you treat your drinking water? (multiple possible) } \\
\text { Boiling }\end{array}$ & $\begin{array}{c}0.32 \\
(0.47)\end{array}$ & $\begin{array}{l}0.05 \\
(0.02)^{* *}\end{array}$ & $\begin{array}{c}0.02 \\
(0.02)\end{array}$ & 0.12 & 2337 & $\begin{array}{l}0.27 \\
(0.44)\end{array}$ & $\begin{array}{l}0.05 \\
(0.03)^{* *}\end{array}$ & $\begin{array}{c}0.01 \\
(0.03)\end{array}$ & $\begin{array}{c}-0.00 \\
(0.03)\end{array}$ & 2984 \\
\hline Add chlorine & $\begin{array}{c}0.67 \\
(0.47)\end{array}$ & $\begin{array}{l}0.06 \\
(0.02)^{* *}\end{array}$ & $\begin{array}{c}-0.02 \\
(0.03)\end{array}$ & $0.00^{* * *}$ & 2337 & $\begin{array}{c}0.50 \\
(0.50)\end{array}$ & $\begin{array}{l}0.12 \\
(0.02)^{* * *}\end{array}$ & $\begin{array}{l}0.05 \\
(0.03)^{* *}\end{array}$ & $\begin{array}{l}0.06 \\
(0.02)^{* *}\end{array}$ & 2984 \\
\hline Strain through cloth & $\begin{array}{c}0.07 \\
(0.25)\end{array}$ & $\begin{array}{c}-0.00 \\
(0.01)\end{array}$ & $\begin{array}{c}-0.00 \\
(0.01)\end{array}$ & 0.94 & 2337 & $\begin{array}{c}0.05 \\
(0.23)\end{array}$ & $\begin{array}{c}-0.00 \\
(0.01)\end{array}$ & $\begin{array}{c}-0.00 \\
(0.01)\end{array}$ & $\begin{array}{c}0.01 \\
(0.01)\end{array}$ & 2984 \\
\hline Filter & $\begin{array}{c}0.09 \\
(0.29)\end{array}$ & $\begin{array}{c}-0.00 \\
(0.01)\end{array}$ & $\begin{array}{l}0.03 \\
(0.01)^{*}\end{array}$ & $0.04^{* *}$ & 2337 & $\begin{array}{c}0.11 \\
(0.32)\end{array}$ & $\begin{array}{l}-0.05 \\
(0.02)^{* * *}\end{array}$ & $\begin{array}{c}-0.02 \\
(0.02)\end{array}$ & $\begin{array}{l}-0.04 \\
(0.02)^{* *}\end{array}$ & 2984 \\
\hline Let stand and settle & $\begin{array}{c}0.18 \\
(0.38)\end{array}$ & $\begin{array}{l}-0.06 \\
(0.02)^{* * *}\end{array}$ & $\begin{array}{c}0.00 \\
(0.02)\end{array}$ & $0.00^{* * *}$ & 2337 & $\begin{array}{c}0.17 \\
(0.37)\end{array}$ & $\begin{array}{l}-0.08 \\
(0.02)^{* * *}\end{array}$ & $\begin{array}{c}-0.03 \\
(0.02)\end{array}$ & $\begin{array}{c}-0.04 \\
(0.02)\end{array}$ & 2984 \\
\hline Do not treat & $\begin{array}{c}0.03 \\
(0.17)\end{array}$ & $\begin{array}{c}0.00 \\
(0.01)\end{array}$ & $\begin{array}{c}0.00 \\
(0.01)\end{array}$ & 0.67 & 2103 & $\begin{array}{c}0.02 \\
(0.15)\end{array}$ & $\begin{array}{c}0.01 \\
(0.01)\end{array}$ & $\begin{array}{c}0.01 \\
(0.01)\end{array}$ & $\begin{array}{c}0.01 \\
(0.01)\end{array}$ & 2955 \\
\hline How often do you treat your water? [1 - never, 4 - always] & $\begin{array}{c}3.23 \\
(0.80)\end{array}$ & $\begin{array}{c}0.02 \\
(0.04)\end{array}$ & $\begin{array}{c}0.07 \\
(0.04)\end{array}$ & 0.20 & 2103 & $\begin{array}{c}3.32 \\
(0.79)\end{array}$ & $\begin{array}{c}-0.07 \\
(0.04)\end{array}$ & $\begin{array}{c}-0.02 \\
(0.04)\end{array}$ & $\begin{array}{l}-0.11 \\
(0.04)^{* *}\end{array}$ & 2955 \\
\hline \multicolumn{11}{|l|}{ NON-PRESPECIFIED HEALTH OUTCOMES } \\
\hline Number of diarrhea incidences per child u 5 in last 3 months & $\begin{array}{c}0.44 \\
(0.92)\end{array}$ & $\begin{array}{l}-0.15 \\
(0.05)^{* * *}\end{array}$ & $\begin{array}{l}-0.11 \\
(0.05)^{* *}\end{array}$ & 0.31 & 1682 & $\begin{array}{c}0.37 \\
(0.84)\end{array}$ & $\begin{array}{c}-0.06 \\
(0.05)\end{array}$ & $\begin{array}{c}-0.03 \\
(0.05)\end{array}$ & $\begin{array}{c}0.08 \\
(0.05)\end{array}$ & 2357 \\
\hline
\end{tabular}

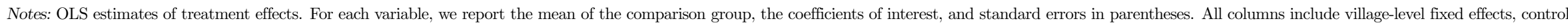

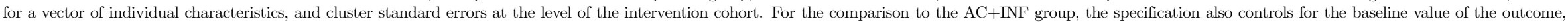
for those that were collected at baseline. 